\title{
Democracy in the face of disagreement: Environmentalist opposition to Escarpment Mine on the Denniston Plateau
}

\author{
Lillian Fougère
}

Thesis

ENVIRONMENTAL STUDIES 591

A 120 point thesis submitted to Victoria University of Wellington

in partial fulfilment of requirements for the degree of

Master of Environmental Studies

School of Geography, Environment and Earth Sciences

Victoria University of Wellington

March 2013 





\section{Abstract}

\section{Democracy in the face of disagreement: Environmentalist opposition to Escarpment Mine on the Denniston Plateau}

Despite New Zealand's Resource Management Act 1991 (RMA) being lauded as offering democratic decision-making processes, those in opposition to consent applications often feel their input has minimal influence on the decisions made. This research explores how democracy is actualised or constrained through environmentalist opposition to decisions made about coal-mining on conservation land, including both informal and formal participation.

Escarpment Mine is a proposal for an open cast coal mine on the Denniston Plateau on the West Coast of New Zealand. The mine was granted resource consents in 2011 by the two local councils. Environmental activists engaged with these decisions through the formal council led submission process, a requirement under the RMA, and informally through activism, protest and campaigning. Their opposition was founded on concerns about the mine's effects on conservation and climate change.

Drawing on theories of deliberative democracy and radical democracy, I create a framework for democracy that includes agonism and antagonism, situated within the overarching democratic principles of equality, justice and the rule of the people. Through interviewing environmentalists opposed to Escarpment Mine and the council officials involved, my research discusses the way environmentalists were constrained from participating meaningfully in the formal process due to perceived bias and the privileging of neoliberal discourses. I suggest that this case reflects a lack of agonism in most areas, and a delegitimising of antagonistic activism despite such activism working towards equality and justice. Thus, the case does not fulfil the democratic ideals of working with disagreement.

Key words: environmental management, environmentalism, Resource Management Act 1991, activism, agonistic planning, radical democracy, communicative planning, deliberative democracy 


\section{Acknowledgements}

This research would not be what it is without the generous time, support and guidance gifted to me by numerous people, both known to me and strangers.

I am wholeheartedly grateful to the wide range of people who so willingly gave their time and shared their experiences with me during interviews. Your passion and dedication to your values and to society is an inspiration.

My supervisor, Dr. Sophie Bond, has given me invaluable support, guidance and reassurance throughout the entire research process. I am incredibly grateful for working with such a brilliant academic and compassionate person during this time.

Thank you to my dear family, loved ones, friends, flatmates and fellow musicians that gave me constant encouragement and feedback in various forms. Although there are many others, I would particularly like to thank Janet Thomson, David Fougère, Ed Hearnshaw, Nina Hall, Joe Beaglehole, Cristian Leaman, Maria Williams, Chris Bean, Cindy Jemmett, Sonja Bonn, Sarah Adams, Sharon Renfro, Tim Divett and Kiri Stevens.

Thanks also to the Social Theory and Spatial Praxis research group at Victoria University of Wellington, and other staff and fellow post-graduate students, who discussed, listened and explored various aspects of social research and my research on a number of occasions.

I also express sincere gratitude to the Todd Foundation, who provided funding for my thesis fees and field research costs. 


\section{Table of contents}

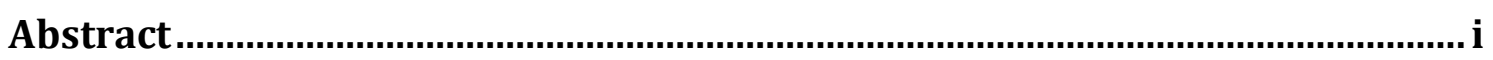

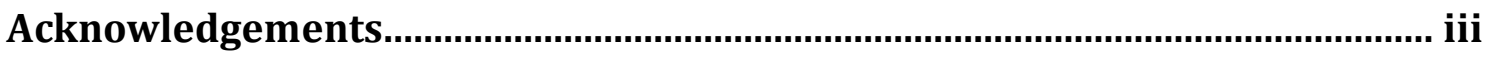

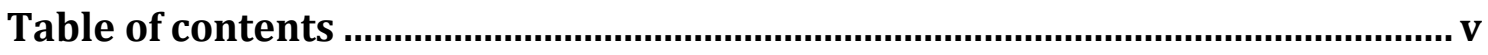

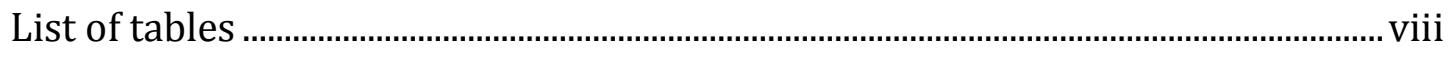

List of figures .................................................................................................................. viii

Abbreviations .........................................................................................................

Chapter one: Introducing opposition to Escarpment Mine and issues with

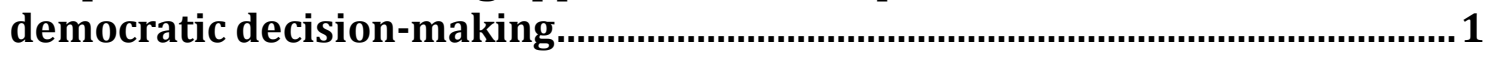

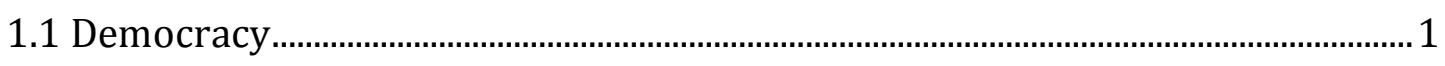

1.2 Escarpment Mine and environmentalist opposition ................................................

1.3 Research objective and thesis overview..................................................................

Chapter two: Methodology …….....................................................................

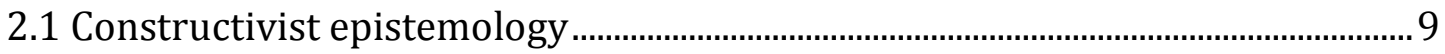

2.1.1 Post-structuralism....................................................................................................... 10

2.1.2 Power and discourse .......................................................................................... 10

2.1.3 My positionality ........................................................................................................ 12

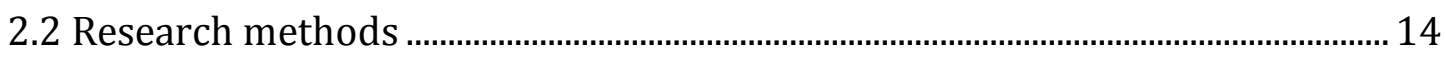

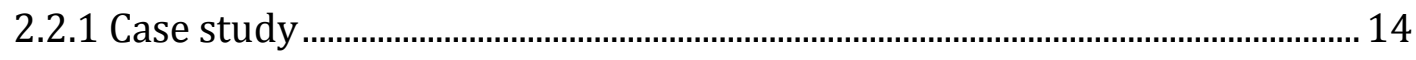

2.2.2 Literature review methods ..................................................................................... 16

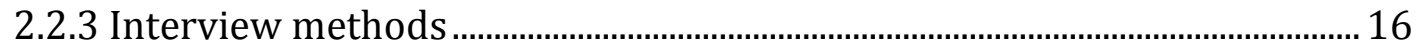

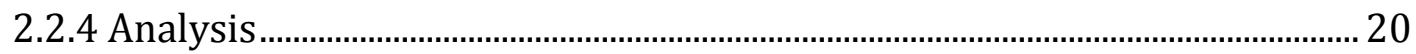

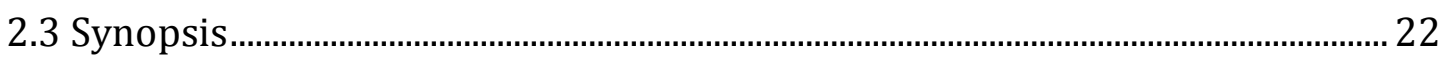

Chapter three: Environmental activism and politics in New Zealand ............. 23

3.1 Escarpment Mine on the Denniston Plateau and parallel cases............................. 24

3.1.1 Environmentalist opposition to Escarpment Mine............................................ 27

3.1.2 '2 precious 2 mine': New Zealand's conservation land and the art of nationwide protest ........................................................................................................... 28

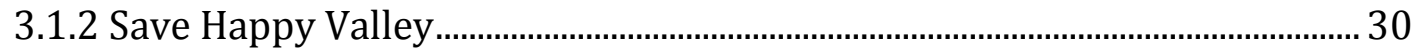

3.1.4 Mokihinui............................................................................................................... 32

3.2 Formal participation processes under legislation ………………………………..... 35

3.2.1 Resource Management Act 1991..................................................................... 35

3.2.2 Crown Minerals Act 1991 and the Conservation Act 1987............................... 37

3.3 Environmentalism and the rise of a neoliberal agenda ........................................... 38 
3.3.1 Save Manapouri and the legacy of environmentalism.....................................39

3.3.2 The rise of neoliberal decision-making..............................................................40

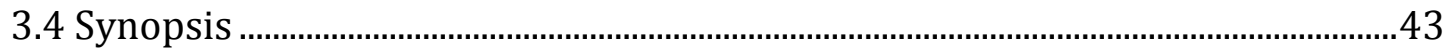

Chapter four: Participation, disagreement and democracy .............................45

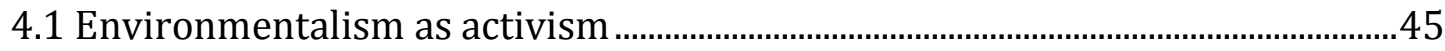

4.2 Democratic principles and participation ...................................................................48

4.2.1 Equality, justice, freedom and the rule of the people.......................................48

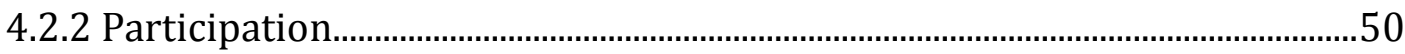

4.3 Deliberative democracy and radical democracy ......................................................53

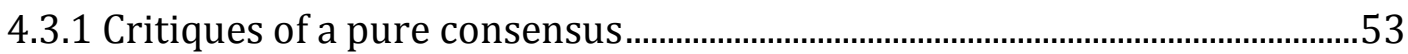

4.3.2 Rational deliberations: the potential for coercion? ........................................54

4.3.3 Deliberation, consensus and exclusion ..............................................................56

4.3.4 Agonism, the adversary and moments of agreement .......................................58

4.4 Framework for democracy and disagreement in decision-making ....................60

Chapter five: Environmentalists' influence in the decision.............................67

5.1 Influence of environmentalist actions outside formal processes .......................68

5.2 Influence within formal processes .................................................................................

5.3 What knowledge counts: Privileged perspectives and negating the big picture

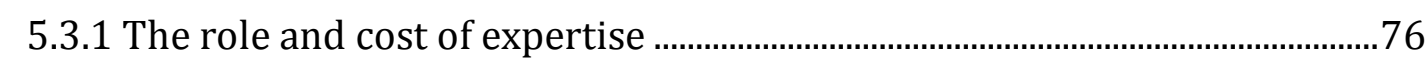

5.3.2 The economic development rationale ..............................................................7

5.3.3 The dismissal of climate change .............................................................................

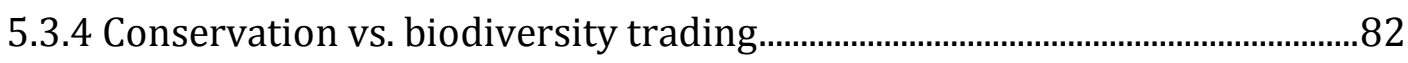

5.3.5 The future of the Denniston Plateau ....................................................................8

5.3.6 Fragmented approach to the environment........................................................8

5.4 Perceived objectivity and the "philosophical stance" ..............................................90

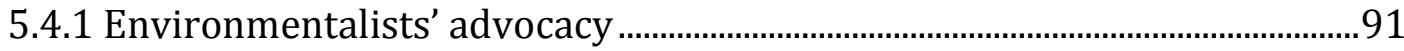

5.4.2 The bias of "independent" experts .....................................................................93

5.4.3 Councils and commissioners: neutral facilitators and decision-makers?

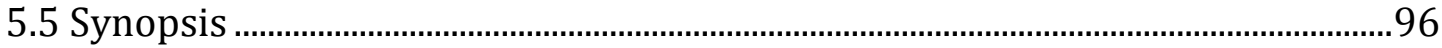

Chapter six: Escarpment Mine and reflections on the democratic framework

6.1 Power, equality and democracy ………...............................................................100

6.2 Transparency of process and access to information ............................................103

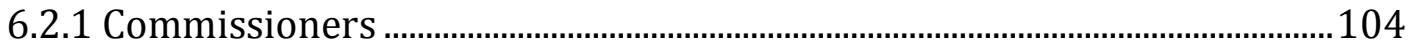




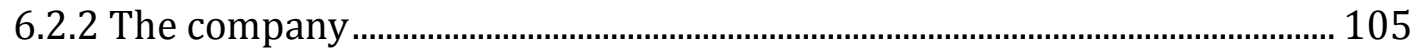

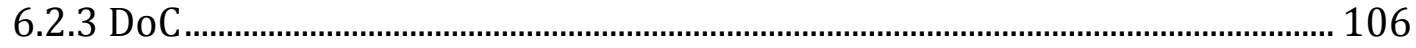

6.3 Temporary agreements, open to further debate ................................................... 108

6.4 Accepting underlying difference ................................................................................ 111

6.4.1 Environmentalists' relationships with the councils and local communities

6.4.2 Aiming for consensus and the flaws of mediation and compromise ...... 113

6.4.3 The binding formal process with the impossibility of agreement ........... 118

6.5 Noise, antagonistic activism and legitimate voices .............................................. 119

6.6 Synopsis: Disagreement and democracy as expressed through agonism and

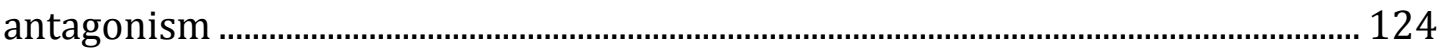

Chapter seven: Concluding and including disagreement in democracy .......129

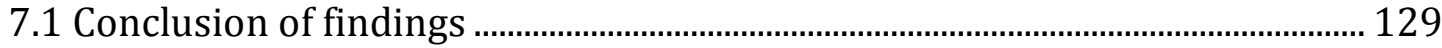

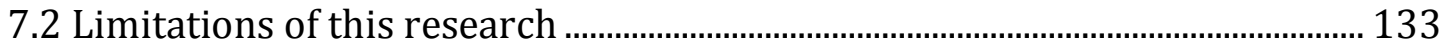

7.3 The way forward for disagreement in democratic environmental decision-

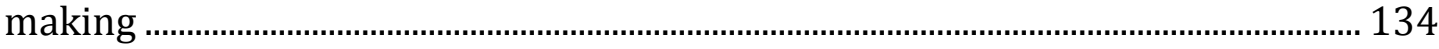

7.3.1 Future research: agonism and the impossibility of agreement................ 134

7.3.2 Recommendations for planning consent practice ........................................ 136

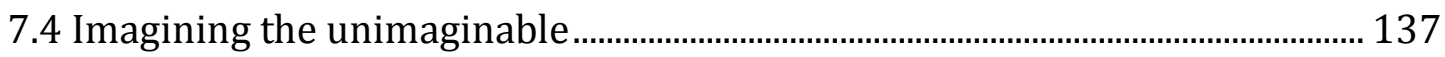

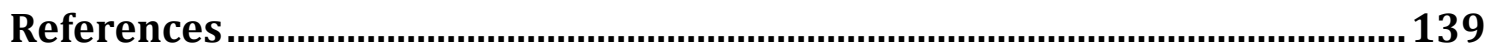

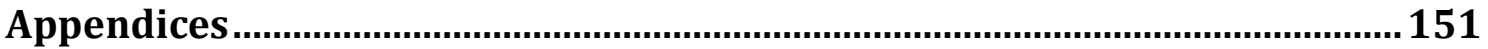

Appendix 1: Interview information sheet and consent form .................................. 151

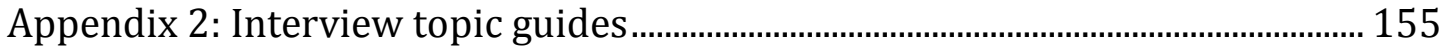

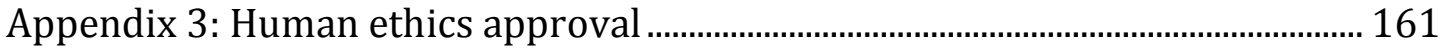




\section{List of tables}

Table 1.1: How the objective of this thesis will be fulfilled .................................... 6

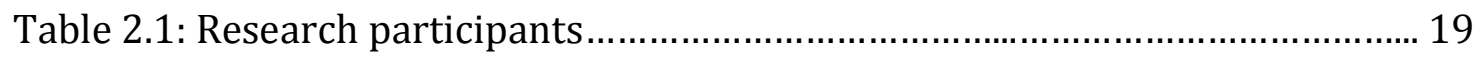

Table 3.1: Important dates in the formal process of Escarpment Mine .................. 25

Table 4.1: Expanded framework for democratic decision-making.......................... 64

\section{List of figures}

Figure 3.1: Map of New Zealand, with the location of the Denniston Plateau........ 25

Figure 3.2: The Denniston Plateau in relation to Westport................................... 26

Figure 3.3: The West Coast Regional Council's boundary area, illustrating the

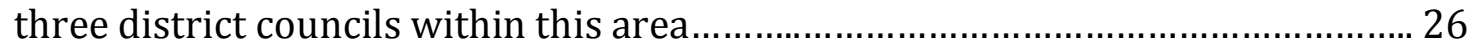

Figure 3.4: DoC owned land across New Zealand ................................................. 30

Figure 4.1: Eight Rungs on a Ladder of Citizen Participation (Arnstein, 1969, p.

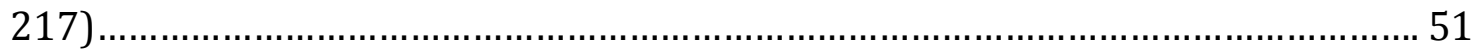

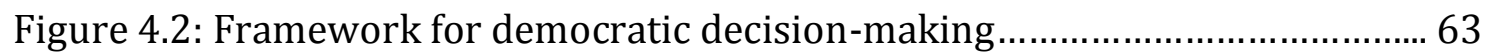

Figure 6.1: Framework for democratic decision-making (with relevant section numbers for this chapter in the headings) 100

Figure 6.2: The democratic framework as per the case of Escarpment Mine, the decisions and environmentalist participation.... 


\section{Abbreviations}

CMA - Crown Minerals Act 1991

DoC - The Department of Conservation

OIA - Official Information Act 1982

RMA - Resource Management Act 1991 


\section{Chapter one:}

\section{Introducing opposition to}

\section{Escarpment Mine and issues with democratic decision-making}

Coal mining on conservation land is a convergence of multiple environmental and democratic concerns. Climate change is primarily caused by human-induced greenhouse gas emissions, and thus, the use of coal and consequent release of carbon dioxide contributes to climate change. Additionally, a mine that is proposed on conservation land risks damage to flora and fauna. Yet those most concerned about these environmental issues are not being heard by decision-makers. Dominant discourses of neoliberalism and economic gain that drive extractive industries often prevail over environmentalists' concerns. This raises questions about justice, equality and democracy. The overarching research objective of this thesis is to understand how democracy is actualised or constrained through environmentalists' actions about decisions made for coal-mining on conservation land. This is explored through environmentalist opposition to Escarpment Mine on the West Coast of the South Island, in both informal participation in democracy through activism, and formal participation as prescribed by legislation.

\subsection{Democracy}

Democracy is a contested concept, an ideal under which society has aspired to govern itself and be governed. Democratic decision-making is also a generally accepted criteria for good environmental governance and management. People affected by a decision have a right to have a say in that decision. This broad principle is underpinned by concepts such as equality, justice and rule of the people as the founding tenets of democracy. Theories of democracy are broad and 
dissatisfaction with liberal democracy and representative democracy has led to alternative theories emerging that are more participatory and just. In particular, deliberative democracy (with the planning equivalent communicative planning) and radical democracy (with agonistic planning) propose alternative ways in which to conceptualise and work with disagreement in democracy. Deliberative democracy focuses on rational deliberation and debate, guiding decisions towards consensus (Bond, 2011a; Munton, 2003; Pugh, 2005). Similarly, communicative planning is a planning practice that encourages participation in the form of deliberation, steering towards consensus in decisions (Bäcklund \& Mäntysalo, 2010; Pugh, 2005). Radical democracy, conversely, suggests that some differences in society are irreconcilable, making the aim for consensus unfeasible (Little, 2002). The concept of agonism is central to radical democracy and agonistic planning, whereby disagreement is seen as necessary, not detrimental, for democracy to function (McClymont, 2011).

It is important to explore how such theories are reflected in practice, if we are to advance democracy in cases where there are strong opposing views about decisions affecting the environment and society. This is especially within democratic decision-making and participation processes such as in the Resource Management Act 1991 (RMA). In particular, such research is critical at a time when decision-making about environmentally degrading activities that contribute to climate change continue to be made, despite a broad scientific agreement on the severity of the consequences that will result from increasing greenhouse gas emissions to the atmosphere (IPCC, 2007; Oreskes, 2004). These issues are both pressing and highly contested.

Furthermore, activism and environmentalist action outside the formal processes are part of the functioning of democracy, and worthy of research. Young (2001), a theorist of deliberative democracy, suggests that theories of democracy rarely discuss the role of activism or participation in democracy outside formal processes. This thesis, which includes how environmentalists' activism influenced the decisions made about Escarpment Mine, contributes to such theories of activism in democracy. Additionally, Bäcklund and Mäntysalo (2010) argue that more research is needed in linking theory to practice in agonistic planning theory, 
further connecting democracy and planning. This is an area which this thesis also addresses.

\subsection{Escarpment Mine and environmentalist opposition}

Despite the RMA being lauded as offering democratic decision-making processes, environmentalist opposition to large projects is often not heard in favour of economic development. Moreover, many groups participate in both activist actions outside of the formal decision-making process as well as participating in the formal process. In light of the understanding of democracy stated above, I ask how do these various activities influence decisions taken on large contested projects with significant environmental effects? Escarpment Mine presents a unique opportunity to explore these questions and is the case study used in this research. It is a proposal for an open cast coal mine on the Denniston Plateau on the West Coast of New Zealand, which was granted various resource consents under the RMA in 2011 by the two local councils (Archer, McGarry, \& Heal, 2011). Environmental activists engaged with the council decisions through the public submission process in 2010 and 2011 (Ridge \& Inwood, 2011). The council decisions were appealed to the Environment Court by two environmental groups, with the decision to be announced early $2013^{1}$ (The Environment Court of New Zealand, 2012). Additionally, environmentalists have undertaken extensive campaigning and activism in opposition to the proposal ${ }^{2}$. While campaigning appears to have had no direct effect on the formal decision-making process, it has prompted public discussion about the environmental effects of such a project through mainstream media channels ${ }^{3}$.

Two factors are of central concern to the environmentalists involved in opposition to this mine; conservation and climate change. First, the biodiversity of the Denniston Plateau is at threat from habitat destruction caused by Escarpment Mine (Forest and Bird, 2012a). The plateau is seen to be a unique ecological environment, with some arguing it should be protected from any mining (Forest

\footnotetext{
1 The hearings were held in late 2012 and at the time of writing, the decision by the Environment Court had not been announced.

2 See Forest and Bird (2012b) and Coal Action Network (2012) for example.

${ }^{3}$ Examples of this case in the media include Berry (2012), Rutherford (2012), TVNZ (2012) and Young (2012).
} 
and Bird, 2012a; West Coast Environment Network, 2011a). Second, the end-use of Escarpment Mine's coal will release greenhouse gases into the atmosphere.

Climate change is primarily caused by high levels of greenhouse gases emitted by human activity (IPCC, 2007). Despite this, the government continues to support exploration for oil and gas, and increased coal mining and production (Ministry of Economic Development, 2011). Opening yet another coal mine ${ }^{4}$ will increase New Zealand's contribution to climate change with irreversible global impacts. Regardless of these issues, most environmentalists felt that their concerns about biodiversity and climate change were not awarded the attention they deserved in the formal participation process under the RMA.

In contrast, the decision-makers at the council-led hearing granted the consents for Escarpment Mine based on the economic benefits to the region (Archer et al., 2011). Bathurst ${ }^{5}$, the project developer and consent applicant, argued that the mine will bring hundreds of millions of dollars into the Buller district and create hundreds of jobs (Archer et al., 2011). The tension between environmental issues and economic interests is nothing new, especially in regions dependent on extractive industries for economic growth. Dominant discourses that adhere to neoliberal ideologies and economic growth prevail, and drive the expansion of extractive industries.

Through interviews with environmentalists opposed to Escarpment Mine and council officials involved in the decision-making process, this thesis explores the way in which democracy is actualised or constrained when environmentalists are opposed to such extractive and environmentally degrading activities and where there are tensions between the dominant drive for economic growth, and environmental protection. Understanding the nexus between formal and informal

\footnotetext{
${ }^{4}$ There are approximately 22 coal mines currently operating in New Zealand (Ministry of Economic Development, 2013).

${ }^{5}$ The company with the mining rights that are associated with the Escarpment Mine proposal has changed name and ownership. Initially L\&M Coal, a local company, applied for consents in 2010, but then was acquired by Buller Coal Limited later in 2010 (Bohannan, 2011). Buller Coal Limited is a subsidiary of Bathurst Resources Limited (Bohannan, 2011). Throughout this thesis, I have referred to the company as Bathurst to avoid confusion, as the company's ownership is not a critical part of this research.
} 
participation in democracy is critical to gaining clear insights on how democracy is actualised by environmentalist action.

Little has been written about New Zealand's environmentalism in academic literature, and especially not in the area of environmentalists' influence in formal participation processes led by councils or government. Other research on formal participation processes has analysed stakeholder involvement in planning processes, but little has been undertaken specifically on environmentalist participation. This research focuses on environmentalists' influence in both the formal participation process and in activism, contributing to literature on environmentalism in New Zealand.

\subsection{Research objective and thesis overview}

In light of the discussion above, the overarching research objective of this thesis is to understand how democracy is actualised or constrained through environmentalist actions about decisions made on coal-mining in conservation land, in both informal participation in democracy through activism, and formal participation as prescribed by legislation.

More specifically, my research questions are as follows:

1. How do theories of democracy, participation and activism address disagreement in decisions about the environment?

2. How have environmentalists' actions outside of formal processes influenced resource consent decisions about coal mining on conservation land?

3. How has environmentalists' participation in formal processes influenced resource consent decisions about coal mining on conservation land?

4. How does environmentalist action, both through formal processes and through other actions, reflect democratic principles?

Table 1.1 illustrates how the objectives are to be fulfilled, and where in the thesis they are discussed. In particular, Chapter two discusses the methodology used in this research, with constructivism and post-structuralism as the basis for the methods applied. The primary research, consisting of 15 interviews with 
environmentalists and council officials, is also detailed in Chapter two. Chapter three provides context to the case and to environmental politics and activism in New Zealand. This includes the influence that environmentalists have had in three previous cases of environmentalism in New Zealand, both through formal participation processes and outside of these formal processes. In the case of '2 precious 2 mine', protests around the country and numerous formal submissions spurred the government to retract a proposal to remove protection from mining for some areas of conservation land. Conversely, the direct action of the Save Happy Valley Coalition was unsuccessful in halting the expansion of the Stockton Mine. In the Mokihinui case, environmentalists' efforts in campaigning in combination with their participation in the formal participation process under the RMA may have contributed to the proposed hydro dam being withdrawn. This chapter includes a review of literature and media and publicity from environmentalist groups, illustrating the nexus of formal participation processes and informal participation through activism, and the influence of both combined.

Table 1.1: How the objective of this thesis will be fulfilled

\begin{tabular}{|l|l|l|}
\hline $\begin{array}{l}\text { Research } \\
\text { question }\end{array}$ & Method of fulfilling research question & Chapter \\
\hline 1 & Literature review & 4 \\
\hline 2 & Interviews with environmentalists and council officials & 5 \\
\hline 3 & Interviews with environmentalists and council officials & 5 \\
\hline 4 & $\begin{array}{l}\text { Interviews with environmentalists and council officials, } \\
\text { analysed in relation to literature from Objective 1/Chapter } \\
\text { four and Chapter three }\end{array}$ & 6 \\
\hline
\end{tabular}

Research question one is discussed through a literature review that is found in Chapter four. The ethos of democracy and the theories of deliberative democracy and radical democracy are discussed and critiqued, from which I create a framework to analyse my case study. Research questions two, three and four have been explored through primary research with the chosen case study, environmentalist opposition to Escarpment Mine. The interviews with environmentalists about the influence of their actions within formal processes and outside of these processes, as well as council officers involved, is discussed in Chapter five. In Chapter six, I present the analysis of the interviews and the case in 
relation to theories of democracy and disagreement, using the framework devised from the literature that incorporates elements of both deliberative democracy and radical democracy. Chapter seven concludes this thesis, as well as making recommendations for further research and for planning practice. 


\section{Chapter two: Methodology}

The primary research for this thesis is a qualitative study with people involved in a consent process for a coal mine in New Zealand. The chosen case study is the council planning process and subsequent decisions made about Escarpment Mine, the proposed open cast coal mine on the Denniston Plateau on the West Coast of the South Island (detailed in Chapter four). The epistemological framework is constructivism with a post-structural methodological approach. My primary research comprises semi-structured interviews with environmentalists involved in the submission process and protest against Escarpment Mine, as well as council officers involved in the decision-making processes for the various resource consents. A Foucauldian discourse analysis was used to analyse the data. This chapter outlines this approach and associated methods in more detail.

\subsection{Constructivist epistemology}

Constructivism $^{6}$ is an epistemology that perceives reality and knowledge as being socially constructed and subjective, whereby an absolute truth is neither possible nor desirable (Baxter \& Jack, 2008; Costantino, 2008; Creswell, 2003; Kobayashi, 2001). The meanings that individuals seek and create of the world "are varied and multiple, leading the researcher to look for the complexity of views rather than narrowing meanings into a few categories or ideas" (Creswell, 2003, p. 8). Thus, the purpose of research is to explore participants' perspectives of the situation under study (Creswell, 2003). Holstein and Gubrium (2011) suggest that "the hows and whats of the social construction process echo Karl Marx's (1956) maxim that people actively construct their worlds but not completely on, or in, their own

\footnotetext{
${ }^{6}$ While there are subtle differences in the history of constructivism and social constructionism, they are often used interchangeably (Costantino, 2008). In this thesis, particularly in Section 2.1, I employ the term constructivism to refer to the commonalities between both constructivism and social constructionism.
} 
terms" (p. 342, emphasis in original). Social, historical and political contexts shape peoples' meanings and perceptions of the world around them. Constructivism lends itself to a post-structuralist methodology, as well as a critical understanding of discourse and power.

\subsubsection{Post-structuralism}

Post-structuralism is my methodological approach because I interpret the knowledge created in this research to be situated in participants' understandings and subjective experiences, as well as ways of telling and re-telling such understandings. Post-structuralist approaches reject and deconstruct the idea of overarching structural powers, in favour of an understanding of subjective meaning and power that is social and relational (Davies \& Gannon, 2005; Fawcett, 2008; Limb \& Dwyer, 2001). This reinforces the epistemology of constructivism. The fluidity and dynamic nature of meanings is emphasised (Fawcett, 2008; Limb \& Dwyer, 2001), while "meaning can be produced and temporarily fixed only in specific contexts" (Fawcett, 2008, p. 667). Post-structural qualitative research analysis emphasises the diversity of roles that people have, and how people's descriptions of events are essentially their own construction and interpretation of what has occurred (Fawcett, 2008). Thus, I understand knowledge to be held by the 'knower', meaning that the telling of knowledge is also interpreted through the listeners' knowledge.

A post-structural analysis requires the researcher to take "apart the endless layers that are seen to constitute social reality" (Fawcett, 2008, p. 668), particularly through looking for recurring themes, patterns, contradictions and variation within research participants' accounts (Fawcett, 2008). This understanding of knowledge makes the interpretation of language key to the analysis of the data. A post-structural approach lends itself to discourse analysis (discussed below), and an acknowledgement of the researcher's positioning in the world (see 2.1.3).

\subsubsection{Power and discourse}

Under a constructivist approach, knowledge is not in the mind of an individual, but is created socially (Gergen \& Gergen, 2008). Holstein and Gubrium (2011) state that Foucault recognised how historical and cultural contexts shape people, their 
knowledge and their meanings of the world. Discourse can be considered as socially constructed bodies of language with certain associations and meaning (Cook, 2008). Followers of Foucault emphasise that discourses "are not merely bodies of ideas, ideologies, or other symbolic formulations, but are also working attitudes, modes of address, terms of reference, and courses of action suffused into social practices" (Holstein \& Gubrium, 2011, p. 344). From a Foucauldian perspective, different socially constructed knowledges and groupings of language interact, demonstrating relationships of power (Cook, 2008; Kobayashi, 2001). This perspective argues that language and the way language is used is critical to understanding how society functions and the various dimensions of power in social relations (Robbins, 2012).

When there are dominant discourses, or when knowledges are assumed to be universal or absolute, other knowledges, understandings or assumptions are undermined and considered outside the realm of possibility (Gergen \& Gergen, 2008; Holstein \& Gubrium, 2011). Foucault's theories suggest that "some logics come to pervade a network of power relations so that people, groups, and institutions within that web come to naturalize and accept these logics as their own" (Robbins, 2011, p. 75). Fawcett (2008) suggests, of Foucault's work, that while it may appear that some people stand a lot to gain from a dominant discourse, these people "are voluntarily more constrained by regulatory aspects than others occupying less privileged positions" (p. 667). Hence, prevailing discourses involve power and the governing of individuals' actions for all those involved, regardless of their positioning.

Kobayashi (2001) suggests that social science research aims to "understand the conditions under which human actions have more or less efficacy, more or less power to affect others and to effect change" (p. 67). Robbins (2012) proposes that researchers investigate how people create their environmentalist identities in asking "what systems of control do such subjects make social and political sense?" (p. 76). Studying the efficacy of actions and the relationships of power between various knowledges is fundamental to my research on how environmentalist action is able to have influence in planning decisions about coal-mining on conservation land, particularly when there are certain discourses that dominate in 
the decision-making process. It is important to reveal how power is actuated in such a way as to deny meaningful participation in a so-called democratic decisionmaking process.

\subsubsection{My positionality}

With discourse as "the nexus between power and knowledge" (Cheek, 2008, p. 355), all language is laden with value and there will be unstated meanings associated with language used between researcher and research participants (Cheek, 2008). Creswell (2003) states "the researcher filters the data through a personal lens that is situated in a specific socio-political and historical moment" (p. 182). The researcher's awareness of their positioning in relation to those under study, as well as self-reflection about the research process, is part of a poststructuralist approach (Davies \& Gannon, 2005; Fawcett, 2008) and qualitative approaches (Limb \& Dwyer, 2001; Mason, 2002). In using a discourse analysis approach to interpreting data, the researcher must acknowledge that they will be associating their own meanings with language used by research participants, and therefore transparency in their positionality is critical for sound research (Cheek, 2008; Waitt, 2010).

As a researcher I am aware of my own positionality, and the way that this influences how I interpret and analyse information offered to me. Here I briefly discuss things in my life that influence my positionality. I am a member of Forest and Bird and several other environmentalist groups. Prior to this research I received information about the case studied here and followed it with interest, along with other information on issues to do with conservation and climate change. I also sometimes participate in petitions or protests, although I have not been involved in coordinating such actions. I have experienced working as a council officer between 2008 and 2011. This helped me understand the neutral, socalled objective stance that council officers tend to present when talking about council processes and decisions, out of a perceived necessity to promote fairness. In this sense, there is the potential for my research to be interpreted through the knowledge I have constructed in myself with experience of both environmentalism and work as a council officer. Being aware of the potential for my bias creates a 
transparency in the research process, aiding me to conduct fair and thorough research.

Kobayashi (2001) discusses the challenges of remaining neutral during interviews. She argues that while not revealing her opinion on the issues discussed during the interviews and ensuring that questions gave opportunities for a wide scope of answers, neutrality is simply not possible. There is always naturally more rapport with some interviewees compared to others (Kobayashi, 2001). Furthermore, there are often "a few hostile to our stated intentions" (Kobayashi, 2001, p. 64). While I did not experience hostility from any research participants, I sensed that my positionality and the personalities of those I interviewed shaped the way participants communicated with me in interviews. Clearly some people chose their words very carefully (in particular one of the council officers), while others were very open with what they disclosed. Many participants welcomed me into their homes, with one offering for me to stay in their spare room and others inviting me for meals. Mostly I declined such offers due to time restrictions, but I accepted where it felt fitting. There were also moments where environmentalists expressed such depth of emotion about issues that I, too, have views about. I expressed empathy in such situations, particularly when interviewees noted very personal concerns, such as threats to personal safety or health.

In her research about racism in Canada, Kobayashi (2001) also discusses the ethical obligation to present subjects fairly, while also contributing to research and understanding about oppressive relations. At times during interviews, participants responded to my interview questions in ways I could not have anticipated. I have sought to represent their opinions in a way that is fair and can contribute to understandings about such perspectives. I respected each individual's views and knowledge as equally valuable to the research, while also considering views in the context of all the data collected. Although during interviews I was not explicit about my opinions on new coal mines, in some cases it may have been apparent where my position lay. However, my opinions about coal mining did not change the nature of the questions I asked (research questions and objectives, as well as interview questions), which focus on democracy, disagreement, and meaningful participation in decision-making. 
While I am aware of my positionality and how it may shape the interview process and subsequent analysis of my interviews, I have aimed to conduct fair and just research that provides a thorough analysis of the situation by acknowledging various points of view and the complexity of the decisions made.

\subsection{Research methods}

In this research I conducted fifteen semi-structured interviews with people in a single case study. I used a Foucauldian discourse analysis to explore the data, with particular attention to diverse knowledges and power relations between discourses. Qualitative methodologies acknowledge the dynamic and subjective nature of reality and experience (Limb \& Dwyer, 2001), fitting with a constructivist post-structuralist approach. Under qualitative approaches, data cannot be statistically measured and the idea of 'truth' is negated, in favour of lived experience and shared meanings (Limb \& Dwyer, 2001).

\subsubsection{Case study}

I have chosen a single case study as a focus for my research. This case study is discussed in depth in the next chapter. The Escarpment Mine fulfils a number of characteristics that are particularly relevant to gaps in the literature about environmentalist participation in planning decision-making processes, the role of activism in democracy, and environmentalism in New Zealand. Stark and Torrance (2005) suggest that case studies in social science research seek "to engage with and report the complexity of social activity in order to represent the meanings that individual social actors bring to those settings and manufacture in them" (p. 33). This aligns with constructivist and post-structural approaches which emphasise subjectivity and the context specific nature of peoples' experiences and meanings. This assists in answering the research questions by exploring how environmentalists, through their experiences, were able to influence the decisions made about Escarpment Mine.

Yin (2009) suggests that case study research is appropriate when the context is particularly relevant to the focus of the study, and also for in-depth studies focusing on answering 'how' and 'why' questions about a particular situation. The 
context of my chosen case study is critical to exploring how the context of dominant discourses has influenced environmentalists' ability to affect the planning consent decision. The previous cases of environmentalism in New Zealand and legislation which frames the formal participation processes, as discussed in Chapter three, illustrate the privileging of economic development and the way in which activism outside the formal process in combination with formal participation can effect the most change in environmental decision-making.

Baxter (2010) suggests that case studies can either test theory or generate theory, and in some occasions do both. There are varying opinions as to whether single case studies are able to create generalizable theory. Stark and Torrence (2005) state that case study research "privileges in-depth inquiry over coverage: understanding 'the case' rather than generalizing to a population at large" (p. 33). Flyvbjerg (2006) suggests that depending on the case chosen and the way in which it is chosen, singular case study research can provide valuable generalisations. On the other hand, George and Bennett (2005) suggest that "for most qualitative researchers, the development of a coherent theory itself is of primary concern, not necessarily whether the findings challenge hegemonic wisdom or whether findings adhere in all or even most cases at the time they are studied" (cited in Baxter, 2010, p. 95, emphasis in original). This argument is consistent with constructivism's approach to knowledge, in which there is no absolute truth to be sought after, and that knowledge is subjective, suggesting that multiple case studies are not directly comparable due to the varying context of specific situations. Thus, the choice of a single case study for this research is consistent with a constructivist approach, whereby the complexity of social, historical and political contexts are the basis for individuals' way-of-knowing and understanding the case.

Baxter (2010) and Yin (2009) each suggest that the value of case study research lies in the revealing of in-depth understandings about the causes of various social phenomena while integrating the various contextual factors that may be critical to understanding the circumstances. While the case of Escarpment Mine is specific in some respects (coal mining on conservation land), others are likely to contribute to 
generalizable theories about democratic processes in planning consent decisions and the role of activism in democracy.

\subsubsection{Literature review methods}

While my chosen case study and parallel cases have been important in New Zealand's history of environmental activism, there is very little written about them in academic literature. Hence, many references in Chapter three and throughout this thesis are from websites, newsletters and newspaper articles. When indicated, I have also drawn on material from interviews with participants who have been involved in various other cases.

The literature review in Chapter four fulfils my first research question, to explore how theories of democracy, participation and activism address disagreement in decisions about the environment. First, I sought literature about environmentalism and environmental activism, in order to demonstrate how environmentalism connects to literature about activism in democracy. Second, theories of democracy were reviewed to provide a framework with which I could analyse my case study. I focussed on literature that was based on the role of activism and disagreement in theories of deliberative democracy and radical democracy. Consequently, I created the framework for democratic decision-making from these various theories as explored in academic literature.

\subsubsection{Interview methods}

Constructivism lends itself to qualitative research through semi-structured interviews, as this type of research allows the researcher to foster in-depth understanding of the participants' perspectives and meanings (Creswell, 2003; Mason, 2002). There are many benefits to conducting interviews as a form of qualitative data collection. Interviews allow the researcher to gain profound understanding of people's subjective perspectives (Dunn, 2010; Peräkylä \& Ruusuvuori, 2011), as well as allowing for an analysis of situations in the past (as in this case study) or at a physical distance (Peräkylä \& Ruusuvuori, 2011). Semistructured interviews allow the researcher to progress with the aims of a constructivist approach and qualitative methodology: to enrich understandings of the contextual causes of a situation (Rubin \& Rubin, 1995). 
My primary research methods consisted of fifteen individual semi-structured interviews. Participants were chosen through their involvement in decisions made about the Escarpment Mine. Participants mainly fell into two groups:

environmentalists from groups who participated in formal consultation processes as well as environmentalist action, and council officials who were involved in processing the decision. I travelled to Nelson, Westport and Greymouth in June/July 2012 to complete nine interviews with environmentalists and council officials. All interviews were individual, bar one interview that involved two people. These interviews were held either in people's offices, homes, or cafes and other public places. Between June and August, four further interviews were held in Wellington and Palmerston North, and two via Skype, depending on the location of and convenience for the interviewees.

I targeted environmentalists from four environmental groups: one established conservation organisation, a more recent network of climate justice campaigners ${ }^{7}$, and two local environmental groups in opposition to the mine. I also met with individuals who opposed the mine on environmental grounds who were not currently affiliated with the various groups. Environmental activists who were associated with these groups were chosen (rather than individuals opposed) as their involvement in these groups indicates their broader and on-going commitment to environmentalism. These environmentalists enabled me to identify significant elements of the democratic nature of the decision-making process, and the effect of oppositional action (in this case, environmentalist action), both within and outside the formal consultation process. I made contact with environmentalists through identifying key actors in the media, and press releases, newsletters and websites from various environmental organisations. My personal networks also assisted in contacting certain environmentalists. Various environmentalists interviewed had been involved in the formal processes and activism surrounding similar cases, with two environmentalists not directly involved in opposition to Escarpment Mine. Comments about other cases were

\footnotetext{
7 'Climate justice activists' refers to activists or campaigners who are opposed to fossil fuels as the main contribution to climate change and its associated effects (P. Bond \& Dorsey, 2010). Although not in this particular case, climate justice activists also campaign for the rights of those that will be most impacted by the catastrophic effects of climate change.
} 
used to support findings about Escarpment Mine. Additionally, two people I interviewed were recommended contacts from other environmentalists, and while they did not fit the environmentalist criteria, their perceptions and experiences of opposing Escarpment Mine supported other participants' views.

I also interviewed selected council officials who were involved in the decisions and participation processes for the Escarpment Mine proposal. The aim of the interviews with council officers was to gauge how others involved perceived the environmentalists and their influence. Council officers are involved in the decisionmaking process in two main areas. First, they are responsible for publicly notifying the proposal and communicating with the public about submissions. Second, they prepare a report and recommendations for the council hearing commissioners, based on the application and the range of submissions received. Thus, their perceptions of environmentalists involved in the process was critical to fulfil the research objectives, and complementary to the interviews with environmentalists. Council officials were approached through contact details provided on council websites. Interviewees included officers from the West Coast Regional Council and the Buller District Council, as well as one of the three commissioners who were chosen by the councils to make the decision.

Table 2.1 illustrates the research participants, the groupings they belonged to, and how they were involved in different aspects of the case. In the following chapters, I have referred to participants by a randomly assigned number between 1 and 16 when discussing their ideas or quoting them directly. 
Table 2.1: Research participants

\begin{tabular}{|l|l|l|l|l|}
\hline Affiliation & $\begin{array}{l}\text { Number } \\
\text { of } \\
\text { people }\end{array}$ & $\begin{array}{l}\text { Involved in } \\
\text { formal } \\
\text { process } \\
\text { and/or made } \\
\text { submission }\end{array}$ & $\begin{array}{l}\text { Involved in } \\
\text { another } \\
\text { similar } \\
\text { formal } \\
\text { process }\end{array}$ & $\begin{array}{l}\text { Environmental } \\
\text { activism }\end{array}$ \\
\hline $\begin{array}{l}\text { Environmentalist } \\
\text { groups }\end{array}$ & 4 & $\checkmark$ & $\checkmark$ & $\checkmark$ \\
\hline $\begin{array}{l}\text { Small } \\
\text { environmentalist } \\
\text { group }\end{array}$ & 2 & $\checkmark$ & $\mathrm{X}$ & Minimal \\
\hline Council & 4 & $\checkmark$ & $\checkmark$ & $\mathrm{X}$ \\
\hline $\begin{array}{l}\text { Local } \\
\text { environmentalists }\end{array}$ & 3 & $\mathrm{X}$ & $\mathrm{X}$ & $\checkmark$ \\
\hline $\begin{array}{l}\text { Other } \\
\text { environmentalist } \\
\text { groups }\end{array}$ & 2 & $\mathrm{X}$ & $\checkmark$ & $\checkmark$ \\
\hline TOTAL & $\mathbf{1 6}$ & $\mathbf{1 0}$ & $\mathbf{6}$ & $\mathbf{1 1}$ \\
\hline
\end{tabular}

Approval from the Human Ethics Committee of Victoria University of Wellington was received in June 2012, as per Appendix 3. Any potential ethical issues arising from the interviews were discussed and resolved through the ethics application process. All interviewees were given an information sheet and consent form to sign (see Appendix 1). Interviewees were reminded that they were not required to answer all or any questions they did not wish to. With participants' consent, I digitally recorded the interviews. While opinions and data have remained confidential and participants' names and organisation are not identified, there may be situations where other individuals who are intimately involved in the case may be able to identify participants in my research. This is potentially problematic, as individuals and organisations involved have reputations to uphold that may be damaged if certain responses were attributed to them. This possible identification was acknowledged in the consent form and information sheet provided to interviewees (Appendix 1), and discussed with each interviewee. I have ensured that any identifiers such as age, specific occupation, resident location and role in organisation are not revealed in my thesis to avoid the potential for such identification. Interestingly, many of the participants stated, without prompting, that they had no objection to their real names being used in association with their 
opinions, but for consistency, I have opted for all participants to remain confidential.

Semi-structured interviews make use of a topic guide, where the interview uses questions or topics to guide the conversation with the freedom to ask further questions as other issues arise (Dunn, 2010). My topic guide (Appendix 2) was based on my objectives and various theoretical frameworks of democracy. Questions referred to participants lived experiences of the planning process, aiming to gather an understanding of their experiences and perspectives on what had occurred, as per the constructivist qualitative research approach discussed earlier in this chapter. This is in contrast with undertaking a social survey interview method, which would ask about "what they 'would do', or what they have 'generally done' under certain circumstances" (Mason, 2002, p. 64). Such survey interview methods would imply an approach that is aiming to uncover statistical 'factual' information, contrary to a constructivist and post-structural approach. Because of the semi-structured nature of interviews, some interviews also contained a variety of unplanned questions depending on the flow of the conversation. The topic guide was indicative of general themes of the conversation, and new avenues of discussion emerged as each interview progressed. Furthermore, I used open-ended questions, which are crucial for a constructivist approach as they allow the research participants to express their perspectives from their own cultural and historical context (Creswell, 2003).

In July and August, I transcribed or summarised interviews, depending on the level of relevance to my research. I provided transcripts or summaries of the interviews to each participant, which they were invited to amend, comment on, or withdraw information from. Three participants made minor amendments to the transcripts and four replied that no changes were necessary. Other participants did not respond to this invitation. My completed thesis will also be available to participants, so that they are able to utilise any findings for their own work.

\subsubsection{Analysis}

I used a Foucauldian discourse analysis to analyse my data, using both inductive and deductive coding techniques. In line with using a constructivist approach, I 
focused on generating theory rather than verifying theory (Creswell, 2003). I used largely an inductive approach to analysis, although as Creswell (2003) notes, qualitative research is an iterative process, often with inductive and deductive processes used alternately to develop ideas and group data. In coding data, I found that certain codes were developed intuitively (inductively) as a result of the interview process, interview content and reflection. In addition, part of my analysis involves using theoretical frameworks of democratic decision-making from my literature review to code my data (deductive coding). Nonetheless, in accordance with a constructivist and discursive approach, I am emphasising interviewees' own perspectives and the discourses that emerge through the interviews, which involved building on the codes that arose from the data and expanding on them with codes from the literature.

In using discourse analysis, I aimed to gain understandings of the circumstances that have led to privileging particular discourse practices (Mason, 2002; Waitt, 2010), as opposed to simply exploring the contextual factors for actions, as an interpretivist would do in their analysis. There are numerous forms of discourse analysis, with the common factor being that the analysis focuses on language and its role in society (Potter, 2008). Here a Foucauldian discourse analysis was used to explore power relationships evident between knowledges, or, the way in which discourses are normalised and become dominant over alternative knowledges (Cheek, 2008; Waitt, 2010). Another critical element is the identification of 'silences' or omissions of information, as this indicates the power that a privileged discourse may have over silenced, alternative meanings or ways of thinking about the world (Waitt, 2010).

While discourses appear to have fixed structures (about what is considered common-sense, normal or true), the way that discourses are embedded in social relations makes them prone to continuous instability (Waitt, 2010). This makes space for discourses to be constantly challenged, in turn generating contradictions and ambiguities within texts (which are interview transcripts in this case) (Waitt, 2010). Contradictory themes often emerge in qualitative research given the complexity of participants' meanings (Rubin \& Rubin, 1995). The role of the research is to interpret the meaning of these contradictions (Rubin \& Rubin, 1995), 
particularly in Foucauldian discourse analysis, where such contradictions may indicate challenges to and/or the invisibility of dominant discourses (Waitt, 2010). My research uses this concept to reveal the intensity of such discourses, and the efficacy of challenging them. This is particularly the case in Chapter five, where I discuss the power relationships between different knowledges presented in the formal process, and in Chapter six, where certain discourses and understandings of democracy prevail over others.

Foucauldian discourse analysis also acknowledges the iterative nature of analysis, whereby the research influences the researcher, which in turn influences the way that the researcher interprets data (Waitt, 2010). This iterative process has been beneficial in my research process to uncover new layers of meaning from the data.

\subsection{Synopsis}

A constructivist epistemology and post-structural approach to this research allows for the subjective perspectives of the research participants to be analysed in relation to power and discourse. The research process is made more transparent through the acknowledgement of my positionality and the influence that my own subjective experiences may have on the interpretation and analysis of data. Semistructured interviews were used with the purpose of allowing participants to talk about their experiences from their perspective and to allow for new topics of importance to emerge. The activism surrounding Escarpment Mine and the planning consent process, as a single case study, fosters an analysis which is indepth, and while the findings are context specific, there are findings that contribute to the broader understanding of the discourses at play in planning consent processes in general. 


\section{Chapter three:}

\section{Environmental activism and politics in New Zealand}

This chapter discusses the context of environmentalist participation in formal processes and informal participation through environmental activism. This illustrates how environmentalists are able to be effective in government and/or council decisions about the environment, and what expectations may have been established about the influence of different environmentalist mechanisms on decisions taken. More specifically, this chapter discusses the factors that create the nexus between formal processes and informal participation through activism, and how different compositions of the two are able to effect change.

I start by introducing the proposal for Escarpment Mine and associated factors: the company Bathurst; the submission process led by councils for formal participation; and the environmentalist opposition to the mine. I then discuss Escarpment Mine in relation to other similar cases where environmentalism has been prevalent. These parallel cases are most closely related to issues which are evident in the opposition to Escarpment Mine, in particular, highlighting the nexus between influence in formal processes and environmentalist action or protest outside of these formal processes. I have chosen cases that also link to the RMA and the Crown Minerals Act 1991 (CMA). These cases are: '2 precious 2 mine'; the Save Happy Valley Coalition; and the campaign against the proposal for a hydro dam on the Mokihinui River' I discuss how the '2 precious 2 mine' protests in 2010 provide a backdrop for the way mining on conservation land is perceived in New Zealand. This is also an example of how protest action can be highly effective

${ }^{8}$ There have been many campaigns that have been far-reaching that are not discussed in this chapter (such as the Native Forest Campaign of the late 1970s, or the protests against genetic engineering from the late 1990s). These are also important cases but have less in common with the Escarpment Mine proposal. 
alongside formal participation. Secondly, in comparing the Escarpment Mine case with the Save Happy Valley Coalition, I illustrate two different approaches to environmentalist opposition to coal mining on conservation land when the RMA is the primary legislation applicable. Thirdly, I show the resemblance between Escarpment Mine and the Save the Mokihinui campaign, highlighting the nexus between formal participation and informal participation, and the effectiveness of combined participation.

In addition to environmentalist protest, all of these examples operate under legislation which has differing requirements for formal participation. I primarily discuss the RMA, as well as its relationship to the Conservation Act and the CMA, in order to demonstrate the legislative requirements enabling participation. These statutes tend to favour neoliberal ideals, raising issues for democracy. Furthermore, these requirements for formal participation may lead decisionmakers to deny the validity of activism. The hegemonic idea that participation can only occur through formal processes also raises issues for how democracy is practised, especially by those with decision-making power.

\subsection{Escarpment Mine on the Denniston Plateau and parallel cases}

The Denniston Plateau lies north of Westport on the West Coast of the South Island, as shown in Figures 3.1 and 3.2. Bathurst Resources Limited, an Australian mining company, was granted resource consent in 2011 for an open-cast coal mine in the Denniston Plateau ${ }^{9}$ (Archer et al., 2011). This project was considered under the RMA ${ }^{10}$, by the West Coast Regional Council and the Buller District Council, the boundaries of which can be seen in Figure 3.3. As listed in Table 3.1, the formal written submission process was 24 September to 22 October 2010, with significant opposition to the project on environmental grounds (Ridge \& Inwood, 2011). The hearing committee was held over 13 days in June and July 2011 (Archer et al.,

\footnotetext{
9 The Denniston Plateau was the site of an underground coal mine from the 1870s, peaking in the late 1800s, and slowing to a halt from the 1960s to the 1990s (Nathan, 2013; Sherwood \& Phillips, n.d.). However, one participant stated that the underground mining and associated infrastructure only modified up to $7 \%$ of the plateau (participant 2). It seems this modification was mainly underground, meaning that most of the plateau still comprises of undisturbed conservation land (participant 2).

${ }_{10}$ The RMA process will be detailed in Section 3.2.
} 
2011). In 2012, Forest and Bird and the West Coast Environmental Network Incorporated appealed the decision to the Environment Court, with the decision on the hearing to be announced in 2013 (The Environment Court of New Zealand, 2012). The Escarpment Mine proposal and associated environmentalist concerns have many similarities to the three parallel cases chosen; concern about mining on conservation land, formal participation under the RMA and other submission processes, and activism outside of these processes.

Table 3.1: Important dates in the formal process of Escarpment Mine

\begin{tabular}{|l|l|}
\hline Time period & Activity \\
\hline $\begin{array}{l}\text { September and October } \\
2010\end{array}$ & Formal submission process \\
\hline June and July 2011 & Hearing committee (council led) \\
\hline October to December 2012 & Environment Court hearing \\
\hline Early 2013 & $\begin{array}{l}\text { Environment Court decision to be } \\
\text { announced }\end{array}$ \\
\hline
\end{tabular}

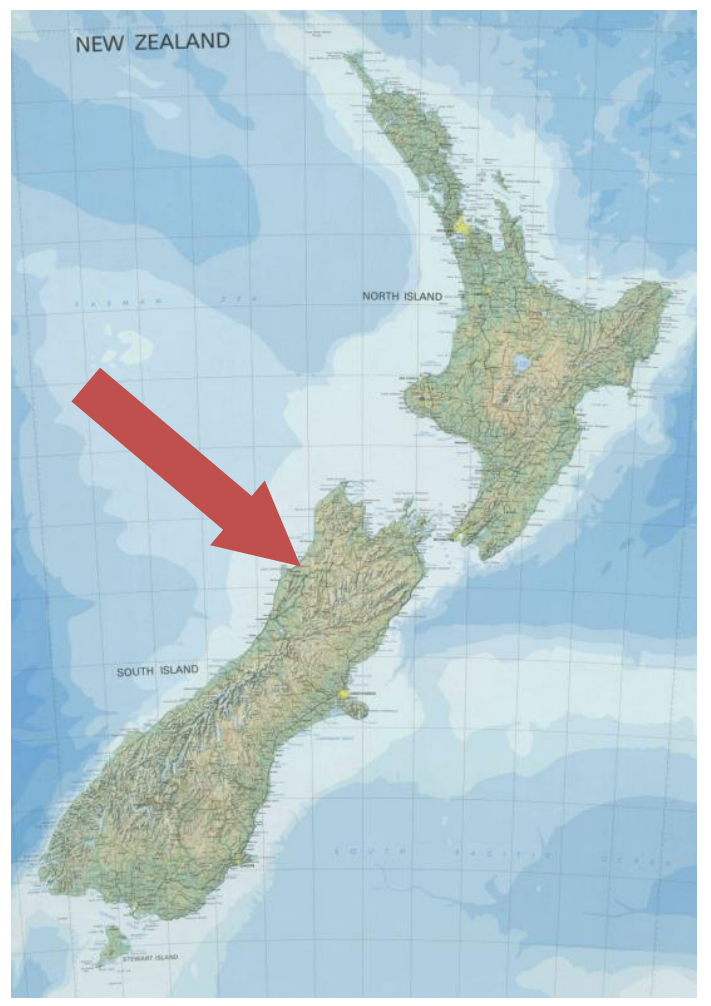

Figure 3.1: Map of New Zealand, with the location of the Denniston Plateau (as indicated with red arrow). Source: Land Information New Zealand (n.d.). 


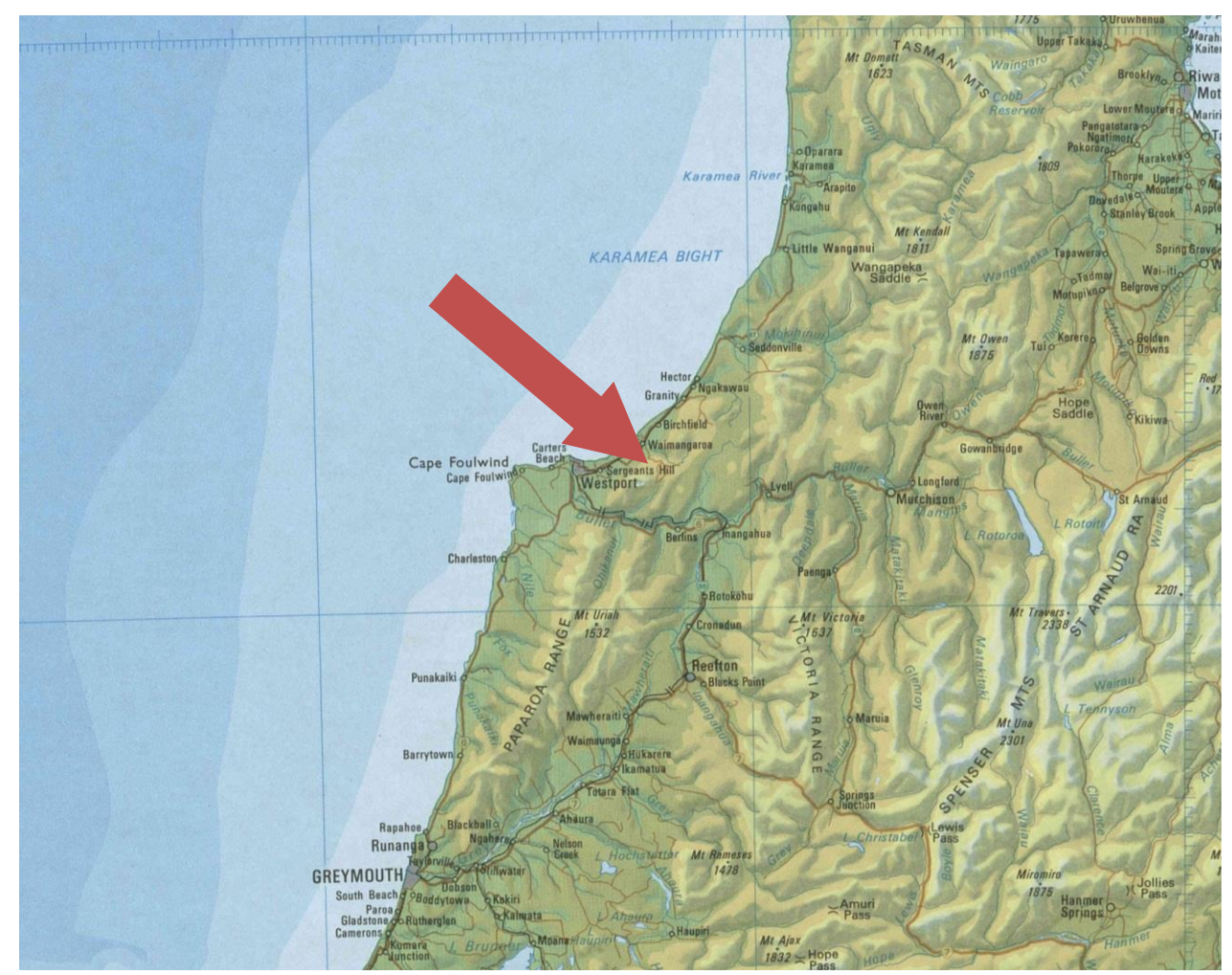

Figure 3.2: The Denniston Plateau (as indicated with red arrow) in relation to Westport. Source: Land Information New Zealand (n.d.).

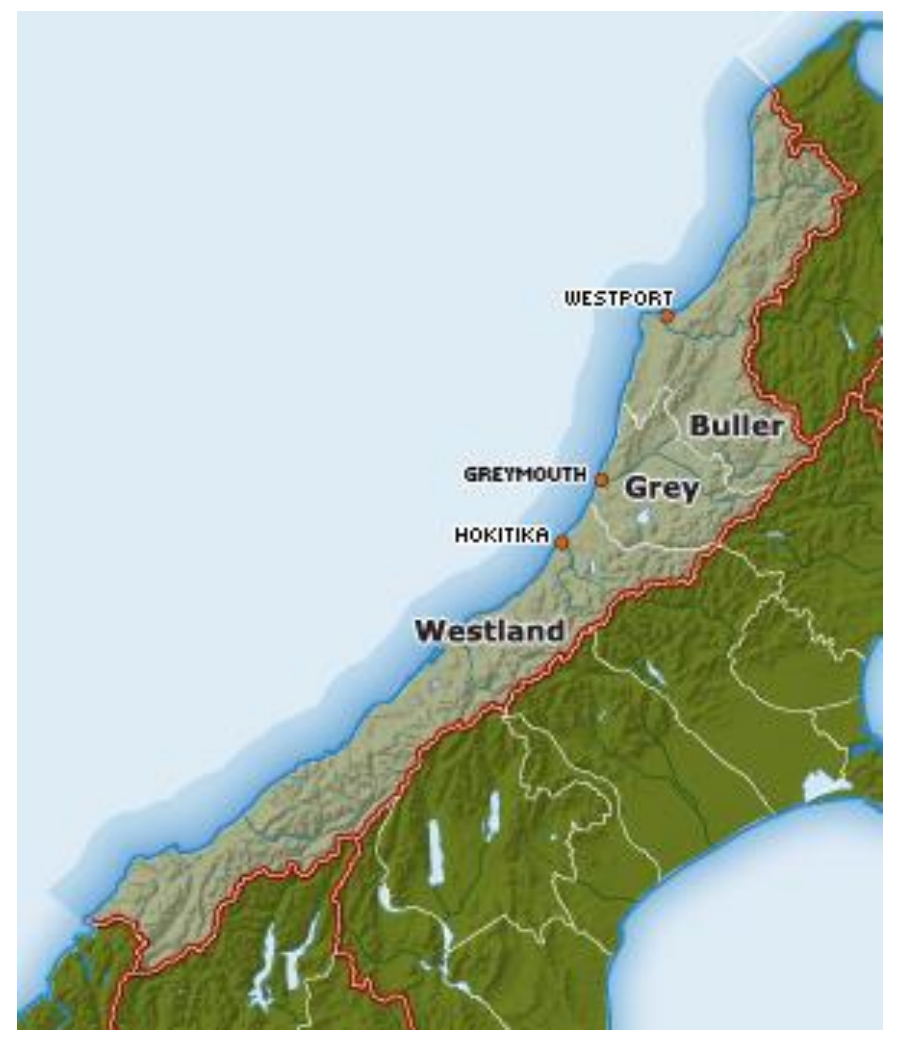

Figure 3.3: The West Coast Regional Council's boundary area, illustrating the three district councils within this area. Source: Department of Internal Affairs (2011). 


\subsubsection{Environmentalist opposition to Escarpment Mine}

There are various groups in opposition to the mine, with three appearing to be the most publicly active: Forest and Bird, West Coast Environment Network, and Coal Action Network Aotearoa. The West Coast Environment Network is a group local to the West Coast, while the Coal Action Network is a nationwide network of climate justice campaigners against coal mining and processing in New Zealand (Coal Action Network Aotearoa, 2012). Forest and Bird is a well-established New Zealand conservation organisation that has been in operation since 1923 (Forest and Bird, 2012b).

Two factors are of central concern to the environmentalists involved in protest against this mine: conservation and climate change. The end-use of Escarpment Mine's coal will release greenhouse gases into the atmosphere, regardless of where it is used. Human-induced greenhouse gas emissions are the primary cause of climate change, with severe global consequences (IPCC, 2007; Oreskes, 2004). However, the New Zealand government continues to support exploration for oil and gas, and increased coal mining and production (Ministry of Economic Development, 2011), increasing greenhouse gas emissions. More coal mines ${ }^{11}$ will increase New Zealand's contribution to climate change, and thus, to severe global impacts. Forest and Bird say that Escarpment Mine will increase New Zealand's coal exports by up to 63\% per year (Forest and Bird, 2012a).

Furthermore, the biodiversity of the Denniston Plateau is at threat from habitat destruction caused by Escarpment Mine (Forest and Bird, 2012a). The area is a prime conservation area for native flora and fauna, and DoC has also listed significant ecological concerns in their technical report about the proposal (West Coast Environment Network, 2011a). Forest and Bird say that the area should be under Schedule 4 of the CMA, which would protect it from mining (Forest and Bird, 2012b). Bathurst Resources has argued that these conservation concerns will be mitigated through conservation projects, yet environmentalists state that these efforts would not be able to repair the damage done by the mine (Martin, 2011).

\footnotetext{
11 There are approximately 22 coal mines currently operating in New Zealand (Ministry of Economic Development, 2013).
} 
While Escarpment Mine is one specific case of a proposal for a mine on conservation land, the 2 precious 2 mine campaign illustrates strong public opposition to any form of mining on conservation land across New Zealand.

\subsection{2 '2 precious 2 mine': New Zealand's conservation land and the art of nationwide protest}

The 2010 " 2 precious 2 mine" campaign started as a response to the government's proposal to remove conservation land from the protection of Schedule 4 of the CMA, in order for it to be possible to mine on this land. Land listed in Schedule 4 is protected from any mining activity and includes some of New Zealand's most prized areas of native flora and fauna.

This case demonstrates the nexus between participation in formal processes and environmentalist protest outside of formal processes. In May 2010, New Zealand had its largest protest march yet, with approximately 50,000 people marching in different centres around the country in protest to the government's proposal of removing 7058 hectares of conservation areas from Schedule 4 (Coleman-Ross, 2010; NZPA and NZHerald Staff, 2010; ONE News, 2010). The protest included an estimated 40,000 people who marched up Queen Street in Auckland (NZPA and NZHerald Staff, 2010; ONE News, 2010). A representative from the Federated Mountain Clubs stated "The message to the Government is clear - keep your greedy hands off our precious landscapes" (NZPA and NZHerald Staff, 2010, para. 17). The protest was spurred by the proposal for allowing mining in National Parks ${ }^{12}$, the highest tier of conservation land (Parliamentary Commissioner for the Environment, 2010). Alongside raising awareness around mining on conservation land, the protests highlighted related issues, with many protestors holding antimining views and calling for action against climate change (Greenpeace, 2010).

This protest, campaigning and relentless public debate through the media, was combined with over 37,000 formal submissions on the legislative changes, with the vast majority being against any conservation areas being removed from Schedule 4 (Ministry of Economic Development, 2010). Concerns cited were mostly focused

\footnotetext{
${ }^{12}$ All National Parks are included in Schedule 4 of the CMA, as well as some areas from the other categories of conservation land (Parliamentary Commissioner for the Environment, 2010).
} 
on conservation, as well as concerns about climate change and the lack of economic viability (Ministry of Economic Development, 2010). As a consequence of these submissions and the protests, in July 2010, the government abandoned their plans to remove the proposed areas from Schedule 4 (Ministry of Business Innovation and Employment, 2011). Participation in formal processes and actions outside these processes both clearly had a strong impact.

Escarpment Mine is not on Schedule 4 land; in fact it is classed as Stewardship Land, having one of the lower levels of conservation protection while still being managed by DoC. It was therefore unaffected by the government's proposed changes to mining rules. Figure 3.4 shows the distribution of the different types of conservation land across the country. Approximately sixty percent of land managed by DoC is currently not protected from mining (Parliamentary Commissioner for the Environment, 2010). However it was unclear whether the public was aware of this figure or the diversity of conservation land, and how the outcomes of the protest would or would not affect the remainder of this conservation land. Opposition to Escarpment Mine can be considered a specific case that aligns with the values of the ' 2 precious 2 mine' protests, despite it not being in Schedule 4 of the CMA. '2 precious 2 mine' illustrates the widespread concern for preserving the conservation estate, but also perhaps a lack of understanding about the diversity of conservation land and the permitted activities that already exist on conservation land. 

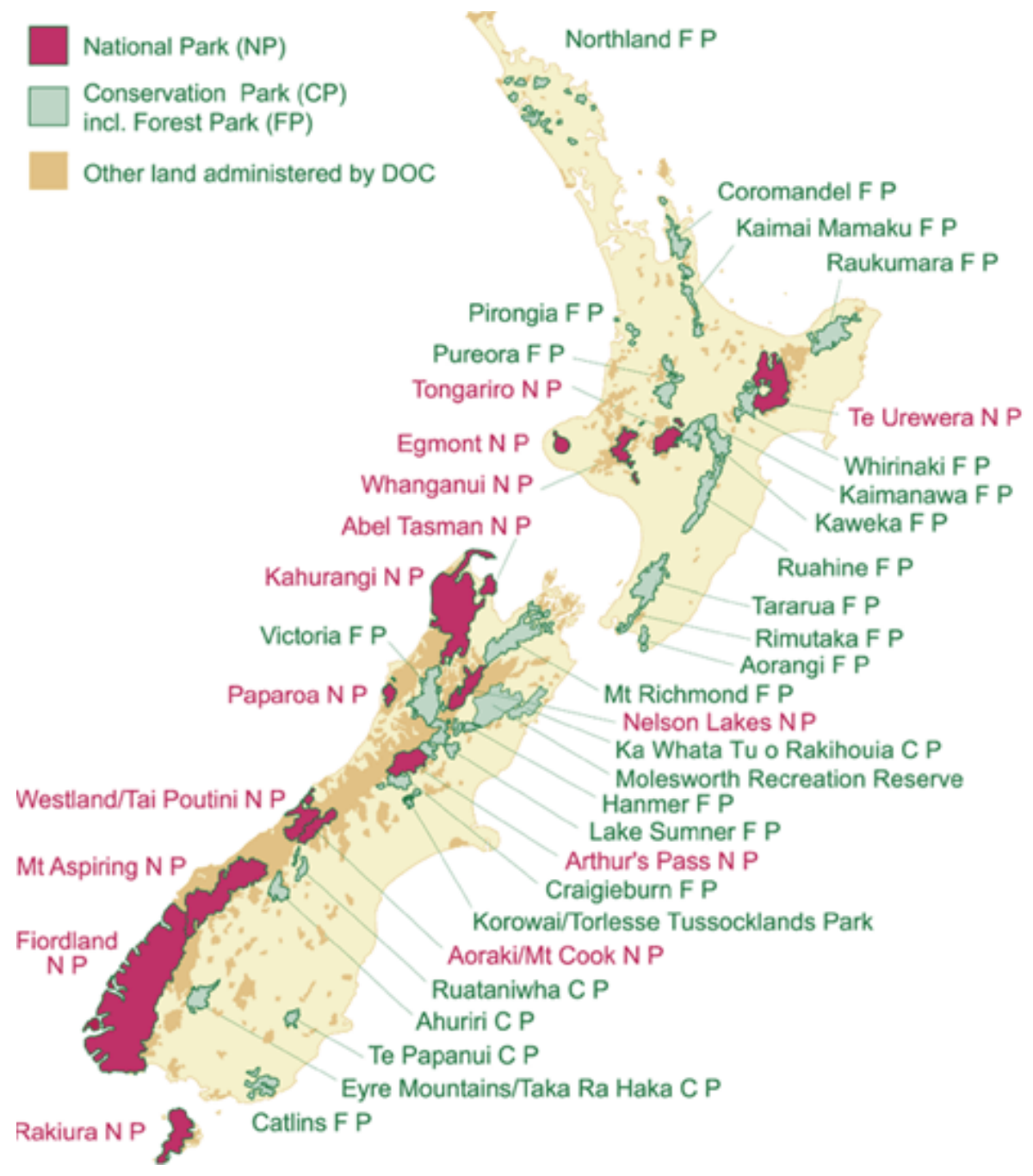

Figure 3.4: DoC owned land across New Zealand. Source: Department of Conservation (2011).

\subsubsection{Save Happy Valley}

Another specific example of mining on conservation land is the Stockton Mine, which has included different parcels of conservation land at various points in the mine's development (Parliamentary Commissioner for the Environment, 2009). The Stockton Plateau lies 35km north of Westport (Solid Energy, 2012), just north of the Denniston Plateau where Escarpment Mine is proposed. Since the late 1980s, the Stockton Mine has been in operation as New Zealand's largest open cast coal mine, currently owned by the Stockton Alliance ${ }^{13}$ (Solid Energy, 2012). The Escarpment Mine proposal is also for an open cast coal mine, with environmental concerns similar to those identified with the Stockton Mine. Mining's destruction of the Stockton Plateau is often cited as a reason for protecting the Denniston Plateau, given that they were the last two landscapes of their kind (Forest and Bird, 2012a).

13 The Stockton Alliance is comprised of Solid Energy, a State Owned Enterprise, and Downer EDI Mining NZ, a works and engineering company (Solid Energy, 2012). 
The landscapes of both plateaus have included tussock, unusual rock formations, and low-lying scrub, with native fauna thriving in the area including kiwi and a high diversity of invertebrate (Forest and Bird, 2012a). The Stockton mine has expanded gradually into the Upper Waimangaroa Valley, or Happy Valley (participant 11), employing a strategy that is allowable under the RMA, of seeking additional resource consents as needed. This means that only the effects of the additional activities are considered, and not the wider cumulative effects in relation to the adverse effects of other activities already consented (participant 11).

In 2004, the Save Happy Valley Coalition began, with a group of young radical activists from around the country who felt that it was futile to rely on participation under the formal processes of the RMA to halt the mine's expansion. As they would state to the media, " the process will fail this valley and therefore we are doing all the other work of public education and direct action and campaigning' ... which was totally true, cos every court did fail the valley" (participant 11). After a High Court decision in December 2005 upheld the consents granted for the Stockton Alliance's Cypress Extension Mine in Happy Valley (NZPA, 2006), the Save Happy Valley Coalition decided that non-violent direct action was their best option for opposing Stockton Mine's expansion (Martin, 2011). Their main action was establishing an occupation of the proposed mine area in 2006, and occupying the area for three years (Martin, 2011). Activists lived on site (a one hour drive from Westport followed by a three to five hour tramp) and had logistical support from other activists (participants 8 and 11). There were also Save Happy Valley Coalition meetings held in a number of cities across New Zealand, with various other protests and media exposure. The Save Happy Valley Coalition held a number of public meetings, although they tended to focus on more radical action such as the occupation of the valley and other non-violent direct actions (The Wire (Radio show), 2007; participants 8 and 11).

Over seven months in 2006 and 2007, the group was infiltrated by someone posing as an activist on behalf of Thompson and Clark, a private detective agency supplying information to Solid Energy ("The activist who turned police informer", 2008; The Wire (Radio show), 2007). The spokesperson for the Coalition, said in a 
radio interview that it was unlawful that Thompson and Clark hired an infiltrator "to undermine these campaigns that are trying to raise important issues such as climate change which are really critical in our society at the current time"(The Wire (Radio show), 2007). In 2012, the outgoing chair of Solid Energy defended their stance, claiming there was legitimate concern to warrant spying on the Save Happy Valley Coalition, and that protestors "will use whatever tactics no matter how lawful or how scurrilous, they will use whatever tactics they can to pursue their ends" (John Palmer, as quoted in Steeman, 2012, para. 18).

This case highlights the power and privilege that mining companies have in the political system and in society. It is difficult to measure the influence that these activists have had on society, but certainly it appears that their protests were highly challenging to the companies involved. In this case, radical protest and direct action, not accompanied by participation in the formal process, was ineffective in influencing the decisions to grant the consents. A Solid Energy annual report states that the construction for access to the Cypress Extension site began in 2010, and it appears that the mine will come into production over 2011-2014 (Solid Energy, 2011). There has been little information publicly available about whether this has already begun.

\subsubsection{Mokihinui}

This next case demonstrates the nexus of formal and informal participation, and how having diversity in the formal decision-making panel, in combination with a strong public campaign, can lead to a successful outcome for conservation. The Mokihinui River is approximately 50km north of Westport. Meridian Energy applied for resource consents for the Mokihinui Hydro Power Scheme in 2007, which would have involved damming part of the river (West Coast Regional Council and Buller District Council, 2010). The project would have generated 85100 megawatts of power (Meridian Energy, 2010), securing cheaper electricity supply to the West Coast, which is currently expensive due to the reliance on one main transmission line entering the region (Arnold, 2010).

The hearings for the consents, led by the West Coast Regional Council and the Buller District Council, were held between August 2008 and April 2009 (Meridian 
Energy, 2009). These were the same two councils involved in the Escarpment Mine consent process. There were 298 submissions against the Mokihinui proposal (Arnold, 2010) ${ }^{14}$, yet despite this, in 2010, the commissioners granted consent for the dam, stating that they had "determined that the scheme is consistent with the sustainable management of natural and physical resources and should be allowed to proceed"15 (Mokihinui Hydro Proposal Decision Summary 31 March 2010, 2010). One of the three commissioners, an ecologist, did not agree to the consents being granted, and in the decision summary, he stated:

Environments such as the Mokihinui catchment are finite resources confined to parts of New Zealand and I consider that the change that the proposed dam and its associated reservoir would impart to this unmodified environment cannot be adequately mitigated, nor can it be recreated to the same degree or scale now or in the foreseeable future (Mokihinui Hydro Proposal Decision Summary 31 March 2010, 2010, section 123).

A number of groups appealed the consents through the Environment Court on similar grounds: DoC, Forest and Bird, the West Coast Environment Network and Whitewater New Zealand (Department of Conservation, 2010; Meridian Energy, 2012). DoC (2010) argued that the dam and associated infrastructure would significantly damage the river, native bush and threatened wildlife in the area. In contrast, Meridian Energy's position on the appeals was that the Mokihinui was one of two "exceptional renewable energy projects that can extend New Zealand's reputation for creating world class engineering, environmental and socially acceptable solutions" (Meridian Energy, 2010, p. 3). Furthermore, and similar to arguments made about the economic benefits of Escarpment Mine, Meridian Energy stated "It is very important to our country's growth aspirations that projects like these are built" (Meridian Energy, 2010, p. 3). The argument of economic growth has often been used to support the use of natural resources in generating income, often to the detriment of the environment.

As well as being involved in the formal processes, environmental groups were involved in a nationwide public campaign to save the Mokihinui River from being

\footnotetext{
14 In comparison, there were 109 submissions in support of the project (Peacock, Allan, \& Bayley, 2008), less than half the number of those opposed.

${ }^{15}$ Section 5 of the RMA states that the purpose of the act is to promote sustainable management, followed by a definition of sustainable management. This is discussed further in Section 3.2.1 of this chapter.
} 
dammed. The strength of the campaign by various groups and their involvement in the formal processes clearly had an impact. In May 2012, Meridian Energy announced it would not proceed with the project, and formally withdrew the application from the Environment Court (Meridian Energy, 2012). Meridian Energy (2012) expressed that while the project was economically beneficial to the area, the potential costs involved for gaining access to DoC's stewardship land were too high to risk proceeding with the project. Forest and Bird president, Andrew Cutler, said that "It's great to see that grass roots campaigns can still win against developments backed by huge businesses" (Forest and Bird, 2012d, para. 10).

While the Mokihinui Hydro proposal was formally considered under the RMA, the Mokihinui planning consent process had significant input from DoC, unlike Escarpment Mine where DoC did not present an oral submission at the council hearing. Participants I interviewed criticised DoC's lack of involvement in the hearing for Escarpment Mine (participants 3, 5, 8, 9, 10, 13 and 14). Although the Mokihinui project consents were granted by the hearing committee, having appropriate ecological expertise on the committee appeared to emphasise the environmental concerns with the project. In the case of Escarpment Mine, there was minimal ecological expertise on the hearing committee, and Bathurst appeared to be un-phased by the cost of the Environment Court hearings or the DoC access arrangement, unlike Meridian, who cited these costs as the main reason for withdrawing the proposal (Meridian Energy, 2012).

While the outcomes of each of these three cases were different, they highlight the ways in which activism can be effective in influencing decisions made about the environment, and that formal participation is not isolated from informal participation in democracy through activism. It is evident that context is critical. Save Mokihinui and ' 2 precious 2 mine' demonstrated the strength of the combination of formal participation and actions outside formal processes, but the outcomes of this combination are yet to be seen in Escarpment Mine. Save Happy Valley illustrated the privileging of the company's economic reasoning, and the inability for radical direct action to halt the mine. These cases demonstrate that activism is a central part of democracy, that the formal decision-making process 
under the RMA is not consistent, and that decisions made about such projects are susceptible to activism and public pressure. In order for democracy's key principles of justice, equality and people's participation ${ }^{16}$ to be fulfilled, there must be acknowledgement of the nexus between formal participation processes and activism.

\subsection{Formal participation processes under legislation}

Escarpment Mine is a proposal that encompasses various decision-making processes under the RMA, the CMA and the Conservation Act 1987. In my research on how environmentalists have engaged in the formal participation processes, I have focused on the RMA. This is because the permits granted under the CMA do not require public participation, and the concessions that may be required under the Conservation Act have yet to occur.

\subsubsection{Resource Management Act 1991}

The purpose of the RMA "is to promote the sustainable management of natural and physical resources" (Resource Management Act 1991, Part 2, Section 5).

The definition of sustainable management includes:

(a) sustaining the potential of natural and physical resources (excluding minerals) to meet the reasonably foreseeable needs of future generations; and

(b) safeguarding the life-supporting capacity of air, water, soil, and ecosystems (Resource Management Act 1991, Part 2, Section 5).

Under the RMA, city, district and regional councils are given the authority to make decisions about the environment and must consider the environmental effects of any proposals, as well as the social, economic, and cultural effects on communities. Any adverse environmental effects must be avoided, remedied or mitigated (Resource Management Act 1991, Part 2, Section 5).

The applicant, in the Escarpment Mine case Bathurst Resources Limited, applied to both district and regional councils depending on the type of consent required. Regional councils and district councils oversee activities that have more than minor effects on the environment via policies and rules in district and regional plans as prescribed by the RMA. Plans provide for types of activities that require

16 This is discussed in detail in Chapter four. 
different types of resource consents in order to be undertaken. District councils are responsible for land-use consents and regional councils are responsible for water permits and discharges to air and water. Accordingly, Bathurst applied to the West Coast Regional Council for discharge and water permits associated with mining the coal, as well as for coal processing, transportation and stockpiling facilities (Ridge \& Inwood, 2011). In addition, Bathurst applied to the Buller District Council for a number of land use consents: mining; widening a road; constructing and operating two pipelines, a coal processing plant, a coal handling facility and an electrical substation; and using and transporting hazardous substances (Ridge \& Inwood, 2011).

On receiving the applications, council officers decide whether it will be publicly notified based on the extent of the effects on the environment (Fuller, 2008). This public notification enables the public to make submissions for or against a project (Fuller, 2008). Escarpment Mine, like other large scale projects, was publicly notified in late 2010. After the submission process and time for officers to prepare a report and recommendations, a hearing was held for the applicant (Bathurst) and submitters (including environmentalists) to make oral presentations. At this point, the councils involved can delegate their decision-making authority to chosen commissioners (Resource Management Act 1991, Section 34A). In this case, members of four environmentalist groups were amongst those that submitted against the mine (Ridge \& Inwood, 2011). Bathurst was granted the consents for Escarpment Mine by the councils, with the commissioners emphasising the considerable economic benefits to the region (Archer et al., 2011). These benefits of the proposal were given significantly more weight than the ecological and conservation concerns accentuated by the environmentalists opposed to the project (Archer et al., 2011).

If a person who has made a submission during this council process does not agree with the decisions made by the councils, they are able to make an appeal in the Environment Court (Ministry for the Environment, 2009a). The court is able to overturn a decision or to enforce a council's decision (Ministry for the Environment, 2009a). Forest and Bird and the West Coast Environment Network appealed the councils' decisions in the Environment Court in late 2012, with the 
decision to be announced later in 2013 (The Environment Court of New Zealand, 2012). The Environment Court makes a decision after hearing all the evidence provided at the council hearing, and additional expert evidence where supplied by the appellant or defendant (Ministry for the Environment, 2009b). The Environment Court decision may be taken to the High Court, but only on points of law (Ministry for the Environment, 2009b).

\subsubsection{Crown Minerals Act 1991 and the Conservation Act 1987}

The CMA governs permits for exploration and extraction of minerals, oil and gas (Heatley, 2012). While developers of a mining project have to apply for resource consents under the RMA for environmental effects of mining activities such as discharge to air and water and the construction of any buildings, the permits granted under the CMA are for permission to explore or extract minerals and to access land. As such, Bathurst bought the mining permits from L\&M Coal (who had originally acquired the permits) in early 2010 , and then also bought out L\&M Coal to become Buller Coal Ltd, a subsidiary of Bathurst Resources Ltd (Hartley, 2010). The CMA also defines the royalties that are paid to the Government by mining companies (Heatley, 2012). Under the CMA, specific access permits are not publicly notified, and thus, my analysis of formal participation in the Escarpment Mine case instead focuses on the RMA.

The Conservation Act 1987 is the legislation under which DoC grants concessions to build on land managed by DoC. Part 3B, Sections 170 to 17ZJ of the act outlines the process for making decisions about concessions. However, as per Section $170(3)$, "a concession is not required in respect of - (a) any mining activity authorised under the Crown Minerals Act 1991". This means that factors normally considered under the Conservation Act are not considered if the area has been authorised for mining, such as with Escarpment Mine.

There are various categories of conservation land, and the Denniston Plateau is categorised as stewardship land, meaning it has minimal conservation protection. There have been various calls for the Denniston Plateau to be classed as Schedule 4 land under the CMA, meaning that it would be protected from mining (TVNZ, 2012). Despite being granted mining permits under the CMA, a company still needs 
permission from the landowner for access arrangements in order to proceed with the mine. In the case of Escarpment Mine, Bathurst still needs access permission from the Department of Conservation, which administers the land on the Denniston Plateau. Under the Conservation Act, if DoC recommends to the Minister of Conservation that a concession be required for the use of conservation land associated with the functioning of the mine, the company will have to apply for a concession. This concession application will involve public notification and a submission period. This is yet to occur for Escarpment Mine.

There are interesting intersections of these two acts. In 2011 before the national elections, Minister of Conservation Kate Wilkinson and Minister of Energy and Resources Gerry Brownlee said that significant proposals to mine on conservation land should involve the public, signalling that a case like Escarpment Mine would be publicly notified (Stephenson, 2011). However, a day after elections, this statement was retracted (Stephenson, 2011). This has been criticised by the public and numerous environmentalists. It is interesting to note that the Ministers are responsible for making these permit and concession decisions under the CMA and Conservation Act, while decision-making under the RMA gives the responsibility to a hearing committee that perhaps could be considered less biased than the government of the day.

This section has illustrated the complex interactions of the legislation involved in proposals for mining on conservation land. These acts also raise questions surrounding the value of public involvement, and how environmentalists may have significant contributions to make when permitted to voice these concerns formally through public notification processes.

\subsection{Environmentalism and the rise of a neoliberal agenda}

As will be discussed in Chapter four, types of participation in democracy are critical to understanding the interconnectedness between environmentalist activism and political decision-making. This chapter thus far has discussed the current state of affairs with recent cases which are comparable to Escarpment Mine. Nevertheless, the history of how these decision-making frameworks came 
about is also important to understand how particular processes and values are privileged by decision-makers.

Downes (2000) suggests that the Muldoon Government (1975 to 1984) used the global energy crisis to hasten political decisions about energy without public involvement in New Zealand, leading to strong environmental movements calling for participation. Eckersley (1992) reiterates this concept by suggesting that "the early wave of environmental activism was generally seen as but a facet of the civil rights movement in its concern for more grassroots democratic participation in societal decision-making, in this case, land and resource usage" (Eckersley, 1992, p. 9). While activism was about specific environmental concerns, more importantly, it sought a system change and an increase in formal public participation processes. The Save Manapouri Campaign illustrates this well.

\subsubsection{Save Manapouri and the legacy of environmentalism}

Controversy over proposals to increase the level of Lake Manapouri spurred protest, public meetings, petitions and media attention from the 1950s to 1970s across the country in a way that was unprecedented in New Zealand's history (Peat, 1994; Wilson, 1982). The proposal involved building a hydro-electric power station in such a way that would raise the levels of Lake Manapouri and Lake Te Anau between 8 and 26 metres, to provide enough electricity to power Comalco's aluminium smelter plant at Tiwai Point (Peat, 1994; Wilson, 1982). This rise would have caused the destruction of a large area of native flora and significant habitat for native fauna, including species that were nationally endangered (Peat, 1994).

Opposition was initiated largely by local people, and the Save Manapouri campaign spread significantly in 1969, with a large meeting in Invercargill rousing numerous 'Save Manapouri' committees that were established in various parts of the country (Wilson, 1982). A 'Save Manapouri' petition with 265,000 signatures was delivered to parliament in 1970 (Peat, 1994). Due to public pressure, a Commission of Inquiry took place over three months in 1970, whereby three commissioners heard evidence from over 30 groups, only two of which supported the proposed rise to lake levels (Peat, 1994). Despite this opposition, the commission concluded 
that the Crown was contractually bound to raise the lake levels in order to increase electricity generation (Peat, 1994).

The Save Manapouri campaign was elevated to such a level that it became an election issue, and in 1972, the Labour government was elected with the promise that it would protect Lakes Manapouri and Te Anau, maintaining them at their natural levels (Wheen, 2002; Wilson, 1982). As a consequence of the campaign, the Guardians of Lakes Manapouri and Te Anau were established via legislation. The first guardians appointed were leaders of the Save Manapouri campaign (Wheen, 2002). Their purpose was to be an independent advisory body to review the effects of the hydro-electric power schemes and to make recommendations to the Minister of the Environment (Peat, 1994). Peat (1994) states that "[t]he Manapouri issue arose because those in authority thought they could decide first and consult later, and to hell with public opinion" (p. 10). Yet it was public protest that eventually held the power and changed the course of the decision. This protest was before the rise in neoliberal policies in New Zealand, and demonstrated environmentalists' push for more public participation in environmental decisionmaking (Downes, 2000; Eckersley, 1992).

\subsubsection{The rise of neoliberal decision-making}

Neoliberal restructuring in New Zealand changed the nature of public involvement in environmental decision-making. The so-called 'New Zealand Experiment' beginning in 1984 saw New Zealand undergo market liberalisation in various sectors, in addition to many public organisations being partially or fully privatized (Larner, 2002). From the 1990s, neoliberalism in New Zealand is considered "rollout" neoliberalism, which is "concerned specifically with the aggressive reregulation, disciplining, and containment of those marginalized or dispossessed by the neoliberalization of the 1980s" (Peck \& Tickell, 2002, p. 389). This entailed more government involvement in issues compared to earlier versions of neoliberalism where there was more deregulation (Peck \& Tickell, 2002). The RMA was enacted in 1991 after some years of policy development, and is very much situated within a range of neoliberal reforms in New Zealand. 
The RMA can in part be interpreted as a neoliberal policy, framing the environment as something that can be compromised for the benefit of socioeconomic factors, (Grundy \& Gleeson, 1996, as cited in Jackson \& Dixon, 2007). Yet the RMA arose in complex interactions between a strong neoliberal agenda and a global focus on sustainable development (Grundy \& Gleeson, 1996, as cited in Jackson \& Dixon, 2007; Perkins \& Thorns, 2001). So, counter to neoliberal tendencies and in order to achieve sustainable management, the RMA gives the state and local government the mandate for regulation and monitoring. This is an example of what Peck and Tickell (2002) call anti-regulation where neoliberalisation features deregulation while simultaneously consisting of overarching invisible normalised regulations, or "metaregulation" (Peck \& Tickell, 2002, p. 400).

The RMA's neoliberal traits also manifest in the way that public participation was formally incorporated into the Act, yet simultaneously limited. Under the RMA, considerable public participation occurs in the development of the district and regional plans, the aim of which is to assist the councils in achieving the purpose of the act to promote sustainable management (Resource Management Act 1991, Part 5). The plans prescribe what activities are acceptable in designated areas; therefore in principle most consent applications should result in little opposition, except in cases which do not comply with the plans. Specific cases which do not comply are generally publicly notified, providing an opportunity for public participation. Yet this dual participation process, and indeed the legislative requirement for participation as Downes (2000) suggests, weakens the unity created when the public were entirely excluded from participating:

The danger for movement groups in a market-liberal political environment... is not that they may be drawn in, neutralised and co-opted by the state, but rather that the dismantlement of the state dissipates the movement's energies and leaves it with a much smaller target for political action (Downes, 2000, p. 488).

With the RMA in place, environmental groups in New Zealand are therefore forced to formally approach each case separately, rather than unifying their efforts and addressing the systemic issue which may be the cause of multiple concerns. One example of this is the need to approach the climate change concerns about 
greenhouse gas emissions through formal participation in each coal mine consent, rather than addressing fossil fuel extraction in New Zealand more broadly.

Furthermore, Gunder and Mouat (2002) suggest that issues of power are not fairly dealt with under the RMA, leaving some actors unable to resist or participate, and other actors dominating decisions. This is of particular concern when it is apparent that certain actors, knowledges or values are consistently privileged over others. In order for the free market to prevail, the main tenet of neoliberalism, neoliberal policy simultaneously favours knowledges and values that are considered measurable, technical or economic (Castree, 2010; Peck \& Tickell, 2002). Perkins and Thorns (2001) suggest that in order for efficiency to prevail in the distribution of resources under the RMA, science is used to support different interests. They state that " $[\mathrm{t}]$ he effectiveness and efficiency criteria upon which costs and benefits were to be judged were not specified in the legislation but reflect the dominance of the economist's model of efficiency" (p. 641). In the case of genetic engineering in New Zealand, Weaver and Motion (2002) suggest that "in a neo-liberal political economy, public relations may be used to promote wealth creation as a public interest priority" (p. 325) over "the public's democratic right to make informed decisions" (p. 340). Economic development and hard science are still prioritised as legitimate knowledges when considering environmental management under the RMA.

Due to the technical nature of these knowledges, they are also considered apolitical. This is consistent with neoliberal economic management, whereby these processes "are increasingly technocratic in form and therefore superficially "depoliticized," acquiring the privileged status of a taken-for-granted or foundational policy orientation" (Peck \& Tickell, 2002, p. 389). Similarly, McCarthy and Prudham (2004) suggest that neoliberalism's hegemony is illustrated through "the ways in which profoundly political and ideological projects have successfully masqueraded as a set of objective, natural and technocratic truisms" (p. 276). One example of this is a case where information provided by a public interest group was not incorporated into a decision because "they did not present evidence in the accepted legal manner, or produce an acknowledged specialist to give expert advice" (Gunder \& Mouat, 2002, p. 139). A more recent example of the limitation of 
knowledges that are deemed acceptable under the RMA concerns climate change. Despite the RMA being New Zealand's primary environmental legislation, the effects of the end-use of coal on the climate cannot be considered under the RMA, as the decision-makers have no authority to consider the causes of climate change as a concern (Re applications for declarations by Buller Coal Limited and Solid Energy Limited, and West Coast ENT Incorporated [2012] NZEnvC 40). This privileging of certain knowledges (namely economic and technical) is particularly prevalent in the case of Escarpment Mine, and will be discussed in Chapter five.

In order to participate in decisions made about the environment, it may be necessary for environmentalists to operate outside of the formal participation processes offered by legislation, to broaden the debate about how such issues are dealt with in politics. In 1999, the New Zealand Study of Values found that of those responding, nearly $90 \%$ had signed a petition, and nearly $20 \%$ had attended demonstrations, amongst other actions (Perry and Webster, 1999, as in Bellamy \& Henderson, 2002, p. 100). However, many people believe that they have little influence over politicians after elections (Bellamy \& Henderson, 2002). As seen with Save Manapouri, environmentalist actions outside formal processes were, in the past, able to change the course of politics. Environmentalist opposition to Escarpment Mine illustrates some of these tensions about participating in neoliberal politics and how actions outside of formal processes intersect with political decisions. Despite the successes in increasing public participation, the more recent privileging of neoliberal knowledges may exclude important voices and environmental concerns from the arena of debate, raising questions about the democratic limits of formal decision-making processes.

\subsection{Synopsis}

Environmentalist opposition to Escarpment Mine has been evident in both formal participation processes under the RMA and through activism such as campaigning, protest, petition, media and ecological information gathering. Since the RMA was enacted in 1991, participation in environmental decision-making, and indeed democracy, has been shaped by formal processes under a neoliberal agenda. Under the RMA, formal submissions in opposition to developments are limited to specific 
cases only and therefore are unlikely to have an overarching long-lasting effect. However, the parallel cases of environmentalists' actions in New Zealand highlight that participation in the formal processes does not act in isolation from informal participation in democracy. Campaigning and increasing public involvement in issues certainly increases the chances that decision-makers will consider environmentalist perspectives, even if they deny the influence that activism has in formal processes. These two areas of political participation are critical for influencing decisions. This raises questions for the way in which we think about democracy in environmental decision-making. Who participates in decisions about the environment, and what is deemed to be valid or legitimate participation? How could formal decision-making incorporate environmentalist activism in such a way that delivers democracy?

Environmentalist activism is part of democracy, and a significant driver to political change. Attaining and maintaining democracy is not as simple as employing a formal process for participation. The interactions between formal participation and informal participation through activism raises questions about democracy. Furthermore, environmentalists' concerns about biodiversity conservation and climate change effects of Escarpment Mine raises issues for how democratic decision-making considers concerns of a public nature despite limited public participation. How does democracy function when strong disagreement is present? The next chapter discusses such theoretical questions, and poses a new framework for considering disagreement in democracy. 


\section{Chapter four: \\ Participation, disagreement and democracy}

This literature review explores theories of disagreement in democracy in relation to participation and activism. First I discuss definitions of environmentalism and activism, which provides the foundation for how environmental activism corresponds with theories of democracy. Secondly, I discuss democracy, with a particular focus on deliberative democracy and radical democracy. Each of these frameworks has a different way of incorporating disagreement, which highlights a number of issues about how activism is perceived within democracy. While deliberative democracy focuses on rational deliberations between decision-makers and stakeholders that ideally lead to consensus and harmony, radical democracy encourages the empowerment of disagreeing voices, with the understanding that disagreement will always be present. These theories highlight how reconceptualising activism and disagreement as an essential part of democracy necessitates a critical analysis of formal processes for public participation (or a limited submission process, as the case may be) and how the underlying quest for consensus decreases democratic ideals.

At the end of this chapter, I develop a framework for democracy that incorporates selected aspects from the models of democracy discussed. This framework is used in Chapter six to analyse the interview data about the decision to grant consents for Escarpment Mine.

\subsection{Environmentalism as activism}

The concept of environmentalism includes a multitude of identities and actions. Environmentalism is often defined as a movement with individuals and groups 
aiming to conserve or protect some element of the environment, and/or support pro-environmental technologies and behaviours (Rootes 1997 as cited in Carter, 2007; Gottlieb, 2001; Guha, 2000; Jasonoff, 2006) ${ }^{17}$. Carter (2007) suggests that conceptualising the environmental movement as united is inaccurate. The diversity of the environmental movement includes well established conservation NGOs, international groups, direct action and more radical groups, and local grassroots groups (Carter, 2007; Doherty, Paterson, \& Seel, 2000), with emphasis on diverse discursive frames such as wildlife management, conservation, preservation, environmental health, and environmental justice (Brulle, 2010).

One direction that some environmental groups have taken is to become more professionalised. Gottlieb (2001) and Carter (2007) discuss the institutionalisation of such groups, with conservation groups being more highly institutionalised and having a stronger business focus. This involves a reliance on money from supporters and employing professional protesters and activists. Rootes (2003) reflects on how the role of environmental groups has changed with such institutionalisation, including forming partnerships with governments and industrial corporations. These institutionalised groups may have more financial resources and more harmonious relationships with government institutions than other types of environmentalist groups.

Grassroots organisations are different again, with three broad distinctions: "first, radical social movements ... secondly, small local groups campaigning against a specific locally unwanted land use ... and, thirdly, broad coalitions of groups" (Carter, 2007, p. 155). Any of these types of environmental groups may also employ direct action tactics. Doherty et al. (2000) define direct action as "protest action where protesters engage in forms of action designed not only or necessarily to change government policy or to shift the climate of public opinion through the

\footnotetext{
17 While some theorists of New Social Movements would conceive of certain types of environmentalism as being an example of a new social movement (such as environmental direct action (Lawson \& Garrod, 2001) or protest about global environmental concerns (Faulks, 1999)), my research does not make this connection due to the type of environmentalist action being considered in the case study. Environmentalist opposition to Escarpment Mine has taken the form of campaigning, public meetings and education, petitions and ecological information gathering about the proposed site. These environmentalists have also been involved in formal decisionmaking processes as discussed in Chapter three.
} 
media, but to change environmental conditions around them directly" (p. 1, emphasis in original). Cathles (2000) suggests that direct action is important, especially if local environmental groups have found that "petitions, letter writing, representations at public inquiries, legal challenges, and demonstrations" (p. 169) have not been successful.

As illustrated, environmentalism integrates a diverse range of activist strategies and methods, from institutionalised lobbying and campaigning, to grassroots groups and direct action. When activism is conceptualised broadly, we can see that environmentalism incorporates various forms of activism. For Ganesh and Zoller (2012) activism includes communication (in both education and negotiation), confrontation and advocacy. Ganesh and Zoller (2012) also suggest that framing activists as violent or aggressive aims to highlight them as incapable of conversation, dialogue, or relationship building. Yet, on the contrary, activists often attempt and exhaust cooperative techniques before moving onto direct action and protest (Fung, 2005; Ganesh \& Zoller, 2012).

Young (2001) emphasises that theories of democracy very rarely discuss the implications or importance of activism or participation outside formal processes. This could include environmental activism. Given this gap identified in the literature, this research focuses on the role of environmentalism in democracy and decision-making, both within formal processes of participation and outside these formal processes, through activism ${ }^{18}$. Rootes (2003) suggests that while protest is still utilised as a tool by environmentalists:

the increased centrality of environmental issues on public agenda has created greater opportunities for effective action by more conventional means, and it provides fewer provocations to more confrontational (and more newsworthy) forms of action (pp. 255256).

Thus, a central question for this thesis is how the democratic processes of public participation under the RMA allow or constrain the ability of environmentalists to be effective in conventional processes, and accordingly, how activism should be a critical part of democracy.

\footnotetext{
${ }^{18}$ There is vast literature on environmentalism's inclusion in the media and influence on public opinions, leaving no gap in the literature in this area, hence my focus on a less-researched aspect of environmentalism and its influence in decision-making processes.
} 


\subsection{Democratic principles and participation}

New Zealand is a constitutional monarchy with a proportional representation electoral system (Bellamy \& Henderson, 2002). New Zealand is also considered a representative democracy. This means that democracy is seen to be achieved through the electoral system, whereby representatives of the public are elected as government officials. May (2010) suggests that we are encouraged to think of politics only as a duty to vote, and consequently responsibility to respect and obey those in power who are given a mandate to make decisions on our behalf. Similarly, Beetham (2010) states that "[n]othing has more discredited the democratization process than the assumption that it is largely a matter of electoral democracy alone" (p. 8), which is the main principle of representative democracy.

Yet politics is much broader than just voting. May (2010) suggests of Rancière's work, that a democratic politics "emerges from below rather than being granted from above" and is egalitarian, with all those participating considering all others to be equal (p. 22). From a Rancièrean perspective, politics potentially happens almost anywhere, and yet politics seldom happens because "it is so urgently discouraged" (May, 2010, p. 22). Politics, inherently conflictual, is avoided in favour of the perceived ideals of harmony and consensus. Ideas and practices of representative democracy have generated dissatisfaction, leading to extensive theories pursuing a more inclusive, participatory, just and democratic system. Two of these theories that challenge and extend representative democracy are deliberative democracy and radical democracy. Before discussing these alternatives in the next section, I turn to consider an ethos of democracy and a fundamental feature of participation.

\subsubsection{Equality, justice, freedom and the rule of the people}

The ethos of democracy is the rule of the people. As Abraham Lincoln is often quoted, "Democracy is a government of the people, by the people, and for the people" (Mokre, 2006, p. 307). Mouffe (1992) states that "what constitutes modern democracy is the assertion that all human beings are free and equal" (p. 1). Justice, as another key tenet of democracy, can be defined as involving "a sense of connectedness and obligation to others" (Hillier, 2002). While Rawls proposed a justice with a fairness and neutrality of positioning (1971, as in Benhabib, 1992 
and Hillier, 2002), Hillier (2002) and Benhabib (1992) recognise that while the principle of justice is necessary for democracy, how justice will function is influenced by people's differing identities, values and discourses. The pursuit of justice is critical to and intertwined with democracy (Dryzek, 2013).

Bellamy and Henderson (2002) suggest that the principles of democracy are twofold: "popular control over public decision-making and decision-makers; and equality between citizens in the exercise of that control" (p. 4, emphasis in original). With equality and freedom at the core, democracy has also become something associated with institutions of the state (Patton, 2005). Barry (1996) states that democracy is "a communicative process, a political procedure between individuals and institutions, where the former decide collectively binding decisions which are then enforced by the latter" (p. 118). While equality, freedom and the rule of the masses are at the core of democracy, institutions and states have often taken the role of coordinating democratic decision-making and actualising democracy. Yet May (2010) suggests that from a Rancièrean perspective, "the state-form is necessarily hierarchical, and cannot therefore be a model for instituting equality" (p. 104), which is one of the key tenets of democracy. This clearly has implications for how the state implements democratic decision-making processes.

There are various characteristics and ideals that a democracy is expected to demonstrate, yet these are seldom fully realised. Derrida suggests that democracy can never be achieved but is always working towards itself (May, 2010), which is consistent with radical democrats' idea of democracy as a "never-ending process, always to come" (Bohman, 1996, p. 4). Thus, it is important to analyse what is working well about the current state of democracy and what is lacking in order to progress it. In discussing a model for assessing various countries' levels of democracy, Beetham (2010) suggests that core values of democracy are participation, authorization, representation, accountability, transparency, responsiveness and solidarity. For the purposes of this research, I focus on participation in democracy, who should participate and why. 


\subsubsection{Participation}

Frameworks of democracy are often defined by how much and what type of participation is idealised or practiced. The ethos of democracy, the rule of the people, lends itself to the concept that individuals know their own interests best (Faulks, 1999). This is consistent with Orum and Dale (2009), who suggest that at the core of modern democracy is "that people are free to participate in the actions that govern and direct their own lives and fates" (p. 287). Faulks (1999) proposes a broad definition of political participation being:

the active engagement by individuals and groups with the governmental processes that affect their lives... [including] conventional political participation such as voting, standing for office, [or] campaigning for a political party ... and unconventional acts, which may be seen as legitimate, such as signing a petition or attending a peaceful demonstration, or illegal, such as violent protest or refusing to pay taxes (p. 143).

Participation in democratic decision-making allows individuals to voice their interests, and is considered essential for democracy to function.

Requirements for meeting democracy's ideal of participation are the right of people to participate, having the capacity to participate, having agencies for participation and an adequate level of participatory culture (Beetham, 2010). Innes and Booher (2004) suggest many reasons for undertaking participation: to investigate public preferences; to enhance decisions utilising local knowledge; increasing fairness in society; validating decisions; and to fulfil legislative requirements. Participation is also beneficial as it can transform societal issues, create collectivity, and be public and visible, as well as be an opportunity to test ideas and gain feedback (Orum \& Dale, 2009). Given these reasons and benefits of participation, in addition to various struggles by the public to be involved in governments' decisions, many government policies have formal participation processes or requirements for engaging the public.

One way to think about participation is to redistribute power in society. Arnstein (1969), a key theorist in participation, suggests that participation is:

the redistribution of power that enables the have-not citizens, presently excluded from the political and economic processes, to be deliberately included in the future. It is the strategy by which the have-nots ... can induce significant social reform which enables them to share in the benefits of the affluent society (p. 216). 
This redistribution of power is critical to understanding the frameworks of democracy that I discuss shortly.

Although in practice types of participation overlap and interrelate, various theoretical distinctions can be made. As demonstrated in Figure 4.1, Arnstein (1969) groups the various types of public participation into a scale from the least to the most power devolved from decision-makers.

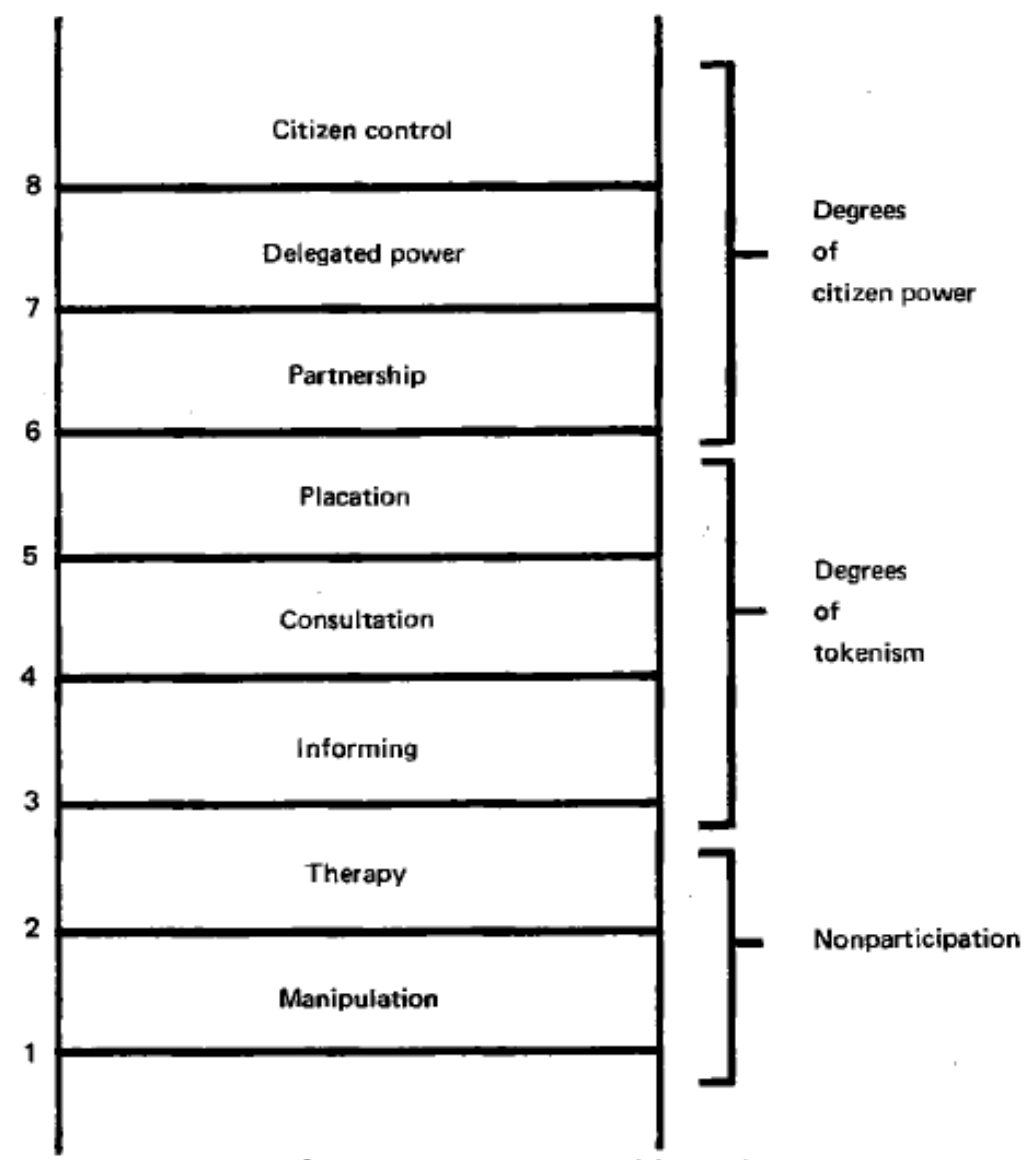

Figure 4.1: Eight Rungs on a Ladder of Citizen Participation (Arnstein, 1969, p. 217).

Here, forms of non-participation are manipulation and therapy (where the individual is made to feel at blame for wanting to participate and, instead, is educated about what they could do better). Arnstein (1969) suggests that informing, consultation and placation are only tokenistic versions of participation, whereby the public may have their voice heard, but decision-makers still have the authority to decide whether to incorporate their opinions. Arnstein (1969) states that "participation without redistribution of power... allows the power-holders to claim that all sides were considered, but it makes it possible for only some of those 
sides to benefit" (p. 216). This is highly prevalent in the degrees of tokenistic public participation. Higher up the ladder depicts types of participation that give more power to the public, or, with citizen control, the public obtaining the majority of decision-making or managerial power (Arnstein, 1969).

This ladder is consistent with other theories of participation. Informational communication, as defined by Rowe and Frewer (2000), is where a project manager or governmental body informs the public of an activity or decision without any opportunity to offer feedback. Consultation can be seen as information being requested and collated from the public by the project manager or governmental body on a specific topic (Rowe \& Frewer, 2000). However, this process is defined and controlled by those collating the information (Rowe \& Frewer, 2000), similar to Arnstein's tokenistic participation. Collaborative participation, as proposed by Innes and Booher (2004), is multi-dimensional, where communication, learning and action all happen simultaneously, with a wide range of stakeholders interacting and influencing each other.

Nevertheless, there are theorists who propose that increased participation does not necessarily lead to better deliberations or better outcomes. Cohen and Fung (2004) suggest that better deliberation may occur with less participation, and that more participation might lead to inferior discussions. Similarly, the public may not comprehend complex environmental issues and therefore are unable to participate meaningfully (Jeong, 2002). Maloney and Miller (2008) argue that activism, participation and deliberation are separate concepts that need to be considered individually, while they may certainly interact and reinforce each other. These distinctions illustrate how participation, particularly that as led or required by governments, can be limited and not achieve the goals that democracy aspires to. Nonetheless, there is scope for meaningful participation in deliberations if designed with democratic principles in mind. Furthermore, the inclusion of activism outside formal processes in political participation (or confrontational disagreement) is one of the major differences between deliberative democracy and radical democracy, which I discuss more in the following section. 


\subsection{Deliberative democracy and radical democracy}

A fundamental difference between deliberative democracy and radical democracy is the way they regard harmony and disagreement. Deliberative democracy is founded on Habermas's theories, in which rational deliberation and debate are privileged, guiding decisions towards consensus (Bond, 2011a; Munton, 2003; Pugh, 2005). Communicative planning also shares this fundamental concept, as a planning practice that promotes participation in the form of deliberation and aiming for consensus-like decisions (Bäcklund \& Mäntysalo, 2010; Pugh, 2005). Deliberative democracy implies a high level of rational deliberation in decisions that are made, and can be seen as an extension of representative democracy (Carpini, Cook, \& Jacobs, 2004). Deliberative democracy advocates for increased participation in deliberations especially by those affected by collective decisions (Walter, 2008), which is seen as an improvement on representative democracy.

The underlying aim for consensus is contested by radical democrats. Mouffe and Laclau, key theorists of radical democracy, instead theorise that disagreement will always be present in society, and that these underlying differences may be irreconcilable (Little, 2002). Thus, theories of democracies that believe in the possibility of consensus will never be functional nor fulfil the ethos of democracy (Little, 2002), whereby justice and equality prevails. Radical democracy promotes agonism, whereby those in disagreement relate as adversaries in respectful engagement (Mouffe, 1992, 2000, 2005). Despite fundamental differences, I suggest radical democracy and deliberative democracy must not be dichotomised. There is significant room to deploy aspects of both theories in such a way that benefits understandings of democratic decision-making, as I illustrate in this section, after discussing the differences.

\subsubsection{Critiques of a pure consensus}

Rancière (2004) states that consensus was proposed as a "pacification of conflicts... and yet it brought about anything but peace" (p. 4). Radical democracy places disagreement and diversity of opinion at the centre of democracy, meaning that "democracy is envisaged not as the mechanism for solving disagreements but rather as a means of enabling their expression" (Little, 2002, p. 378). Some differences will be irreconcilable, thus, there is a need for making space in the 
public and political realm to "enable the expression of difference" (Little, 2002, p. 380). Accordingly, one of radical democracy's main critiques of deliberative democracy is its aim for consensus.

However, while deliberative democracy leans towards consensus, Mouffe's critique overemphasises deliberative democrats' goal of achieving pure consensus (Bond, 2011a). Dryzek (2001), one of the key proponents of deliberative democracy, states that consensus is clearly not possible when there are competing discourses, and suggests that deliberative democrats have long asserted that consensus is not the aim of deliberative democracy. Similarly, Young, a deliberative democrat, also suggests deliberative democracy "does not require that consensus upon a unified 'common good' be the aim of public discussion" (2000, as in Talisse, 2005, p. 423). Moreover, Benhabib (1992) suggests that consensus remains open for future deliberations.

Instead of a pure consensus, Dryzek (2001, p. 661) proposes “workable agreements" whereby agreement can be reached "for courses of action for different reasons". Dryzek (2001) emphasises that the more resonance within an agreement, the more discursive legitimacy there is in the decisions made. Such agreements are made via rational deliberations - a point also contested by radical democrats.

\subsubsection{Rational deliberations: the potential for coercion?}

In deliberative democracy, deliberation can be defined as "discussion that involves judicious argument, critical listening, and earnest decision-making" (Gastil 2000, p. 22, as in Carpini 2004, p. 317). Participating in deliberations involves justifying one's beliefs or preferences with convincing reasons, rather than simply stating these preferences (Bohman, 1996). Deliberation can happen both inside and outside government (through media, conversation, public meetings for example), and between diverse groups of people (Abelson et. al, 2003; Carpini, Cook and Jacobs, 2004). Mutz (2008) states that various theorists disagree "whether it must necessarily be public, or whether informal conversations among ordinary people qualify" (p. 525). Most relevant to this research, is the idea that deliberation occurs between the public, local authorities, and project developers, making participation 
a significant part of democratic decision-making. It is important to note here that local authorities are as much participants in the decision-making process as any other actor, although they are deemed to be the 'neutral' and objective facilitators of decision-making processes in planning practices that employ deliberative democracy ideals such as communicative planning (Pløger, 2004; Pugh, 2005).

While the emphasis on rationality in deliberations has been critiqued by more recent deliberative democrats (for example, Dryzek 2001, and Young 2001), early proponents of deliberative democracy emphasised the requirement for rational deliberations (Held, 2006). A rational argument considers facts, the future and other people in place of individual preferences (Offe \& Preuss, 1991, as in Held, 2006). The aim is to uncover impartial truth, meaning "being open to, reasoning from, and assessing all points of view before deciding what is right or just; it does not mean simply following the precepts of self-interest" (Held, 2006, p. 239). Such deliberations do not allow for strong emotion, despite decisions often being fraught with emotion, or personal values that may not be contested through reason. Held (2006) also suggests that such impartiality is not appropriate for deliberations involving high moral conflicts, because "the matter cannot be resolved by appeal to the facts (for what facts are to be counted as relevant will be determined by prior conceptual choices) or an analysis of the relevant concepts involved (for those will also be contested)" (p. 242). Similarly, Bohman (1996) states that "[d]eliberation, it would seem, works only for relatively homogeneous groups who share many values and beliefs" (p. 2). But, as is common throughout society, differing values and morals create strong disagreement.

Deliberation does pose benefits to society. Abelson (2003) suggests that problemsolving as a group is central to deliberation, "allow[ing] individuals with different backgrounds, interests and values to listen, understand, potentially persuade and ultimately come to more reasoned, informed and public-spirited decisions" (Abelson et al., 2003, p. 241). Ideally, learning and increased understanding of diverse views occurs through sharing of information and knowledge in deliberations (Held, 2006; Munton, 2003; Talisse, 2005). Key tenets of deliberative democracy include "reciprocity, publicity, accountability, basic liberty, basic opportunity and fair opportunity" (Gutmann and Thompson 1996, as in Hillier, 
2002, p. 254). These outcomes and principles are based on an ideal situation, yet power relations between different actors and the exclusion of some people in the deliberations can make this ideal implausible.

While Held (2006) states that the ideal of deliberative democracy involves "a rationally motivated agreement, not an outcome produced by coercion, manipulation or bargaining" (p. 238), others suggest that deliberations may be a site for manipulation, coercion and compromise (Carpini et al., 2004; Ganesh \& Zoller, 2012). With consensus being the foundation of deliberative democracy, Hillier (2002) suggests "one should always be aware of what trade-offs, compromises and omissions have gone into the making of any apparent consensus" (p. 59). Walter (2008) suggests that the possibility for deliberations to be non-coercive only holds true if those involved have equal abilities to challenge arguments. Furthermore, coercion can occur when an issue is deemed to be outside the scope of the discussion (for example, if the issue is deemed to be applicable to another law and not the one in question), and is not permitted to be considered by those with decision-making power, despite being raised as an issue (Walter, 2008). Ganesh and Zoller (2012) suggest that activists can be disadvantaged in dialogue with corporations and governments, as discussions of more serious issues may be evaded by those with more power. This may intensify the power that corporations or governments already have (Ganesh \& Zoller, 2012).

Ganesh and Zoller (2012) further suggest that when there is the aim for consensus in deliberations, activists may be reluctant to engage in dialogue, as there is a strong risk of co-option. This reluctance may drive the notion of activists as being incapable of dialogue and agreement (Ganesh \& Zoller, 2012). However, a radical democratic approach proposes that given there is always potential for an underlying difference and disagreement, dialogue or discussions are unlikely to lead to consensus, meaning that the site of discussion is less likely to be one of manipulation or co-option, and the very process of discussion is also negotiable.

\subsubsection{Deliberation, consensus and exclusion}

In addition to being a site of potential coercion, deliberations may also exclude some people from the process. While the above highlights issues that might arise 
when deliberation is faced with strong disagreement, other times opinions may simply be excluded from the deliberations entirely. Fishkin (1995, as in Carpini 2004) suggests that there is always an incompleteness to public deliberation. Therefore, deliberation can only ever be improved upon, not perfected.

From a radical democratic perspective, Mouffe $(2000,2005)$ suggests that there are inherent weaknesses in the deliberative model. She suggests that deliberations that are inherently predisposed towards consensus will always exclude some voices and possibilities, as it creates a divide between 'us' and 'them'. The excluded 'them' are then classed as enemies in an antagonistic relationship, meaning they are unable to be engaged with respectably as adversaries (Mouffe, 2005). Furthermore, as Ganesh and Zoller (2012) argue, activists are more likely to be excluded on this basis, as processes that emphasise reaching agreement, firstly, privilege dialogue over activism, and secondly, privilege "dialogic activist methods ...over contestation" (p. 84). This limits the opportunities available for activists' engagement. Encouraging the involvement of underlying differences without the pressure to achieve consensus stimulates a fuller and more meaningful participation of activists and citizens.

In addition to advocating against consensus building, radical democracy, like Arnstein's (1969) early work on participation, advocates that power be redistributed in a way that encourages the empowerment of marginalised groups (Little, 2002). Mouffe's aim in radical democracy is to construct a framework that brings to light the various ways that power relations are assembled, highlighting forms of exclusion (Little, 2002). This redistribution of power is also alluded to in deliberative democracy. Dryzek and Young's versions of deliberative democracy "seek to make deliberation as flat as possible [so] that hierarchical relations between voices are avoided" (Walter, 2008, p. 532). Furthermore, both Young and Dryzek agree that "expertise must find its place among other voices" (Walter, 2008, p. 537), being considered as equals with storytelling and non-expert knowledge. This augments earlier versions of deliberative democracy that emphasise the rational nature that deliberations must have. In theory, these problems of exclusion, coercion and power may be diminished if those that 
disagree are accepted and respected as part of a bigger picture of difference, rather than enemies to be undermined.

\subsubsection{Agonism, the adversary and moments of agreement}

Radical democracy argues that difference and disagreement will most often be present. Rancière's theories of disagreement assert that "it is not in the name of an identity or of a sameness that equality is acted out; it is in the name of difference" (May, 2010, p. 15). In other words, granted that one of the key features in the ethos of democracy is equality, for the ethos of democracy to be achieved, difference must be allowed to be expressed. Mouffe's radical democracy suggests that while elements of consensus may happen momentarily, these moments of consensus will not endure and there may be underlying differences that are irreconcilable (Little, 2002). This gives rise to the concepts of agonism and the adversary.

In Mouffe's radical democracy, those in disagreement are not enemies to be fought against, as in antagonism, rather they are to be engaged with as adversaries with respect for each other and respect for the process of engagement (Mouffe, 2000, 2005). This social conflict is central to democracy (Ganesh \& Zoller, 2012).

Furthermore, in such agonism, there is a sense of "a permanent provocation that lies between adversaries that are legitimate enemies" (Mouffe, 1995, as in Bond, 2011b, p. 797). Similarly, Hillier (2002) suggests agonism is the "possibility of permanence of conflict" (p. 14). McClymont (2011) defines agonism as:

irresolvable disagreement over political meanings and actions, though each party accepts the right of the other to express an opinion. It is a form of political engagement which acknowledges the permanence of conflict, viewing this as necessary for democratic politics to function, rather than as detrimental to it (p. 240).

Agonism is central to the ideas of radical democracy and agonistic planning, which have arisen out of critiques of deliberative democracy and collaborative planning.

Agonism is contrary to the approach to disagreement in antagonism, whereby identities are compromised through discourses that are fundamentally different to their own and cannot be resolved. The limits of these conflicting identities and their associated discourses have no commonalities (Howarth, 2000). Antagonistic social relations arise when parties "are unable to attain their identities (and 
therefore their interests) and because they construct an 'enemy' who is deemed responsible for this 'failure'” (Howarth, 2000, p. 105). These parties are not simply different or opposite, but 'anti' the other (Laclau \& Mouffe, 2001). Antagonisms simultaneously form and threaten each other, an interdependent instability, where "the presence of the 'Other' prevents me from being totally myself" (Laclau \& Mouffe, 2001, p. 125). Because of this fundamental 'anti' identity, enemies compete for their opinion and position to be more powerful and become hegemonic discourses (Mouffe, 2005). As Bond (2007) articulates, antagonism is key to the formation of political identities, and "it is through antagonism that the limits of discourses are made visible" (p. 61).

Ganesh and Zoller (2012) quite rightly argue that if accepting Mouffe's idea of the adversary, "then research on activist dialogue should treat tension as inevitable throughout the process instead of either escalatory or abnormal" (p. 85). With radical democracy's emphasis on agonism, activists become included as adversaries, instead of enemies to be overpowered, excluded or coerced. The vibrancy created through agonistic relations is core to Mouffe's (and others') ideals of democracy (Mouffe, 2005).

In planning practice, Pløger (2004) duly suggests that planners and public authorities would have to approach conflicts very differently if conflicts between irreconcilable points were treated as disagreements between adversaries in an agonistic relationship rather than antagonistic relationships. One reason, he suggests, that conflicts are seen as antagonism, is that "antagonism as 'unsolvable' has to be dealt with by power (legal means), whereas agonism demands timeconsuming or 'endless' communicative processes" (p. 72). Bond (2011b) provides practical examples of how spaces may be re-created to establish agonism, including:

rethinking how meetings are run, agendas are set and who takes part in the group... holding them in different places, in a workshop or small discussion group style, as walking tours of development sites, thus drawing in groups who would not normally visit the town hall even when meetings are open to the public (p. 19).

These different methods may initially require time, skills and resources that planners and public authorities may not be willing or able to invest, especially if 
they are approaching problems and differing viewpoints with an antagonistic lens. A deliberative democratic approach implies that deliberations and processes of communication will 'solve' any issues of disagreement. Yet as Pløger (2004) stresses, agonism cannot be erased through legal procedures and it necessitates novel approaches to place disagreement at the centre of planning practices.

As well as making difference central to democracy, agonistic relationships, identities and interests are theorised as fluid and not fixed in time or place (Ganesh \& Zoller, 2012). Radical democracy emphasises the fluidity of social relations: "[i]t becomes necessary to constantly discuss and challenge all existing definitions of society, as well as collective and individual identities" (Mokre, 2006, p. 315). This fluidity is essential for understanding agonism. The concepts of the adversary and agonistic relationships returns us to Dryzek's (2001) concept of workable agreements in deliberative democracy, whereby agreements are reached but remain open to further deliberations, particularly as social relations change over time and space. Despite coming from two theoretical perspectives, these workable agreements, whether from a deliberative democrat perspective or the concept of agonism from radical democracy, may result in similar processes and outcomes for recognising and working with disagreement.

\subsection{Framework for democracy and disagreement in decision- making}

I propose a framework that incorporates aspects of both deliberative democracy and radical democracy. I developed this framework by drawing on the key points already raised. Beaumont and Loopmans (2008) analyse two cities' urban democracy approaches and conclude that neither communicative planning (like deliberative democracy) nor agonism and pluralism were "sufficient for ensuring a deepening of democratic engagement in urban governance" (p. 110). While questioning the practicalities of doing so, they posit the synthesis of both theories as a possibility for furthering democracy. The framework developed for this research contributes to generating such theory. 
One of the main critiques of radical democracy is that there has been little empirical evidence of its practical applications, although some research has been undertaken to evaluate agonistic theories in regard to planning practice (see Brand \& Gaffikin, 2007; Bäcklund \& Mäntysalo, 2010; Hillier, 2002; McClymont, 2011; Pløger, 2004). It is hard to imagine how decisions would progress when accepting there is irreconcilable disagreement. There are similar critiques of deliberative democracy, with a weak relationship between theories and evidence (Carpini et al., 2004; Mutz, 2008). Carpini et al. (2004) suggest that while benefits of public deliberation are numerous, these benefits are often untested assumptions. Mutz (2008) also states that there are various ways of achieving the outcomes that deliberation proposes, and advocates that studies be undertaken that demonstrate the effectiveness of deliberation compared to other methods. This research investigates such gaps in the literature and illustrates evidence of how aspects of both theories can be realised in planning practice.

Mouffe's radical democracy, while advocating for dissensus, does require a consensus on the way that democratic institutions function (Mouffe, 2005). It requires a consensus on the democratic ideals of equality and liberty (Bond, 2011a) and the principles of pluralism, or, "the right to believe in different things from others in our society and to have democratic opportunities to express those differences" (Little, 2002, p. 379). I also propose that agreement needs to be met on these fundamental principles, as well as justice and the rule of the people (this is represented by the green circle in Figure 4.2 below).

Whilst proponents of deliberative democracy and radical democracy insist on their fundamental differences, I argue that in practice, these two theories overlap and interrelate. The main difference between them is that founding theorists of deliberative democracy rely on Habermas, who perceives humans' desire to reach agreement as the basis for all communications. Mouffe and Laclau instead emphasise that "focusing on conflict and dispute instead of consensus, maintain[s] that the possibility of contesting claims to power is the most important quality of democracy" (Mokre, 2006, p. 312). However, while these are different starting points, when discussing features of each of these forms of democracy, there is significant scope for overlap. For example, Dryzek's (2001) deliberative democracy 
is building towards workable agreements, not pure consensus. Mouffe proposes an agonistic approach with temporary moments of agreement (Little, 2002), and fluidity in relationships, interests and identities. This sounds remarkably compatible with Dryzek's (2001) workable agreement.

Nevertheless there are still differences. The idea that agonism and antagonism are diametrically opposed is simplifying the nature of disagreement. Both of these concepts are relational, and require more than one party. I suggest these relations, as agonistic or antagonistic, are not fixed, but fluid and bound to change as relationships change. A relationship might be agonistic on one aspect of difference, and antagonistic on another, or have one party antagonistic with the other agonistic. This also highlights the nexus between informal political participation through activism and participation in formal processes, and how both types of participation express various dimensions of both agonism and antagonism. Institutions may also partake in creating these dynamics, such as the adversarial nature of decision-making under the RMA, and choosing which values are privileged or drive a decision, leading to parties becoming increasingly (or decreasingly) antagonistic. Pløger (2004) suggests that while working with agonism is favourable and possible in planning processes, it is yet to be developed.

As a result of these considerations, I propose that a framework for working with disagreement in a democratic way should incorporate the following objectives, in order to fulfil the ethos of democracy, equality, justice and the rule of the people. Figure 4.2 illustrates the relationships between each principle of the framework. In the diagram, orange circles (and arrows coming from agonism) represent a principle that when expressed, is aligned with agonism. Red circles indicate expressions of antagonism, which sometimes also relate to agonistic principles (as with the case of informal antagonistic activism interacting with the concept of temporary and fluid agreements). The one purple arrow that is dotted indicates a less significant relationship emerging from the literature. The green circle, encompassing all other principles, represents the overarching democratic ideals of equality, justice and rule of the people. 


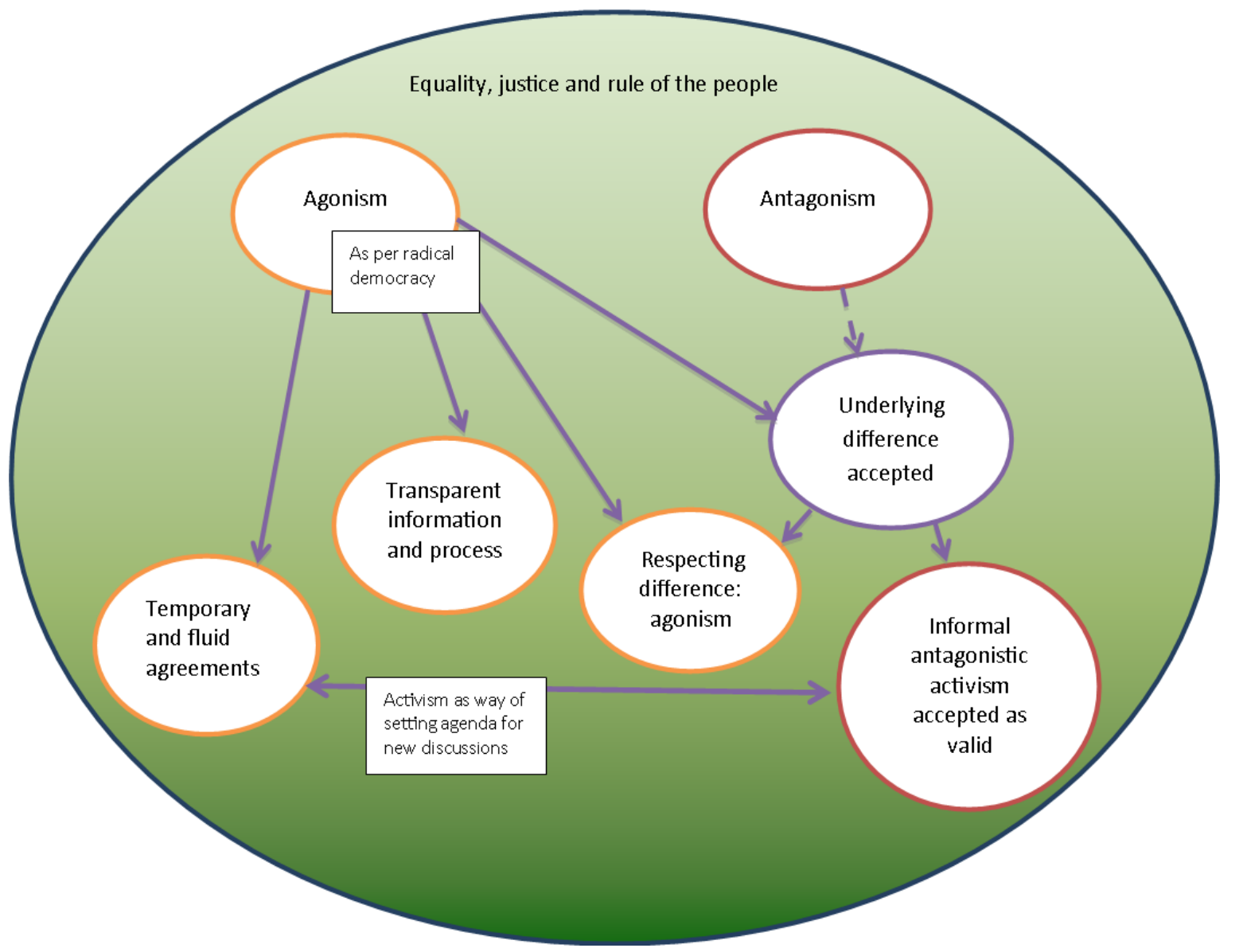

Figure 4.2: Framework for democratic decision-making. 
Table 4.1: Expanded framework for democratic decision-making

\begin{tabular}{|l|l|l|}
\hline Principle & Defining feature & $\begin{array}{l}\text { Theoretical } \\
\text { association }\end{array}$ \\
\hline $\begin{array}{l}\text { Underlying } \\
\text { difference } \\
\text { accepted }\end{array}$ & $\begin{array}{l}\text { Some differences are irreconcilable, and } \\
\text { space for these differences to manifest is } \\
\text { critical for democracy }\end{array}$ & $\begin{array}{l}\text { Radical } \\
\text { democracy }\end{array}$ \\
\hline $\begin{array}{l}\text { Antagonistic } \\
\text { activism } \\
\text { accepted as valid } \\
\text { participation }\end{array}$ & $\begin{array}{l}\text { Antagonistic activism is valuable for } \\
\text { creating debate on important issues, } \\
\text { specifically when issues relate to the } \\
\text { overarching democratic principles of } \\
\text { equality, justice and rule of the people. }\end{array}$ & $\begin{array}{l}\text { Unclear in the } \\
\text { literature on } \\
\text { democracy. } \\
\text { Ganesh and } \\
\text { Zoller (2012) } \\
\text { on activism } \\
\text { and dialogue. }\end{array}$ \\
\hline $\begin{array}{l}\text { Antagonism shifts } \\
\text { to agonism }\end{array}$ & $\begin{array}{l}\text { Antagonism that does not fulfil the } \\
\text { democratic ideals of equality, justice and } \\
\text { rule of the people must shift towards } \\
\text { agonism to still remain within the realm of } \\
\text { democracy. }\end{array}$ & $\begin{array}{l}\text { Radical } \\
\text { democracy, } \\
\text { Hillier (2002) } \\
\text { and Pløger } \\
\text { (2004) }\end{array}$ \\
\hline $\begin{array}{l}\text { Temporary and } \\
\text { fluid agreements } \\
\text { process }\end{array}$ & $\begin{array}{l}\text { Transparency allows for agonism, } \\
\text { meaningful participation, and for the } \\
\text { overarching principles of equality and } \\
\text { justice. }\end{array}$ & $\begin{array}{l}\text { Deliberative } \\
\text { democracy }\end{array}$ \\
\hline opents of consensus are temporary and
\end{tabular}

Table 4.1 presents the defining feature of each of the principles of the framework, as well as the body of literature that each principle has arisen from. Having introduced the framework that will be used to reflect on the case in Chapter six, I now explain these principles in more detail. I have developed these principles through uniting what I see as the most valuable elements of deliberative democracy and radical democracy.

\section{Underlying difference accepted}

Decision-makers and those participating must acknowledge that there could be underlying difference and in such cases, that long-term full agreement is unlikely to be reached. Opposition will come in various forms throughout formal 
participation processes as led by the state, and informal participation through activism. Differences should be considered and engaged with in agonistic ways. This is central to Mouffe's $(2000,2005)$ radical democracy.

\section{Antagonistic activism accepted as valid participation}

Disagreement will always be present, regardless of the scope of formal participation processes. Formal processes will never be able to contain discussions about agreements to be made. Protests and other antagonistic activism can be a way for society to prepare for dialogue, and the antagonistic approaches create possibilities or imaginings for deliberation that might not have occurred otherwise (Ganesh \& Zoller, 2012). Talisse (2005) argues that deliberative democracy accepts activism as a way for increasing or "establishing a properly deliberative system" (p. 439), but that deliberation must be privileged over activism once this has been attained. But, perhaps more appropriately, Fung (2005) suggests that formal deliberations will most often be unsuccessful because of inequality, and thus, activism has a place in democracy in order for such power relations to be challenged and for democracy to be achieved. Deliberations will not be able to solely fulfil democratic principles, and a continuing recognition of activism as part of decision-making is needed to achieve democracy. Activism is a strength the public can mobilise to raise issues and set the agenda that is often defined by those with power (e.g., the state or corporations). Such activism will be an on-going process.

\section{Antagonism shifts to agonism}

While some antagonistic relationships aim to challenge lack of equality, justice and rule of the people, other antagonisms are not so worthy. In order for democracy to be advanced, such antagonisms need to work towards agonism to respectfully engage with adversaries. This concept arises both from radical democracy (Mouffe, 2000, 2005) and agonistic planning (Brand \& Gaffikin, 2007; Bäcklund \& Mäntysalo, 2010; Hillier, 2002; McClymont, 2011; Pløger, 2004).

\section{Transparency in information and process}

Deliberations between all parties should be transparent, both in terms of the process and the availability of information, so that negotiations are fair. This 
allows for agonism, whereby adversaries are engaged with, and furthers equality. Power differences and inequality may never completely be eliminated, however, this transparency will help deepen an equal capacity to engage in deliberations. This aligns with deliberative democratic approaches that promote more fair, equal and just deliberations (Dryzek, 2001; Young, 2001).

\section{Temporary and fluid agreements}

Moments of consensus should be understood as temporary and still open for deliberations, like deliberative democracy's workable agreement (Dryzek, 2001), with fluidity of relationships, identities and interests (Benhabib, 1992). As well as being derived from deliberative democracy, this also aligns with Mouffe's concept of moments of consensus (Little, 2002).

This framework is utilized in Chapter six to explore democracy in the case of Escarpment Mine. The case is discussed in relation to principles of the framework that are evident through the formal decision-making process under the RMA, as well as through environmentalist actions outside of this process. While the framework's principles are not easily measurable, they are certainly identifiable in my case through qualitative research. The next chapter, Chapter five, discusses the findings relating to the research objectives about the influence that environmentalists were able to have in the decisions that were made about Escarpment Mine. Environmentalists felt they did not have influence in the formal process. Issues that emerged as reasons for this inability to influence the decisions made are discussed, and later associated with the issues they raise for democracy. 


\section{Chapter five:}

\section{Environmentalists' influence in the decision}

This chapter addresses the second and third research questions: to explore how environmentalists' actions both outside and within formal participation processes have influenced the decision to grant consent for coal mining on conservation land in the case of Escarpment Mine. Firstly, I discuss specific actions that are considered to be outside of the formal processes, or environmental activism such as ecological surveys, protest and campaigning, and the way in which this is perceived to have no influence on the formal decision-making process. I then explore the value of environmental activism about Escarpment Mine more broadly, with potential influence on New Zealand society.

Secondly, I discuss how the environmentalists who were involved in the submission process under the RMA see their ability to have influence within the formal participation process. Most felt that their submissions had no influence, and thus I explore the factors that led to this perceived lack of influence. Certain economic and measurable knowledges appear to be privileged over knowledges which have a more holistic, global and interconnected approach to the environment, leading to a discussion of the way the RMA favours a fragmented approach to the environment. Furthermore, perceived objectivity may be given more weight in the process. The prevalence of neoliberal discourse is also discussed. Lastly, I discuss how the favouring of certain knowledges raises serious questions for democracy.

The primary data in this chapter is from interviews with 16 people (see Chapter two). Other sources complement and expand on the interviewees' views, such as 
council reports, the commissioner's final decision, written and oral submissions from environmental groups, applicant evidence and academic literature. As established in Chapter two, the methodological approach uses a Foucauldian discourse analysis to explore the power of different knowledges, and how these discourses or knowledges dominate or are undermined in relation to each other and the people that present such knowledges.

\subsection{Influence of environmentalist actions outside formal processes}

Before discussing the way in which environmentalist action against Escarpment Mine may have influenced the decisions made, it is necessary to describe what kinds of actions have taken place. The most wide-reaching actions have been undertaken by Forest and Bird, which nominated Save the Denniston Plateau as one of their main campaigns of 2011 and 2012 (Forest and Bird, 2012a). This campaign has involved a variety of media coverage, including press releases, blog posts, email newsletters and a petition. One of the main actions coordinated by Forest and Bird was the Denniston Plateau Bioblitz whereby New Zealand's top entomologist, invertebrate specialist, liverwort specialist, botanist and other experts led teams of volunteers on the plateau over a weekend to record and assess the ecosystems and species present (participants 2, 3, 9 and 11). A number of species were discovered to be living there that were not known in this habitat, some were living in ways unusual to their species (for example, a tree weta burrowing in the ground) and at least one new species ${ }^{19}$ was discovered, the Avatar Moth (participant 2). The Bioblitz covered 5900 hectares of the Denniston Plateau, an area much larger than the proposed coal mine (participant 2). Based on ecological information gathered at the BioBlitz, Forest and Bird has made a proposal for a protected area of the whole of the plateau, due to its unique ecology (participants 1 and 2).

Various other groups and individuals also took part in other environmentalist actions against Escarpment Mine. Actions included writing numerous letters to the local paper and circulating email newsletters to their members and interested

\footnotetext{
${ }^{19}$ Other potential new species were still being classified at the time of interview(participant 2)
} 
parties (participants 8, 9, 10,12 and 16). There was also a protest of approximately 200 people outside Bathurst's new offices in Wellington in March 2012, coordinated and supported by various environmentalist groups (Rutherford, 2012).

While it is likely that these actions influenced the public, three people interviewed explicitly stated that the environmentalist campaigning and activism had no influence over the formal decision-making process, nor was it appropriate to have such influence (participants 2, 4 and 7). Only one of these was an environmentalist, who recognised that her actions in campaigning and other activism were more for creating a shift in values in society (participant 2). From the councils' perspective, one participant stressed that the hearing committee can only consider people's formal submissions, not activism or other actions (participant 4), while another stressed that in general, activism "should be given no weight whatsoever" (participant 7). One environmentalist recognised this, and stated the formal processes with the hearing committee and the Environment Court are "not worried about what you're saying out in the public arena; they're focusing totally on what you put before them" (participant 2). However, past cases where activism was a strength that influenced the decisions made were mentioned by various participants. These cases included the Mokihinui (participant 3 and 8) and the Save Manapouri Campaign (participant 8), both discussed in Chapter three, nuclear free legislation (participant 8), the creation of the RMA (participants 2 and 8), and establishing DoC (participant 2). This indicates that perhaps the influence of such activism is more visible in hindsight.

While the environmentalists' actions were not perceived to have any influence on the decisions made by the hearing committee, there were mentions of it affecting the company and society. Firstly, the actions may have cost the company money through increased security measures and decreased shareholder support. Secondly, the environmentalists felt that their actions contributed to a shift in values in society towards environmental protection.

In terms of costing the company extra money, one example given was that the company had hired security guards for the start of the hearing due to fears there 
would be radical protest action, despite no previous indications this may occur (participant 5). Other environmentalists noted that activism can highlight the obstacles that Bathurst still has to face before gaining permission and initiating the project, which discourages shareholders (participants 9 and 12). Delaying the mine by opposing it was seen as a positive effect of campaigning and extending the formal decision-making process. Even though it may not stop the project completely, delaying it could mean weakened support by shareholders, as was the case here (participants 9 and 12). This idea that environmentalists' actions can influence the company through potential risks on profit or investment parallels the Mokihinui case. Meridian withdrew their proposal due to the expected high costs of the Environment Court proceedings after DoC, Forest and Bird, the West Coast Environment Network and Whitewater New Zealand appealed the council's original decision in the Environment Court (Department of Conservation, 2010; Meridian Energy, 2012).

For environmentalists interviewed, the most important aspect of their activism was to create an informed public and ultimately a value shift in society, against new coal mines or mining coal on conservation land. One participant noted that environmentalists recognised the activism against Escarpment Mine was probably not going to change the outcome for the Denniston Plateau, but that it was part of a bigger movement building over time against coal's contribution to climate change, and for the conservation of biodiversity (participant 14). One environmentalist with decades of experience noted that "you're never going to get political change unless there is a mass movement calling for it" (participant 1). This emphasises the importance of political activism that occurs outside of the formal participation processes as offered by government. It suggests that campaigning and garnering public support is highly valued by environmentalists in seeking to effect change.

Similarly, the value of local action and protest is recognised. An experienced environmentalist said she was largely against new coal mines for climate change reasons (participant 1). She had lost hope in international agreements against climate change, but emphasised that local action against contributions to climate change would "achieve far more than all the international negotiations we've had to date" (participant 1). Another participant noted that "it is far more important to 
struggle and figure out how to collectively organise together to make things different or better, than it is to vote" (participant 11). These comments reflect dissatisfaction with representative democracy models, and with larger institutions that have made decisions about climate change mitigation and the environment.

While the campaigning was seen as important, one local noted that campaigning was more effective in gaining support from people nationwide than from the town itself (participant 13). This was perceived as being because Westport is very promining, with livelihoods depending on it (participant 13). Walton (2007) discusses a different case where there was strong opposition to mining in the town of Reefton, also on the West Coast of New Zealand near Westport. She suggests that there is a dichotomy about such decisions on the West Coast: people are either for the sensible management of natural resources through logging and mining, or they are for the "locking up" of resources through "extremist" conservation measures (p. 198). Similarly, participants 8 and 13 expressed the divide between the local "rednecks" and environmentalists who were mostly outsiders. In contrast, two other environmentalists indicated that their own overt opposition to the mine allowed people from the local community - who were neither fully opposed nor supportive of the mine - to openly discuss their concerns about the mine with them (participants 2 and 3).

Two interviewees felt that campaigning was intertwined with the formal process, as it aims to encourage more people to make submissions and be involved in the formal process, though neither participant had been active in campaigning on a large scale (participants 9 and 10). However, another participant noted that "while you've got a government where their central economic strategy is the absolute opposite of what we want and need, then I think no amount of letters to ministers... or lobbying is going to make the slightest bit of difference" (participant 1). One environmentalist suggested that the state enables such companies to destroy the environment, rather than being a neutral facilitator between various interest groups (participant 3). The latter two comments imply a sense of hopelessness about influencing the current government, seen to prioritise mining and development, while yet others still had faith that campaigning could influence government (participants 9 and 10). 
While the importance of activism and campaigning was emphasised for a number of reasons, including raising awareness, creating a value shift in society and inadvertently increasing costs to the company, it was perceived as not having influence on the decisions made - yet neither did the participation through the formal submission process.

\subsection{Influence within formal processes}

Six participants made formal submissions against Escarpment Mine. Overall, environmentalist participants felt their submissions had no or little influence over the decisions made to grant the consents for Escarpment Mine. Two participants explicitly said their submissions had no influence on the final decision (participants 3 and 8). Two were unsure and noted that their submissions seemed to have had no effect (participants 9 and 10). One participant in a coordination role for one group's submission felt that they could not have enough influence because of the way in which climate change was not considered by the decision-makers (participant 2). This was echoed by the experience of participant 15 in another similar case. Three participants who did not make a submission observed that in general, submissions in opposition to mining developments on the West Coast were not taken into account (participants 12, 14 and 16). Either from their experience in making a submission against Escarpment Mine or through observing this case and others, environmentalists felt that participating in the formal process had no influence on the decisions made. In reading the commissioners decision report (Archer et al., 2011), it appears that while the commissioners may have considered the environmentalists arguments in their submissions, they disregarded this evidence in favour of evidence that maintained the economic benefits of the proposal and the quantifiable approach to conservation.

Four participants emphasized that activism and mass movements are more effective than being involved in the formal RMA submission process (participants 1, 2, 8 and 11). One environmentalist said that he was hopeful Escarpment Mine would not go ahead, but that "it will be a result of good campaigning rather than the RMA process, yeah I could more or less guarantee the judge will say yes to it" 
(participant 8). In comparing campaigning and taking part in the formal process, another environmentalist said, "I guess if you kind of weighed it up, maybe there would be no point putting a submission in" (participant 9). Consistent with section 5.1 above, activism and campaigning are seen as significantly more valuable in creating a public call for change than partaking in the formal submission process.

Despite these general feelings, there was also a sense that environmentalist opposition provided some scrutiny to the process. As Orum and Dale (2009) suggest, participation provides "[a] check and constraint on the actions of public officials" (p. 287). One environmentalist felt that their group's actions were valuable to society in scrutinising the proposal and decisions by taking the time to read and critique the applicants' evidence and the DoC reports (participant 10). A sense of responsibility was noted by one participant, as her organisation's role was to act as an independent watchdog to protect nature (participant 2). The three council officers interviewed (participants 5, 6 and 7) also noted that environmentalists submissions contributed to accountability for both the council and the company, with one saying "it may well provide a more informed decision than if there was no opposition" (participant 7).

DoC did not present an oral submission at the hearing, despite making a written submission that expressed some concerns about the project. Some DoC staff members attended to observe the hearing, but did not participate in the discussions ${ }^{20}$ (participants 3 and 10). Five environmentalists and one council officer asserted that this hindered the decision-making process as the absence of DoC's ecological experts meant that conservation concerns could not be fully discussed (participants 3, 5, 9, 10, 11 and 13). This will be discussed in more detail Chapter six, in relation to the transparency of the decision-making process.

Despite this lack of DoC's involvement, there were conditions relating to conservation that Bathurst agreed to as part of the commissioners granting the consents. While it could appear that environmentalists' concerns about conservation, on the surface, may have contributed to the conditions imposed on

\footnotetext{
${ }^{20}$ As explained in Chapter two, DoC declined an interview with me as part of this research, thus I was unable to obtain an answer from DoC as to why they chose not to present at the hearing.
} 
Bathurst in terms of rehabilitation, compensation and biodiversity offsetting, this was not the case, for the reasons set out below (in subsections 5.3.5 and 5.3.7). The conditions that Bathurst had agreed to at the time of the hearing consisted of a 102 page report including conditions about soil conservation and sediment control, vegetation and flora, finished landforms, rehabilitation and monitoring, aquatic ecosystems and water management, natural hazards, historic heritage and amenity value (Resource and Environmental Management Nelson Limited, 2011). The area was established as ecologically significant "by applicant's technical reports and through the review of the application commissioned by Council" (participant 5, by email 14 January 2013), and thus, ecological conditions of the proposal were not established or influenced by submitters' evidence.

Four environmentalist groups who submitted in opposition to the mine specified concerns on climate change and conservation, and argued that they would not be able to be avoided, remedied or mitigated in this case, as required for adverse environmental effects under the RMA (Section 5 (2a)). While it appears their concerns may correlate with a few of the conditions imposed on the company, these groups actually criticised the mitigation offered in the Escarpment Mine proposal. In the words of the expert supporting Forest and Bird's submission: the challenge is to rehabilitate the site in such a way that the ecosystems that are affected by the activity will be restored for the future. The mine rehabilitation plan falls far short of this ideal and this is acknowledged by the applicant's experts. What they do not point out, or possibly realise, is how far short such rehabilitation falls of even mimicking what exists (North, 2011, p. 19).

Similarly, the West Coast Environment Network's (2011b) submission said "the profound changes in substrate and hydrology" would "permanently alter the vegetation" regardless of the rehabilitation efforts (p. 8). Two submissions also noted that the conditions proposed, with Bathurst conducting pest control of the Denniston Plateau in order to support biodiversity, were barely relevant as the plateau already had very low numbers of exotic pests.

The irreversibility of the adverse effects of Escarpment Mine was highlighted by various submitters and interview participants. Submissions by two groups also referred to being opposed on the grounds that end-use of coal contributes to 
climate change. This was not an effect that could be mitigated, and climate change was also disallowed from being considered in the hearing process. The way in which different knowledges were legitimised and the subverting of the climate change argument is discussed in the next section. One participant noted that the group he was part of tended to focus on making submissions on projects they wanted to stop, rather than submitting with the purpose of changing the conditions or lowering the impact of a proposal (participant 14). Because of what he believed to be the irreversibility of the damage of proposals like Escarpment Mine, he suggested that “putting conditions wouldn't actually make much difference;.... once you dig up the ground, you can do it in a good way or a bad way, but either way you've lost what you've had and you're never going to get it back" (participant 14). Thus, the concerns highlighted by this group would not be able to influence the decisions to a level deemed acceptable by the environmentalists, regardless of the conditions imposed. As will be discussed, the difference in values and knowledges of the environmentalists and decision-makers, was such that full agreement would have been impossible.

\subsection{What knowledge counts: Privileged perspectives and negating the big picture}

Certain knowledges were considered to be more important than others in the decision-making process. From the perspective of the environmentalists interviewed and in the commissioners decision report, the social and economic benefits of the proposal were given significantly more weight than the holistic ecological and conservation concerns accentuated by the environmentalists opposed. This aligns with neoliberalism's emphasis on quantifiable and measurable knowledges, through the privileging of economic rationale, as discussed in subsection 5.3.6.

This section considers the role and cost of expertise, followed by an exploration of participants' experiences of knowledges that were privileged or disregarded in the formal decision-making process. These are: economic development, climate change, conservation, biodiversity trading and a fragmented approach to the environment. 


\subsubsection{The role and cost of expertise}

Expert evidence is a crucial part of the formal decision-making process. The applicant company is expected to provide expert evidence to support numerous aspects of their proposal, and the council also employs experts to peer review the evidence provided to ensure its validity and objectivity. Submitters are also able to bring experts to support their case for or against a proposal. However, it is costly to employ experts, leaving NGOs and small community organisations at a significant disadvantage. This creates inequality, particularly as experts' evidence is seen to be far more important to the decisions made than non-expert evidence. Thus, submitters' concerns are less likely to be given as much weight as any evidence offered by the company.

The cost of hiring experts was seen as a barrier to environmentalists' participation being counted in the formal decision-making process. Various participants remarked that it is difficult for submitters to provide expert evidence for all aspects of a large complex project, given the cost involved in hiring experts (participants 2, 3, 5, 10, 13 and 14). This is particularly difficult when an Environment Court hearing is likely, meaning more experts will be needed soon after (participant 10). The Environmental Legal Aid Fund was cited by two participants as useful when they had used it for Environment Court cases (participants 2 and 14), but they also noted that the amount available was "a very small portion of what it costs to run a good case" (participant 2) and only provided funding for one expert and no lawyers. Another suggested that the Environment Court was increasingly less accessible, with more expenses and less financial support available (participant 11).

The commissioners tend to take into account expert evidence that is provided to them, which leaves environmentalists at a considerable disadvantage, as noted, because they generally cannot afford to provide experts to counter each aspect of the company's expert evidence (participants 10 and 14). Opposing voices tend to be lay-people who have worked on their evidence in their spare time (participant 14). While environmentalists may use favours from experts in their support networks to provide their evidence (participant 3), companies have the financial resources to pay for numerous experts to support their case. The imbalance of 
financial resources available to hire experts creates "such a tilted field that I don't think community groups are taken seriously at hearings at all" (participant 14). One of the council officers also suggested that it would be unusual for the commissioners to rely on the lay-person's evidence "unless that particular layperson submitter can come along with ... an expert to refute [expert evidence from the company]" (participant 5). Another environmentalist participant noted that even lay-knowledge of someone who has lived beside a river for 30 years may not be counted simply because the person is not considered a qualified expert (participant 8). This injustice about the financial accessibility of experts led one participant to suggest that "it's very difficult to have a democratic process when one side have all the resources against another" (participant 13). Moreover, the kind of expertise that is engaged by the applicant will obviously be that which most effectively supports their case. Although the same can be said of opposing submitters' expertise, they are less able to cover as many elements of the case because they have fewer resources.

The company's experts provided evidence that tended to be consistent with the privileged knowledges of economic development and the fragmented approach of biodiversity trading for mitigating adverse effects to conservation.

\subsubsection{The economic development rationale}

Most environmentalist participants suggested that economic development and the proposed economic benefits to the region were highly privileged by the decisionmakers (participants 1, 2, 3, 8, 9, 11, 12 and 13), despite the short-term nature of such benefits (participants 1, 3, 8, 9 and 13). One said that short-term economic development effectively "trumped the destruction forever of unique biodiversity of the plateau" (participant 1).

Before citing some environmental concerns, the commissioners in their decision stated that:

We have decided to grant this application, but not without some considerable reservations and anguish. The most and almost overwhelming factor that we had to consider is the enormous financial benefit that the mine will bring to the Buller district and the West Coast region ... The real issue with this application is whether the cost is worth paying for the 
benefits that will be derived. It is the classic development/environment conundrum (Archer et al., 2011, p. 102).

The experts the company employed to provide evidence on the economic benefits from the proposal stated that while the economic impact estimates could be either overstated or conservative, they expected that:

Over the current proposed 5 year mine life, the mine will generate on average in [the] West Coast region an additional 424 jobs and $\$ 138$ million per year of added value, including $\$ 41$ million per year of wages and salaries (Butcher, 2011, pp. 11-12).

Various participants questioned the argument that Escarpment Mine would increase employment in the area, with the main counter-arguments being that the area already had high employment and miners would be residing in other parts of the country (participants 2, 9, 11, 12 and 13). Furthermore, while the local employment potential was lauded by the company in the evidence they provided (Butcher, 2011), one participant suggested that profit, not employment, was the presiding motive for the company. She continued, stating:

there is no way that a company like Bathurst... sat in their Australian board rooms and thought, 'oh what shall we do for the next five years, oh we should create some jobs! Westport! That's a small community on the West Coast that blah blah blah...' Bullshit, bullshit. But it's a narrative that they use (participant 11).

Another participant also noted the injustice in the company reaping the profit by destroying the local environment (participant 13). He went on to say "it's a fallacy that it's going to bring long-term benefits to the area: as soon as they've ripped the guts out of it, or the market declines, it'll be gone" (participant 13). This supports the idea that economic development was privileged at the expense of the environment.

Curiously, one of the council officers interviewed suggested that the process focuses too much on the environment and not the economic benefits:

we get so so focused on the environmental, the physical environmental effects of the flora and fauna and all those sorts of things, but the RMA is also s'posed to be about the economic effects, and I don't think we've got ... that, ... if you're a greenie, you're saying oh ok, this process is real good! [laughs] But I sometimes think, you know, if you look at the benefits that mining industry can bring to a region, it's huge. The jobs and the employment and the money, it's a massive impact. And although we're s'posed to be considering the 
[social] wellbeing and all that kinda thing under the RMA, it seems to play very much a

back foot to the physical and environmental effects of that mining process (participant 5).

This is quite contradictory to the perception of the environmentalists involved, who felt that the economic arguments were hugely privileged over environmental concerns, specifically climate change and adverse effects to conservation. As discussed in Chapter three, the RMA's purpose requires a balance between the social, cultural and economic wellbeing of communities and the sustainable management of the environment. Yet, as illustrated in this chapter, it is contentious as to what exactly this balance means.

\subsubsection{The dismissal of climate change}

The end-use of the coal from Escarpment Mine and its contribution to climate change was dismissed as a legitimate argument by the commissioners. In the Section $42 \mathrm{~A}$ report written by council officers ${ }^{21}$, the summary of submissions stresses the percentage of submissions that commented on a certain issue (Ridge \& Inwood, 2011). Climate change and the potential greenhouse gases released by Escarpment Mine's coal was a contentious issue raised in approximately $8 \%$ of the submissions received by the councils ${ }^{22}$ (Ridge \& Inwood, 2011). Of the twelve environmentalists interviewed, ten cited coal's contribution to climate change as a major concern about the proposal (participants 1, 2, 3, 8, 9, 10, 11, 13, 14 and 15).

However, the councils deemed this to be outside their authority to consider in their decision under the RMA. The commissioners stated:

We cannot say that we disagree with any of the sentiments concerning climate change and its potential danger ... but it is our opinion that the effects of burning coal on global "climate change" as such is not a matter that we can properly consider in our consideration of this application ${ }^{23}$ (Archer et al., 2011, p. 75).

\footnotetext{
${ }^{21}$ This report was presented at the hearing and given to the applicant and all submitters two weeks prior the hearing, as per the RMA, Section 42A.

22 This is a flawed way of presenting the submissions, as they were not a representative sample and some submissions spoke for organisations representing a very large number of people, while other submitters represented only themselves as individuals.

${ }^{23}$ One of two main reasons the commissioners cited for their inability to consider the adverse effects of climate change was that the coal was likely to be burnt in India or China, making the release of greenhouse gases not relevant to New Zealand legislation (Archer et al., 2011). The other reason was that the submitters did not provide sufficient evidence to ascertain the exact significance of effects that Escarpment Mine's coal will have on climate change: "the effects of the contribution of the EMP [Escarpment Mine Project] coal to the world climate change problem caused by greenhouse gas emissions must be trivial and mere bagatelle“ (Archer et al., 2011, p. 77).
} 
The Section 42A report written by council officers states that climate change was not able to be considered under the Resource Management (Energy and Climate Change) Amendment Act 2004 as per Section 3(b)(ii) ${ }^{24}$ (Ridge \& Inwood, 2011, p. 9), which states that:

The purpose of this Act is to amend the principal Act....

(b) to require local authorities-

(i) to plan for the effects of climate change; but

(ii) not to consider the effects on climate change of discharges into air of greenhouse gases. In part due to a submission focused on Escarpment Mine's contribution to climate change, Buller Coal Limited (a subsidiary of Bathurst Resources) and Solid Energy went to the Environment Court in March 2012 to seek a declaration that climate change could not be considered by local authorities under the RMA (Re applications for declarations by Buller Coal Limited and Solid Energy Limited, and West Coast ENT Incorporated [2012] NZEnvC 40). Bathurst Resources did not apply for consents for discharges into air, but rather discharges to land and water, about which the RMA does not explicitly state that councils cannot consider climate change (participant 7). Thus, the environmental groups opposed argued that the effects of the end-use of Escarpment Mine's coal on climate change could and should be considered in the decisions to grant the consents for discharges to land and water (participant 7). While this Environment Court declaration would have more general implications than the Escarpment Mine decision specifically (participant 10), this point could have changed the way that the commissioners should have considered climate change, meaning that their decision to not consider climate change could have been overturned. The Environment Court decision upheld the councils' point of view that the RMA does not give councils authority to consider climate change in such applications (Re applications for declarations by Buller Coal Limited and Solid Energy Limited, and West Coast ENT Incorporated [2012] NZEnvC 40). This was appealed in the High Court by Forest and Bird and the West Coast Environment Network, and is currently awaiting hearing in the Supreme Court (Berry, 2012).

The commissioners' arguments are aligned with neoliberalism's emphasis on certain, quantifiable evidence and inability to cope with uncertainty and wide-ranging scope and boundaries of effects. ${ }^{24}$ This was referred to as RMA Section 3(b)(ii), which actually does not exist as a section under the RMA. Given the context in the report, this is considered a minor error and that the intention was to refer to the Resource Management (Energy and Climate Change) Amendment Act 2004. 
Various participants expressed disbelief that New Zealand's principal legislation about the environment did not allow the decision-makers to consider contributions to climate change, despite it being perceived to be the primary issue facing humanity and the environment (participants 1, 2, 3, 8 and 11). Two people said it was "a no-brainer" to consider climate change in an application for coal mining (participants 2 and 3). Participant 1 stated "this is crazy, this is the most important environmental issue facing humanity and nature, and under our premiere New Zealand environmental statute we can't talk about it?". One participant argued that the RMA's purpose of promoting sustainable management was not consistent with its inability to consider coal's connection to climate change, which she stated was "the most unsustainable thing on our planet" (participant 2).

The commissioners wrote that even if they were able to consider climate change under the RMA, "we would find that the effects of this proposal if it were to proceed, would be very much less than minor on the weather patterns of the world in general and the country and the West Coast region in particular and so we do not propose to refuse consent on this ground" (Archer et al., 2011, p. 75). This sentiment was echoed by participant 1 , who feared that even if the councils had decided that they were legally able to consider climate change, there still would have been the question of how much weight they would have given climate change in regard to the various other factors. These perceptions about the exclusion of climate change are particularly relevant considering that the definition of effect under Section 3 of the RMA includes "any cumulative effect which arises over time or in combination with other effects-regardless of the scale, intensity, duration, or frequency of the effect". This appears to be inconsistent with the adverse effects of the end-use of coal, as by mining coal for export, the end-use will inevitably involve releasing greenhouse gases into the atmosphere and contributing to irreversible global climate change.

One of the council officers interviewed suggested that solutions to climate change need to be led by central government, and was not a consideration for the RMA to deal with on a case by case basis: "Climate change considerations of where the coal's going and what's going to happen to it, you know, aren't for the RMA" 
(participant 5). One reason given was that climate change mitigation needs to be dealt with either on a global or national scale (Archer et al., 2011). This could be through the Emissions Trading Scheme, although three participants noted this had been ineffective in deterring the mining of coal for export when the profits were high (participants 1, 2 and 3). Participant 3 felt that given that climate change is a national issue, the decisions about Escarpment Mine should not have been granted at a local government level:

...the government says climate change is a national issue, and yet how come a local district council, a local tiddly biddly regional council can have the ability, a few commissioners, to make a massive decision like that? I actually think it's beyond them and ... the people making the decisions are not skilled and knowledgeable and experienced enough to be making the decisions [about Escarpment Mine] (participant 3).

One of the council officers interviewed stated that because at the time of the council hearing there was no case-law pertaining to whether climate change could be considered by local authorities, "everyone that actually submitted on greenhouse gases was given a fair say during the hearing" (participant 6). This was in contrast to a later council hearing for a different coal mine where anyone submitting about climate change was requested to discontinue (participants 11 and 15). However, even though these submissions were heard in the case of Escarpment Mine, they were not considered legitimate in the final decisions made. If we are to consider democratic decision-making processes as sites for the public to raise issues and be heard on what is important to them, such as climate change, this outcome certainly goes against democratic principles. This issue of climate change being negated in the formal process raises questions for the constraints placed on democracy, when the adverse effects of climate change are global (participants 2 and 11). Democracy is also constrained in the way the adverse effects of climate change, which are extensive beyond the commissioners' realm to consider, are disregarded because the effects are so vast, uncertain and widereaching that they do not fit within the measurable knowledges that neoliberalism favours. The favouring of measurable knowledges is discussed in Section 5.3.6.

\subsubsection{Conservation vs. biodiversity trading}

While climate change, as a global environmental concern, was disregarded as a reason for halting a new coal mine, other much more local environmental effects 
were considered in the decisions made - but only in a fragmented way. The applicant's technical report on conservation and the peer reviews of the report confirmed the ecological significance of the plateau (participant 5, via email January 14, 2013), which was consistent with the environmentalists' belief that the plateau was unique (participants 1, 2, 3, 8, 9, 10, 11, 13 and 14). However, divergence in the ways adverse effects to the ecology should be mitigated illustrated a difference in how the environment was perceived: as fragmented parts or as a holistic socio-ecological system. The knowledge that was aligned with the fragmented approach, biodiversity trading, was given more weight by the commissioners.

Conservation of the flora and fauna of the plateau was discussed at length both in the hearing and by all the participants. One of the council officers suggested that the area was clearly nationally significant due to its significant indigenous flora and fauna, as per Section 6c of the RMA (participant 5), which states the need to provide for "the protection of areas of significant indigenous vegetation and significant habitats of indigenous fauna". Therefore, the company would need to undertake considerable rehabilitation of the area (participant 5). Two local environmentalists described the plateau as a "natural mainland island" where kiwi thrived, because it was naturally predator free and did not require trapping, fencing or 1080 to be protected (participants 8 and 9), similar to predator free islands where native species also thrive. One suggested that protecting the plateau could potentially save DoC money as it did not require any of the funding that other mainland islands need in order to be predator free (participant 9).

The decision to grant consent for Escarpment Mine and associated coal processing and transport, involved conditions for mitigating or remedying an array of adverse environmental effects. There were 24 consents granted, including various discharge permits for contaminants to water, land and air. The two permits that most directly affect biodiversity conservation are:

To enter or pass across the bed of any waterbody; or damage, destroy, disturb, or remove any plant or the habitats of such plants or of animals in, on, under or over the bed of a waterbody (Resource and Environmental Management Nelson Limited, 2011, p. 6 and 14). 
To enable land disturbance and associated activities (including but not limited to vegetation clearance and structures) (Resource and Environmental Management Nelson Limited, 2011, p. 12).

Prior to the hearing, a participant from an environmental NGO was engaged in early discussions with Bathurst with a view to agree to conservation measures (participant 2). However, while she was initially open to reaching some kind of agreement, she said "it became apparent in that process that what they meant by a reserve and what was an ecologically sound reserve ... was poles apart" (participant 2). She indicated that the mine and associated infrastructure would "ruin the integrity of that whole area", deeming the small reserve that Bathurst was proposing a futile pretence at conservation. The area the NGO proposed as a reserve encompassed and far exceeded the proposed mine area, as that was what they believed to be necessary to protect the significant flora and fauna.

In the application process and before the hearing took place, one of the council officers had noticed that the application was particularly lacking in the area of conservation and rehabilitation, and that the applicant should have consulted more with DoC earlier (participant 5). She said "that part of their application was just really poorly done [and they] ... hadn't realized the importance of that" (participant 5). This was reflected in the Buller District Council's part of the Section 92 report ${ }^{25}$, requesting more information from the applicant primarily about the damage to and rehabilitation of the terrestrial ecology of the plateau (Buller District Council and West Coast Regional Council, 2011b). However, participant 5 still felt that Bathurst's proposal did not meet the requirements in this area by the time of the hearing:

they had sort of rushed around and come up with this weed and pest programme on this 680 hectares ... [and I had said] a number of times, 'look I don't think that's, you know, that's not enough. And you're running the risk of coming along to the hearing and it's all going to fall over' (participant 5).

She felt that this could have been remedied if the company had begun conversations with DoC earlier in the proposal planning stages.

\footnotetext{
${ }^{25}$ In accordance with Section 92 of the RMA, council officers can request more information or action from the applicant.
} 
The conservation, mitigation and rehabilitation conditions as agreed on between the company and commissioners fragment the various aspects of the environment into components that relate to the type of resource consents required and the kinds of effects the RMA controls. Thus, the mitigation focuses on reducing negative effects of discharges and pollution to waterways, and effects on specific species on the plateau (participants 1, 2, 8 and 10). However, the ecology of an area is threatened if divided (participants 2 and 10). One environmentalist suggested that with the consent process under the RMA "you end up with something that's really patchy and the ecological integrity is compromised" (participant 10). One of the council officers also noted that loss of habitat could not be remedied: "you can propose all the rehabilitation under the sun, but we're also talking a very unique environment, and all the specialists [agreed] ... you can't restore that back to its original condition" (participant 5). As Castree (2010) suggests, neoliberal approaches to nature are problematic as the exchange of money does not account for intrinsic ecological value.

One environmentalist also stressed the irreversibility of the adverse effects of the Escarpment Mine proposal (participant 14). The precautionary principle ${ }^{26}$ was highlighted by another environmentalist, who said it should be applied in this case: if there's a risk of having irreversible damage to ecology on conservation land, then I think that the commissioners should err on the side of caution... [especially because] we're not sure what species are up there [and] ... surely we need to find out first, so we need to find out what we're going to lose (participant 9).

Again, this 'precautionary' argument was dismissed by the commissioners in their final decision in favour of the economic benefits of the proposal:

it would have been easy to reject this application had we been inclined to take a more precautionary approach. We are greatly influenced however by the significant economic gains that the district and region and the country as a whole will enjoy if the mine proceeds (Archer et al., 2011, p. 103).

In terms of specific mitigation, success with vegetation direct transfer ${ }^{27}$ (VDT) on the neighbouring Stockton Mine informed some of the rehabilitation measures

\footnotetext{
${ }^{26}$ The precautionary principle states that "Where there are threats of serious or irreversible damage, lack of full scientific certainty shall not be used as a reason for postponing cost-effective measures to prevent environmental degradation" (United Nations, 1992).
} 
proposed for Escarpment Mine (participant 5). However, VDT was only thought a viable option for a small portion of the area (participant 5). One environmentalist stressed that the on-site rehabilitation that was offered by Bathurst would drastically change the ecology of the plateau by replacing the wetlands, moors and tussock lands with free-draining broken rock that would eventually turn into beech forest (participant 8).

The concept of biodiversity trading fits with the paradigm of fragmenting the environment. Biodiversity trading is whereby the developer compensates for the environmental destruction in one area by supporting biodiversity in another, with biodiversity offsetting in similar landscapes or compensation in areas with different biodiversity (participant 7; Walker, Brower, Stephens, \& Lee, 2009). In Escarpment Mine, Bathurst proposed an offset by undertaking pest control in the Heaphy area (Resource and Environmental Management Nelson Limited, 2011). However, as one environmentalist noted, this was hardly compensating as DoC had already been doing pest control in the Heaphy area (participant 13).

The conditions agreed to in the council hearing formed part of the appeal to the Environment Court in late 2012, as noted in Chapter three. At the time of writing, the Environment Court decision was yet to be announced. Forest and Bird stated in a media release following the Environment Court hearing that:

We argued the plateau's conservation values are too high to be destroyed. We argued that plans to put the soil back after mining and replant the surface will not restore what is lost (Forest and Bird, 2012c, para. 2).

It is unknown whether Forest and Bird and the West Coast Environment Network will appeal the Environment Court's decision to a higher court if the outcome is not favourable to the issues they have highlighted.

The problem one environmentalist highlighted with biodiversity trading, is that the baselines for habitat and species numbers on which such trading is based, continuously shrinks as new developments take place:

\footnotetext{
${ }^{27}$ Vegetation direct transfer is where a section of vegetative material (including various microbes and invertebrates) is uplifted and transferred to another site, until the original location (or nearby) is available for replanting (participant 5).
} 
it's destruction by the salami slice syndrome... I feel like ripping up the evidence where people say, ... 'it's only $5 \%$ of this nationally endangered population, there's still $95 \%$ of it out there', well they'll cut out that $5 \%$ and then they'll still be, 'oh it's only another 5\% so we'll cut another [bit]...', until you've pushed it down to a critical level (participant 2).

Participant 2 also suggested "how do you measure the intrinsic value of an ecological ecosystem that exists nowhere else?" She suggested that the profit from coal was more easily measured, meaning that "they kinda get a bit more weight than some nefarious kind of value" such as significant habitats or ecological systems. She also critiqued the way the RMA encouraged "finding science to back up bloody everything" (participant 2).

There are widely divergent views on the value of biodiversity offsetting. Walker et al. (2009) suggest that biodiversity trading "to date has facilitated development while perpetuating biodiversity loss" (p. 149). Maron et al. (2012) suggest that biodiversity offsetting only be conducted when "the impacted biodiversity and ecosystem values can be explicitly defined and measured" (p. 146). Forest and Bird's Bioblitz was an activist attempt to increase information about the Denniston Plateau (participants 9). At best, from environmentalists' perspectives, it could be seen that recognising the significance of the ecosystems on the plateau may to its protection, or, at worst, more ecological knowledge on which to base biodiversity offsetting conditions. But regardless of the ecological knowledge offered, Walker et al. (2009) suggest that weak design and negligent enforcement by authorities will not be overcome. One of the reasons for this is ecological complexity which has:

levels of organization from genes to ecosystems, an extraordinary number of elements at each level that vary in time and space, and diverse interactions within and between levels (Walker et al., 2009, p. 150).

Furthermore, net biodiversity loss is persistently facilitated by "non-equivalent exchanges" (Walker et al., 2009, p. 152). A clear example lies in Bathurst's proposal for pest control of the Heaphy area, which is nothing like the low scrub and wetlands of the Denniston Plateau.

Büscher, Sullivan, Neves, Igoe and Brockington (2012) suggest that "many conservationists can seem to choose the safe road of doing conservation" (p. 15) within neoliberal discourses, that offer technical solutions incentivised through by economic gain such as biodiversity trading. Conversely, those that oppose 
neoliberal conservation practices are typically not heard (Büscher et al., 2012), as was the case in environmentalist opposition to the biodiversity offsetting measures in Escarpment Mine.

\subsubsection{The future of the Denniston Plateau}

Numerous participants, including one council officer, felt that the RMA allowed for companies to apply for consents in a fragmented way. The lack of full plans, due to the ability to uncover them over time through multiple consents, meant that the impacts of the whole project were not able to be considered (participants 2, 3, 5, 8, 10,12 and 13). One council officer interviewed noted that before the final application by the company for consents, the planning team at the council had requested the applicant include more of their plans in the one application, as the coal-handling facility and trucking movements had not been incorporated. Participant 5 stated "we need to see the full package ... you gotta be really careful that you're not dealing with things in a piecemeal fashion and you're getting the whole caboodle, so you can assess all the effects."

While still granting the consents, the commissioners did also suggest that the future of the plateau be clarified, potentially with DoC establishing a certain proportion of the plateau as a protected area (Archer et al., 2011). One participant noted that the current stewardship ${ }^{28}$ status of the land on the Denniston Plateau did little to protect it, even though it was still DoC land (participant 8). Similarly, one environmentalist suggested that a strategic approach be taken to allocate areas that will be conserved, allowing for other areas to be mined (participant 10). While any form of coal mining, in her opinion, would never be acceptable because of coal's contribution to climate change, at a minimum, this would ease some of the conservation concerns.

\subsubsection{Fragmented approach to the environment}

In the case of the Escarpment Mine decision, the environment was perceived by the company and commissioners to be dividable and not interconnected. This was shown with the councils' unwillingness to recognize Escarpment Mine's

\footnotetext{
${ }^{28}$ See Chapter three for details on stewardship land, in particular subsections 3.1.2 and 3.2.2.
} 
contribution to climate change under their interpretation of the $\mathrm{RMA}^{29}$, as the effects were too broad and complex, and the way in which biodiversity conservation was approached in a tradable fashion. The RMA allows this to occur, possibly even encouraging decision-makers to consider the environment as a sum of its parts rather than having much more significant intrinsic value as a whole, despite sections in the purpose (Part 2) of the RMA that indicate the contrary.

This is consistent with the neoliberal nature of the RMA, as under neoliberalism, the free market is privileged, requiring calculable knowledges and trading in order to function (Castree, 2010; Peck \& Tickell, 2002). This is evident in the decisionmaking process for Escarpment Mine, with the favouring of calculable knowledges. As can be seen in the preceding subsections, proposed economic benefits and biodiversity trading were privileged to the extent that arguments founded on other knowledges were extenuated or disregarded. Climate change, with its global effects and lack of containment, was outside the realm that such measurable approaches could consider. The intrinsic value of the ecology of the Denniston Plateau and the irreversibility of the damage that the mine would cause was also disregarded. Ecological aspects of the environment were seen as replaceable, and damage was perceived as able to be mitigated through biodiversity trading and rehabilitation.

Imposing neoliberal paradigms on nature can become problematic as "the way various different actors value the non-human world cannot be satisfied by them expressing their non-monetary values through the expenditure or receipt of money" (Castree, 2010, p. 1731). Similarly, as established in this section, to environmentalists involved, the irreversibility of effects of Escarpment Mine meant that the intrinsic value of the Denniston Plateau could not be replaced, replicated or compensated for. The knowledges that were favoured in the decision-making process were aligned with the dominant neoliberal discourse, with economic development and the separate aspects of the environment privileged over intrinsic values and uncertain knowledges. Neoliberal discourses significantly privilege quantifiable knowledges over other knowledges, and also claim to be apolitical,

${ }^{29}$ As the Escarpment Mine council hearing was prior to the Environment Court hearing in 2012 that determined that climate change could not be considered for applications for coal mining consents, the disregarding of the climate change argument still lay with the council and commissioners' interpretation of the RMA. 
further reinforcing a neoliberal hegemony (McCarthy \& Prudham, 2004; Peck \& Tickell, 2002; Purcell, 2009).

\subsection{Perceived objectivity and the "philosophical stance"}

In addition to quantifiable knowledges being privileged in the decision-making process, the perceived objectivity of evidence and neutrality of submitters was highly favoured. From a constructivist post-structural perspective as detailed in Chapter two, all knowledge is socially constructed, and meaning is created within specific contexts, thus, pure objectivity is unattainable.

Nonetheless, as defined by a senior council officer, an:

objective independent expert would be basically taking an objective perspective and would be necessarily, so they would be ... presenting what they believe as a technical expert, is an appropriate course of action, ... [so] if they've got concerns on the technical aspects of the proposal, they'll be explaining that and why (participant 7).

In a practice note, the Environment Court (n.d.) requires that expert witnesses before the court:

(b) state the witness's qualifications as an expert;

(c) describe the ambit of the evidence given and state either that the evidence is within the expert's area of expertise, or that the witness is relying on some other (identified) evidence;

(d) identify the data, information, facts, and assumptions considered in forming the witness's opinions;

(e) state the reasons for the opinions expressed; ...

(g) specify any literature or other material used or relied upon in support of the opinions expressed;

(h) describe any examinations, tests, or other investigations on which the expert witness has relied, and identify, and give details of, the qualifications of any person who carried them out

While not mandatory at council hearings, such qualification and expertise is generally expected for experts presenting at council hearings.

Elaborating on the previous section, in this case, people who were considered more objective tended to present knowledges that were measurable and specific to this particular application. People who had passion and broader reaching beliefs 
about the adverse effects to conservation and climate change that this mine and other mines would have, were perceived as having less objectivity. While council officers suggested that environmentalists' bias was a reason for doubting their arguments, similarly there was evidence that commissioners and council officers were prone to bias. Yet without the power to make the decisions, the environmentalists were the party that were disadvantaged through these perceptions of subjectivity. Perceived lack of objectivity appears to be a major obstacle for considering environmentalists' evidence as equal to others' expertise, and thus, it is not heard. Here I discuss the perceived objectivity or lack thereof of environmentalists, independent experts, council staff and commissioners.

\subsubsection{Environmentalists' advocacy}

A perceived "philosophical stance" stopped environmentalists' evidence being valued as much as other evidence, according to a senior council officer:

Environmental groups may make submissions which are philosophically based rather than technically based, ... the other thing that needs to be factored ...is, is the submitter being an advocate or is the person speaking on behalf of a submission or on a submission giving objective balanced viewpoints?...Because you can get people who are highly qualified, but if they're advocating a position, then, ah, [pause] their objectivity is at question. ...For example, if someone's come up who's said oh, you know we're opposed to any form of coal mining, then you would have to question whether the evidence they were providing was objective (participant 7).

One environmentalist in particular was also aware of this perception and how it disadvantaged environmentalists in the submission process. She said that she needed experts to advocate for the conservation of the plateau, but their perceived objectivity would disappear if they did, further shrinking their ability to influence the formal process:

I get so frustrated, where I've got experts that are so willing to speak out against something, but because they're [presenting evidence in formal processes], they dare not speak out. And I'm just like, I need them to speak out! I need them to be telling our Prime Minister this shouldn't be happening! But the lawyers are saying don't let them talk because if they talk and if they are out in the media as making a statement of advocacy, that's it, their independence is gone (participant 2).

She also suggested that the RMA "fails to recognise that experts actually naturally of right should and can be advocates" (participant 2). All experts are arguing for a position, yet discourses of objectivity legitimise some evidence over other more 
'objective' evidence. Furthermore, she proposed that experts' opinions, based on expertise and experience, be regarded as valuable rather than being dismissed as advocacy. She emphasized that the focus on objectivity prevented experts from forming an opinion based on their experience and knowledge (participant 2).

This aligns with the way in which measurable knowledges (as in the previous section) are privileged under the dominant discourses of neoliberalism and the pretence that such knowledges are "depoliticised" and thus further privileged in decision-making (Peck \& Tickell, 2002, p. 389). The senior council officer quoted above demonstrates that if a submitter is not deemed to be providing 'objective' views, their evidence is at question (participant 7). As established in Chapter three, subsection 3.2.2, measurable knowledges that are perceived to be objective, are privileged under neoliberal decision-making processes. Such knowledges are considered apolitical and become 'common-sense', forming the hegemonic neoliberal discourse that supersedes other knowledges (McCarthy \& Prudham, 2004; Peck \& Tickell, 2002; Purcell, 2009).

As a consequence of the privilege accorded objectivity, environmentalists have adapted their approaches in order to be effective in this process. Or as one interviewee said, in preparing submissions:

we have to try and persuade them. My view is you must do that with factual information. And what does, I think, blow it completely is when you say something that is a kind of generalised position, um, or a statement that is not actually based on fact. ... you have to just simply give people the facts. ...if you give them the facts, um, then they have to speak for themselves. Um, and so I think the science is really important (participant 3).

While knowledge must come from somewhere, this participant felt that 'fact' was objective and the use of fact in rational arguments had the power to persuade. This emphasis on rationality is consistent with a deliberative democracy approach (Bond, 2011a; Munton, 2003; Pugh, 2005). While the rational deliberations of deliberative democracy advocate participation and inclusion, radical democrats and critics of deliberative democracy suggest that the emphasis on 'rational' debates excludes important voices and arguments (Little, 2002). Such exclusion is contradictory to the ethos of democracy, which is for equality, justice and the rule of the masses. This exclusion is discussed further in Chapter six. 


\subsubsection{The bias of "independent" experts}

In contrast to environmentalists and their experts, experts provided by the company however, tended to be taken as unquestionably objective by the commissioners (participants 5, 10 and 14). During the hearing, Bathurst drew on a number of experts to provide evidence to support their case. There were 27 people presenting on behalf of Bathurst, with experts in the areas of acoustic engineering, lighting, landscape architecture, roading engineering, ecology and rehabilitation, economic, recreation, heritage and others (participant 5; Buller District Council and West Coast Regional Council, 2011a).

Four environmentalists suggested that experts provided by the company were selective in the evidence they presented, both to support the company's argument and potentially secure future employment for themselves (participants 2, 8, 10 and 13). One stated "there are a small number of people that are always employed to do these jobs ... [and they are chosen] for their ability to push their judgments one way or another" (participant 10), while another suggested that they "massage their facts" (participant 8). Another environmentalist stated that she had found information under the Official Information Act 1982 (OIA) on previous cases to suggest that

an expert will write the evidence and then someone working for the company will try and rewrite it to kind of just reword it in their favour and... it's not factually incorrect, but they're picking up on points that ... [are] kinda selective (participant 2).

Participant 8 said that the companies have "got the money to bring in experts to counter anything we say... you can buy experts who will give you what you want". From these environmentalists' perspectives, language can be manipulated to defend Bathurst's proposal, regardless of the actual adverse effects that the mine might cause. One council officer noted that the councils coordinate a peer review of the applicant's evidence prior to the decision-making to confirm that it is not biased (participant 6). Yet this assessment of objectivity is contradicted by participants 2, 8, 10 and 13 who perceived the evidence provided to be subjective.

Three participants suggested that because these experts that are paid by the company, the company will influence their reports "because if they put the wrong thing, they won't be hired again" (participant 2). Participant 13 also said "if they 
don't come up with the answers the company wants, they don't get employed again". Nevertheless, another participant mentioned that any experts have their professional reputation to uphold, and that this made them more likely to present unbiased evidence (participant 6). Experts' perceived desire to uphold their reputation is certainly connected to the privileging of measurable knowledges, whereby those that utilised the dominant, 'apolitical', neoliberal discourses in their evidence would be perceived to be more objective. With the commissioners taking expert knowledge at face value and the experts potentially being selective about the knowledge they present and how they present it, this creates an unfair advantage to the companies who have the resources to employ multiple experts.

\subsubsection{Councils and commissioners: neutral facilitators and decision-makers?}

There were three commissioners on the hearing committee for Escarpment Mine.

One was a local councillor with an environmental management background, another a lawyer, and the third an environmental consultant (participant 5). One of the council staff interviewed suggested that it would have been ideal to have had an ecologist on the hearing committee, but that it was not possible to find one at that time that was not already associated with a mining company in the area (participant 5). Many participants held the view that in general when involved in planning consent decisions, commissioners, elected councillors and council staff had or may have had conflicts of interest (participants 3, 5, 8, 12 and 16).

While only one of three commissioners in this case was an elected councillor, there was a concern that elected members of both councils all have mining or farming backgrounds, and that this makes them biased toward allowing new developments (participants 3, 8 and 13). However, the commissioner interviewed suggested that in general the local community appreciated having a local commissioner (participant 4). Furthermore, a council officer commenting on the local commissioner in this case, suggested that "he's not like, you know, what a lot of people would perceive as a West Coaster, for mining, let's rip shit and bust, you know, that's not [him], he's very middle of the road" (participant 5). This was contrasted with one environmentalist's perception of him which was that he has "always been very anti-green, very pro-development, so I mean, we know [he] is 
always going to say yes" to developments (participant 8). Clearly perceptions of the objectivity or bias of commissioners is also a subjective matter.

Four participants felt that decisions by these councils were often pre-determined $(2,8,9$ and 14), and that hearing panels can be structured to favour certain elements of a proposal (participant 2). One environmentalist stated:

...it seems that often the decision is pre-determined. Like, it doesn't actually matter what you say in your submission, the decision is never going to go your way ... and partly that's because who the commissioners often are... councillors who have been elected on a platform of being pro-mining (participant 14).

This perception that hearing committees may be structured to determine certain decisions is consistent with a council officer's view; that the councils tend not to employ commissioners that they have not worked with before "because it's a real unknown quantity; you don't want to have somebody that then goes left field and turns out to be totally anti-mining [laughs] and has got their own sort of views on it" (participant 5). This quote could imply that it would have been acceptable for a commissioner to be pro-mining, and that this would not have tainted their objectivity. Commissioners were also deemed to be influenced by the fact that they are paid for their work and would not get further employment (participant 8 and 12) "if they go against the wishes of the council" (participant 12).

A council officer suggested that local authorities had variable understandings of what counted as a conflict of interest (participant 5). She cited two cases where various parties in a hearing were family relations (experts, council officers and commissioners), and that senior council officers had been made aware but allowed it regardless. She suggested that this was a "generous view of what constitutes a conflict" and that it contradicts the need for councils to "be seen by the public to be objective and [with] no sort of agendas or bias one way or the other" (participant 5). While one participant noted that commissioners are generally accredited through a central government initiative (participant 4), two others questioned the quality of commissioners on the West Coast in general given the minimal training entailed (participants 10 and 14). The commissioner interviewed suggested that as a commissioner: 
if you feel that you are, compromised in any way, or go into any hearing with strong, ultra strong perceptions, so that you had a pre-meditated outcome or with any hint of perceived bias, then, which results in a conflict of interest, then you should be stepping aside (participant 4).

This was something he felt that commissioners could easily do, yet this is not consistent with the way in which those interviewed perceived the bias of the commissioners.

Certain values that the decision-makers may hold appear to privilege certain knowledges that justify the outcomes that are based on their values. Objectivity is surely a perception, not fact, and thus, those considered to be 'advocates' or with a 'philosophical stance' should not be denied meaningful participation in the decision-making process, as their own position is no less objective than that of the council or applicant.

\subsection{Synopsis}

This chapter illustrates the lack of influence environmentalists were able to have on the decisions, and the ways in which objectivity and certain knowledges were favoured in the formal process, excluding environmentalists' arguments. Environmentalists expressed that activism and mass movements were the most effective ways of creating a value shift where proposals like Escarpment Mine would no longer be acceptable to mainstream New Zealand. However, this is a longer-term gradual process, and in the short-term, environmentalists were unable to have influence in the formal decision-making process led by councils.

Knowledges that were quantifiable and fragmented, such as economic development and biodiversity trading, were privileged in the process, leaving environmentalists global concerns about climate change and holistic ecological concerns outside of consideration. The perception and privilege accorded to objective knowledge, and those presenting such knowledge in the formal process, served to legitimise the applicant's experts and delegitimise the environmentalists' evidence. A mark of objectivity of the applicant's and commissioners' positions ignores the constructed nature of knowledge that applies to all parties. 
Consistent with deliberative democracy outlined in Chapter four, the focus on "rational" debate is a major flaw for how people opposing a decision are able to be equally regarded during the decision-making process, both in terms of the measurable knowledges that are privileged, and the favouring of so-called objectivity. Walter (2008) suggests that Young and Dryzek, both proponents of deliberative democracy, both have "a commitment to equality that overrides any preference that might be given to those forms of argument that are normally privileged on the basis of rationality criteria" (p. 537).

Young (2001) suggests that deliberation and rational debate are constrained by dominant discourses about what types of knowledge are considered rational. This means that activists trying to show opposition are either bound within these dominant discourses or simply left out of deliberations. In this case, the dominant discourses are neoliberal measurable approaches to the environment and to economic development, in contrast with environmentalists' discourses of the plateau's ecosystems as a whole, and the global consequences of climate change. The exclusion of environmentalist discourses denies democracy's aim for equality. McClymont (2011) suggests that "any understanding of the world is political, and that each political ideology expresses this understanding through the articulation of a discourse which aims to express itself as 'reality'” (p. 244). One such political ideology is neoliberal discourse, which has succeeded in becoming hegemonic, depoliticized and, thus, the only knowledge to be considered objective (McCarthy \& Prudham, 2004; Peck \& Tickell, 2002; Purcell, 2009). The hegemony of neoliberal discourse is prevalent in the case of Escarpment Mine. Antagonism manifests the limits of conflicting knowledges (Bond, 2007), which can be seen in the way that the neoliberal knowledges of the council officials conflict and do not overlap with the knowledges of the environmentalists. Thus, an antagonistic relationship emerges, whereby identities of both are simultaneously created and threatened by each other (Howarth, 2000; Laclau \& Mouffe, 2001; Mouffe, 2005). Further exploration of antagonism in this case is discussed in the next chapter.

Neoliberal knowledges alone will never fulfil the democratic ideals of the rule of the masses. Benhabib's (1992) deliberative democracy recognises diversity, and advocates for "sensitiv[ity] to differences of identity, needs and modes of 
reasoning" (p. 8). This includes the inclusion of both the emotional and rational in deliberations (Benhabib, 1992, as in Bond, 2011a). One environmentalist said:

the more viewpoints that are put forward, the more democratic it is in that you're covering a wider range of perspectives. I think that does increase the democracy at play, because ... you're just providing more diversity to, more diverse opinions on various matters (participant 9).

Furthermore, knowledge will never be complete. Brand and Gaffikin (2007) suggest that "agonism recognizes that knowledge is always partial, and sometimes partisan, and that the search for enhanced knowledge is endless rather than exhaustive" (p. 293). Thus, an agonistic approach to democratic decision-making would not privilege certain knowledges to the extent that other knowledges are excluded, as has been the case with the privileging of neoliberal discourses in the Escarpment Mine decision. Elaborating on the democratic framework created in Chapter four, the fragmented approach to the environment raises questions for democracy. How can agonism be expressed when there are such opposing knowledges? How does the justification for excluding dissenting voices fit with democratic ideals? And indeed, how does democracy fare when faced with conflicting knowledges and values? 


\section{Chapter six:}

\section{Escarpment Mine and reflections on the democratic framework}

This chapter explores how the case and the findings reflect the framework I proposed at the end of Chapter four, as presented in the diagram Figure 4.2 (reprinted in figure 6.1 over). The analysis focuses on agonism and antagonism because these concepts are at the core of critiques of deliberative democracy and collaborative planning, and because agonism is the central principle of radical democracy. The character of discussion in this chapter moves from the pragmatic to take a more theoretical approach to questions of democracy.

I start by reflecting on the ethos of democracy, and how ideas of power and equality are expressed in the decisions about Escarpment Mine. I then discuss how these are perpetuated through either agonism or antagonism. I explore the perceptions of transparency in the decision-making process and information shared, and how this contributes to power issues and relationships of an antagonistic nature. I discuss the idea of temporary agreements, open to further deliberation, and limited possibility of this occurring in the case.

Moving to a more theoretical discussion, I explore the acceptance or denial of underlying difference, and how the aim for consensus in decision-making excludes or attempts to co-opt differing opinions. This can be explored through the idea of agonism as accepting difference and engaging adversaries. Furthermore, I discuss the implications of antagonistic activism as being an acceptable way for things to be voiced, and how this relates to Rancière's concept of noise. 
The synopsis of this chapter returns to the framework and illustrates how this case does not reflect the democratic ideals that arose from the literature in Chapter four, despite the Escarpment Mine decision being made under a supposedly democratic process under the RMA.

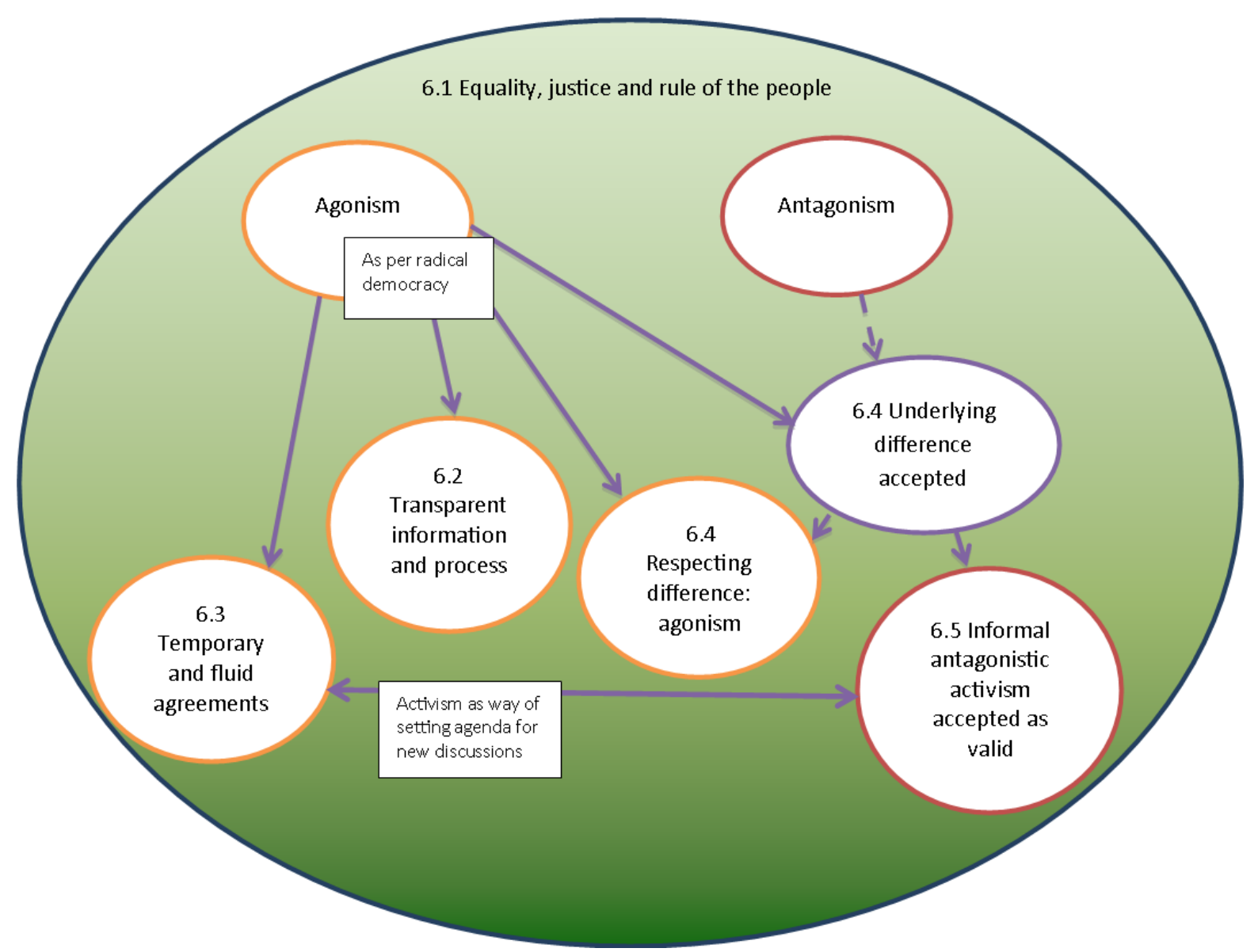

Figure 6.1: Framework for democratic decision-making (with relevant section numbers for this chapter in the headings).

\subsection{Power, equality and democracy}

As established in Chapter four, section 4.2, equality, justice and rule of the people form the ethos of democracy, whereby the citizens have the right to participate meaningfully and equally in decisions that affect their lives. Equality here means that people have equality in access to information and equal opportunity to express their views and to influence decisions made. This framework also realises that equality may never be fulfilled because of structural inequality, but that equality is something that can be consistently worked towards. As Foucault (1982) 
suggests, power relations are inherent in society, which "makes all the more politically necessary the analysis of [them]..., their historical formation, the source of their strength or fragility, the conditions that are necessary to transform some or to abolish others" (p. 343).

However, the hegemonic neoliberalism that prevails tends to result in "decisionmaking practices that are widely accepted as 'democratic' but that do not (or cannot) fundamentally challenge existing relations of power" (Purcell, 2009, p. 141). Purcell (2009) suggests that communicative planning (see Chapter four, section 4.3) does just that; perpetuating prevailing power relations. Nevertheless, Brand and Gaffikin (2007) suggest that even though a critique of collaborative planning is that power inequalities "cannot be dissolved through logical argumentation" as collaborative planning proposes (p. 292), agonistic planning with different methods faces similar challenges as "the issues of power and inequity remain intractable" (p. 308). In echoing the way in which power has an impact on democracy, one participant suggests "[i]t can be mind-boggling when you look at it, sort of globally, it's like, oh my god, power structures at play, and what you're up against, and how on earth do you start to unravel it and put it back together to make it more democratic" (participant 9).

The framework, established after reviewing literature in Chapter four, endeavours to unravel the case study of Escarpment Mine to explore the democratic nature of the decisions made. The framework in Figure 6.1 places equality, justice and the rule of the people as the overarching goals.

Thus, a good starting point for analysing this case is to explore the overarching participation (or rule of the people) in the formal decision-making process. In considering Arnstein's (1969) ladder of citizen participation, this case, with the little influence that environmentalist submitters were able to have (see Chapter four, 4.2.2), would fit into either informing or consulting the public, which she argues are degrees of tokenistic participation. While first appearing that the process was fair and allowed the public to have a say, this participation is clearly limited (as discussed in Chapter five). However, it is important to elucidate that under the RMA, the councils make district and regional plans that involve public 
participation. The rules in the plan govern how, when and for what kinds of activities resource consents will be required. Given the public participation in the development of the district and regional plans, it is deemed that the rules outlined are with the public's endorsement. Therefore, it is only for project applications for certain non-complying activities that have significant effects that the public get an additional 'say' through the submission process.

Two council staff interviewed suggested that equality was present through fair participation in the formal decision-making process:

I sorta felt as though everyone um, had a fair say in the hearing (participant 6).

My role is just to make sure that the process is... a fair process that doesn't disadvantage, or advantage one party over another (participant 7).

Several participants $(3,10$ and 13) also indicated that the RMA was good in that it allowed anyone from the public to make a submission and be heard (in publicly notified cases): "in other ways I think the RMA is probably quite good, anybody can put in a submission and go along" (participant 10). In addition:

I really felt that New Zealand has quite a good system and of an ordinary person like me being able to be heard, and um, with just a little bit of help with some of my written stuff... it's amazing how much respect that judges and commissioners at that level give you as a lay person, you know?... I think that's a fantastic democratic process (participant 3). The commissioner interviewed suggested that because of the fine tuning of the processes under the RMA since it was enacted in 1991, that he "can't think of a better way [to have public participation] than the process that's actually already in place... I think it's probably as good as we're going to get" (participant 4).

Nonetheless, this was contradicted by environmentalists' inability to have an effect in the formal decision-making process, as discussed in depth in Chapter five. Moreover, one participant said that the submission process feels "out of reach to your ordinary citizen" by appearing complicated (participant 9). She suggested that "simplifying the processes of... public engagement" would make it more democratic (participant 9). While some participants stressed the fairness of the process in that it allowed anyone to submit, participant 9 recognised that that this does not account for the exclusive nature of the formal participation process. The formal participation must initially take the form of formal written language, and, as established in Chapter five, the formal process gives preferential treatment to 
submissions that align with the dominant discourses of neoliberalism and rationality. Additionally, council officers and environmentalists alike emphasised that lay-people's knowledge is not given weight in the decisions made (participants 2, 5, 7, 8, 12, 14 and 16). In summary, equality is not met because of the emphasis on formal and rational participation.

The way in which environmentalists were unable to achieve meaningful participation in the process indicates that equality was not paramount, despite claims to fairness and several participants' statements that indicate the contrary. To explore the lack of equality, I turn to the extent to which agonism and antagonism were apparent in various circumstances, starting with another commonly held principle of democracy: transparency. Throughout this discussion and as established in Chapter four, subsection 4.3.4, I take agonism to be based on disagreement between adversaries where one respects the right of the other to disagree, and both parties understand that justice, equality and freedom underpin their relationship. Agonism is the acceptance of the potential permanence of disagreement (Mouffe, 1995, as in Bond, 2011b; Hillier, 2002; McClymont, 2011). Conversely, antagonism is the conflict between identities whose discourses have no commonalities, but simultaneously shape and threaten the other (Howarth, 2000; Laclau \& Mouffe, 2001). Antagonistic relationships display enemy-like behaviour and a competing drive for attaining power over the other's discourses (Mouffe, 2005).

\subsection{Transparency of process and access to information}

Clearly a key issue for equality and the redistribution of power in decision-making is the transparency of the decision-making process, and free access to information. These have arisen as issues in the case of Escarpment Mine, with particular regard to: the potential bias of commissioners; the lack of consultation and information given by the company; and difficulties accessing information from $\mathrm{DoC}$, both under the OIA and with their absence at the council hearing. Dissatisfaction with the lack of transparency of process and access to information was high among environmentalist participants. This demonstrates the power the decision-makers had. A senior council officer suggested that: 
opponents say there's not enough consultation or enough information but there's gotta be a balance and a limit. Because again, if you're opposed to something then you're always going to tend to say there's not enough consultation or there's not enough, so it's very difficult to think of a, how that process could be improved (participant 7).

Yet a lack of transparency and ability to access information prevents equality and justice from being fulfilled. It also implies an antagonistic relation, where the environmentalists have been perceived as enemies, with weakened rights to disagree on equal terms.

\subsubsection{Commissioners}

One of the main criticisms of such transparency, as discussed in Chapter five, was the way in which commissioners were chosen. As discussed in section 5.4.3, one planner indicated that the councils tend to employ commissioners that they have worked with before (participant 5). The council would prefer to know who they are working with rather than risk an unpredictable outcome that may be based on values (participant 5). Moreover, four environmentalists felt the hearing committees were often constructed to create a pre-determined outcome due to commissioners' vested interests (participants 2, 8, 9 and 14).

Four participants recommended removing the authority for choosing commissioners from the council, meaning that commissioners would be independently appointed (participants 8, 9, 12 and 14). A certification programme is currently in place for commissioners to become accredited, and it is mandatory for the majority of a hearing committee to be accredited (participant 4; Ministry for the Environment, 2011). Accreditation involves a two day foundation course, followed by recertification every three years, and by September 2014, all commissioners at a council led hearing will need to have this certification (Ministry for the Environment, 2011). However, given that all three commissioners of the Escarpment Mine hearing committee were already accredited (Buller District Council and West Coast Regional Council, 2011a; Ministry for the Environment, 2011) and the questions that participants raised about their bias, it is dubious whether such accreditation will ensure independence and transparency in the decision-making process. 
The neutrality of commissioners was questioned by a number of environmentalists; in the words of one:

there's agendas that are being pushed that contradict what the RMA is supposed to be about... there needs to be perhaps more neutrality in the process of assessing arguments for and against resource consents... Can more be done to create a more neutral set of commissioners who don't have links with the industry? (participant 9).

How to go about this is indeed a good question, and in need of much review to ensure that the process is transparent, and that commissioners have the ability to engage respectfully in agonistic discussions with diverse opinions. The decisionmaking under the RMA appears to vary in different councils across the country, with certain values being considered differently. Currently, from the perception of the submitters interviewed, it appears commissioners in this case only considered issues that they chose to (such as quantifiable knowledges as established in Chapter five). This does not fulfil equality in decision-making as it prevented environmentalists from participating meaningfully. Furthermore, it created an antagonistic relationship as it did not respect the right for parties to disagree on equal terms.

\subsubsection{The company}

There are diverse perceptions about the way that the company consulted with various parties. The company had endeavoured to consult with the various submitters (participants 2, 5, 6 and 12). Participant 5, a council officer, said from evidence Bathurst provided at the hearing, that they had undertaken broad consultation particularly with residents in the area. However, two participants felt that the company did very little to engage with the local residents, even those living in proximity to the site (participant 12 and 16). Furthermore, when they met with a Bathurst representative, they said he did not mention the larger part of the proposal that would most closely affect them: "he omitted that little bit, you know... It was lies from the start" (participant 12). Another participant suggested that when she met with a representative of Bathurst and visited the plateau with them, that this person did not convey nor know the full extent of the proposal (participant 2). One local said that over the phone, the representative from Bathurst "started to bullshit me and I told him I knew a thing or two" (participant 
13), again expressing the sentiment that Bathurst representatives were being deceitful in their communications with those that might oppose the project.

One environmentalist felt that after initial meetings with the company, she and her organisation did not hear back from the company, despite indications that there would be further dialogue (participant 2). She also remembers discovering that Escarpment Mine was stage one of many stages, as Bathurst had bought extensive mining permits for the whole area (participant 2). It appears that Bathurst did not disclose their full plans for mining on the Denniston Plateau. This can be seen as taking an antagonistic approach, as the concealing of certain information from people who they saw as threats to the project was assuming an enemy-like relationship. It also denies equality for all parties, by preventing environmentalists to engage in informed discussions equally with other parties.

\subsubsection{DoC}

There were two main issues that emerged about DoC in the case of Escarpment Mine: their absence at the hearing, and the lack of information freely available from DoC to submitters.

DoC did not present an oral submission at the hearing, despite some staff members attending to observe ${ }^{30}$ (participants 3 and 10). The main criticism of this was that as a state body funded, established to provide expertise on conservation, they were not available to provide evidence, answer questions from the commissioners or offer counter-arguments about conservation, mitigation, rehabilitation and biodiversity off-setting, despite conservation being one of the major environmental concerns of the proposal (participants 3, 5, 9, 10, 11 and 13). An environmentalist said, "they are on the state's books to do that work and have that knowledge and present that evidence" (participant 11). One participant suggested it was "disgraceful” that DoC wasn't at the hearing (participant 13), while another said "they've just been silent on the matter and I think that's pretty shameful" (participant 9). Nonetheless, participant 3 recognised that even if DoC had been at

\footnotetext{
${ }^{30}$ As explained in Chapter two, DoC declined an interview with me as part of this research, thus I was unable to obtain an answer from DoC as to why they chose not to present at the hearing.
} 
the hearing and provided more ecological evidence, the commissioners' decision might have remained the same.

Two participants suspected that the government or Director General of DoC had indicated to DoC staff that they were not to be involved in the council hearing (participants 3 and 8). A couple mentioned that DoC was the main submitter against the Mokihinui hydro proposal in 2008 and 2009 (participants 6 and 1), as discussed in Chapter three. A council officer suggested that DoC used to present in an advocacy role much more frequently ${ }^{31}$, but that recently due to financial strain, "they concentrate on their own process" (participant 5). She said:

They can't sorta win either way. If they don't turn up, people think oh well, they don't have any issues ... but then if they bowl along, then that's costing them a lot, in terms of time and money, to talk, which they can address generally through their own processes (participant $5)$.

Some participants also mentioned that DoC had indicated they could deal with these issues at the access permit stage ${ }^{32}$ (participants 5 and 10). But compounding with the potential lack of democratic ideals, the access agreements that Escarpment Mine will need from DoC are not publicly notified ${ }^{33}$. This means that the only option to oppose the access agreement is through a judicial review at the high court, which is very expensive, and where the only arguments can be about whether the appropriate decision process was followed (participant 14). This environmentalist stated "it is public land, but the public are so excluded from the process" (participant 14). DoC's absence at the hearing meant that there was insufficient information for thorough engagement with conservation arguments.

Another way in which DoC decreased the possibilities for more ecological information was through access to information under the OIA. Two participants made three OIA requests to access information from DoC in order to provide ecological evidence for their submission. However, in their third request, they were expecting to find evidence of a pre-determined outcome for the DoC led

${ }^{31}$ This is consistent with Section 6 (b) of the Conservation Act 1987, which states that one of the main functions of DoC is "to advocate the conservation of natural and historic resources", but does not mandate in what form this should take.

32 The access permit is where, under the CMA, the mining developer must seek permission from the land owner, in this case the Department of Conservation, to access the land where mining will take place. See Chapter three, 3.2.2

${ }^{33}$ Contrary to concessions, which are publicly notified. 
access arrangements and concessions (as written in a letter that someone had alerted them to). But DoC refused to provide them with more information under the OIA unless they paid over $\$ 1000^{34}$ which they were not willing to do (participant 9). This suggests an antagonistic relationship, whereby DoC were not willing to engage with these environmentalists respectfully. Another also suggested that the DoC reports and research undertaken about the Denniston Plateau had never been made publicly available, despite being "a government organisation funded by the taxpayer!" (participant 13).

Another environmentalist also noted difficulty in the tardiness at which information would be provided after an OIA request (participant 10). This was particularly if the occasion arose that their group would request a judicial review of the decision and relied on the information from their OIA request to DoC in order to build their case (participant 10). She suggested that DoC reports should be available as soon as they are written:

But they say ...it would ah, prejudice the decision-maker or something, because of what we might do with that report I guess. But ... if we wanted to go public with it, to try and influence them to change their decision then I would have thought that would have been fair game (participant 10).

If information is accessible to all parties, then they have the capacity to engage in agonistic relationships and equality is much more likely to be in reach.

\subsection{Temporary agreements, open to further debate}

The framework suggests that moments of consensus should be understood as temporary and still open for further and future debate, as per Mouffe (in Little, 2002) and like Dryzek's (2001) workable agreement. Additionally, agonism respects difference knowing that opinions change over time and over different contexts. There has been no evidence of the kind of temporary agreements I propose in the framework in the case of Escarpment Mine. There are two ways the legislative structures of this case could be interpreted as creating room for future deliberations: the appeal process through the Environment Court, and the way in

\footnotetext{
${ }^{34} \mathrm{~A}$ fee can be charged for an OIA request. Section 15, (2) of the OIA states "Any charge fixed shall be reasonable and regard may be had to the cost of the labour and materials involved in making the information available and to any costs incurred pursuant to a request of the applicant to make the information available urgently".
} 
which the RMA allows applicants to apply for consents on a case by case basis. Nevertheless, I critique the way in which these do not fit the framework in terms of equality, rule of the masses, and offering an agonistic space.

As established in Chapter five, subsection 5.3.6, the RMA facilitates a fragmented approach to the environment, which contradicted the purpose of the act to achieve sustainable management. One way it does this is through allowing applicants to apply for consents at each stage as their larger project unfolds. As a consequence, the full adverse effects of a project on the environment cannot be considered together. Yet one participant felt that while this way of applying for consents was not something she fully understood, it also provided an opportunity for more resistance at each consent application (participant 3). She stated, that particularly given that society will gradually become more aware of environmental issues:

I'm not sure that the company is right in thinking that they will get a rollover in five years, ten years, fifteen years' time, for their ultimate goal which is 35 years. ... if we lose the five years, we're certainly going to fight the next one, and um, I wouldn't expect the laws to be the same, and I don't think they will be looser on environmental issues, they're more likely to be... tighter (participant 3).

Each stage of the appeal process, whereby an applicant or submitter can appeal the commissioners' decision in the Environment Court (or appeal of an Environment Court decision in the High Court), could be seen as a formalized method of having some fluidity and openness in the decisions made. But once the consents have been granted at whichever is the highest level that it has been taken to (the council, Environment Court, or higher), there is no opportunity for further deliberation or engagement of opposing views, and those that have not made submissions to council in the original application process are not able to appeal the decision to the Environment Court. This adversarial system is established to provide certainty, while also giving the right to a hearing and appeal. This is different from agonistic theories that recognise the lack of fixity in decisions and politics more generally. As such, this is not the temporary agreement as proposed by the framework, as it does not allow new discussions on a decision to emerge. Moreover, as discussed in Chapter five, 5.3.1, the process of making an appeal can be costly and time consuming for environmental groups who are working largely on a voluntary basis 
and often have little funding. Here, Forest and Bird and the West Coast Environment Network appealed the commissioners' decision to the Environment Court. A hearing was held in late 2012, with the decision expected to be released after the time of writing 35 (The Environment Court of New Zealand, 2012).

The ideal temporary agreement is agonistic if it continues respectful engagement with those that disagree. As a deliberative democrat, Benhabib (1992) proposes an ethic which recognises "consensus of all to be a counterfactual illusion" (p.8). She promotes the respect of and responsiveness to different needs, identities and approaches to knowledge and argumentation. This suggests that the very framework for the formal decision-making process needs to allow for different ways of making decisions. A different mode of reasoning could include the continuation of deliberations as per a temporary agreement. However, this juxtaposes the formal decision-making process, where decisions are fixed and legally binding, and neoliberal discourses of economic development require the certainty of markets in order to function (Castree, 2010; Peck \& Tickell, 2002). Thus it would be impossible for such a temporary agreement to occur in a case like Escarpment Mine.

Although the access agreements under the CMA with DoC are a separate process, numerous participants noted that after the 2010 ' 2 precious 2 mine' protests, the government agreed to publicly consult on significant mining proposals on conservation land; an agreement that was retracted after the 2011 national elections (Stephenson, 2011; participants 1 and 10). This could have been an indication of a temporary agreement allowing for further deliberations, but this was retracted. A couple of participants suggested that the public were not happy with this lack of public involvement: "people are very angry" (participant 1). This exclusion from the decision-making process indicates elements of antagonism due to the absence of the right to voice opinions or participate.

\footnotetext{
${ }^{35}$ Little evidence about such processes was gathered in this research, as at the time of interviewing research participants, the hearing in the Environment Court had not yet taken place, and at the time of writing, the Environment Court decision had not been announced.
} 
Temporary agreements being open to further debate did not appear in this case, and are unlikely to emerge in similar cases, as the projects require binding agreements in order to enforce the legal frameworks. The appeal processes through the Environment Court and High Court do not fit with the concept of temporary agreements, as the final decisions are still binding, and the appeals do not allow new parties to contest the decisions, only those that submitted in the initial council-led process.

\subsection{Accepting underlying difference}

Having discussed some of the more visible and pragmatic elements of the decisionmaking process that clearly do not exhibit aspects of the framework, I now turn to the fundamental element: the acceptance (or otherwise) of underlying and irreconcilable differences.

This section starts with discussions about relationships and interactions between environmentalists and council officers, and the extent to which they express agonism and antagonism. These expressions of agonism and antagonism are complex and also somewhat fluid depending on the context. I then discuss deliberative democracy and collaborative planning's aim for consensus in relation to the impossibility of agreement in this case. This leads me to consider the perceptions about mediation and compromise, and how they may not allow for the respectful acceptance of difference. Lastly, I consider how the binding nature of formal decisions does not allow for situations where differences are irreconcilable.

\subsubsection{Environmentalists' relationships with the councils and local communities}

Two council officers interviewed noted that they always tried to be as helpful as possible to submitters. One stated "I always try and maintain a good relationship whether I agree with their views or not... because you're trying to facilitate the process and it shouldn't be us against them or anything like that" (participant 5). She also emphasised that in general, she would talk through her report on the case with submitters, and explain how she formed those opinions and what can be considered under the RMA (participant 5). This could be seen as agonistic, however, it also contrasts with environmentalists' experience of their relationships 
with the councils as organisations, rather than with individual staff members. Despite contact with individual staff being good, two participants felt that the councils were difficult to deal with, with a political aversion to anything perceived to be environmentalist (participant 2), and unwilling to offer information (participant 10). Another participant suggested that she and others in the organisation were "a bit of a thorn in their side" because of the way they frequently report concerns to the council (participant 3). One environmentalist noted that previously he had felt frustrated with the councils involved as his views were so different from theirs, although he accepted that they do generally reflect public opinion in the area (participant 8).

Being openly opposed to the mine may have the advantage of creating a respectful relationship where other people feel they can express a range of concerns. This may be an indication of antagonism in one space (as antagonistic environmentalist activism) leading to agonism in another (with non-environmentalists feeling comfortable expressing their similar concerns to environmentalists). One participant said "because we are openly opposed, it gives a license for people who've got reservations to talk to someone about it ... They haven't got the freedom to talk about it so openly within their own community" (participant 2). This was reiterated by another participant, who was surprised to realise people supported her in conversation with them, even though they may never become members of their group (participant 3). Nonetheless, some environmentalists had experienced negative responses to their environmentalism by members of the public (participants 1, 2, 8, 12 and 13), including through the media, face to face and, one participant, through actions of vandalism on their property. One environmentalist said, "I try and placate them [people against environmentalist values]... it's pointless arguing with people. But a lot of these guys are full in your face. There's no point in doing that" (participant 13). Another said "I'm more interested in the people that are maybe open and kinda still listening to what the issues are. ... I think that people don't like... aggressive arguments... so I'm not actually in favour of [an] aggressive sort of stance on something" (participant 3). While being on the receiving end of antagonistic behaviour, these two environmentalists expressed that they prefer an agonistic approach, engaging with people in a respectful manner. However, as we can see, respectful dialogic 
approaches that can be considered agonistic must not be confused or necessarily associated with aiming for consensus, which can arise in dialogic approaches that force the privileging of mediation and compromise.

\subsubsection{Aiming for consensus and the flaws of mediation and compromise}

Collaborative planning and deliberative democracy have both been criticized for generally aiming for consensus, meaning other democratic values are undermined (see Chapter four, section 4.3). In the case of Escarpment Mine, numerous participants expressed that agreement or consensus would simply not be possible (participants 2, 5, 6, 7, 8, 9, 10, 12, 13 and 14).

Mouffe (2000) critiques deliberative democracy's rational argumentation as it overlooks persuasion and relationships of power. As Bäcklund and Mäntysalo (2010) suggest, for Mouffe "consensus would be merely a temporary result of the stabilization of power relationships, necessarily involving exclusion itself” (p. 341). McClymont (2011) also suggests that consensus involves exclusion: "the growing hegemony of consensus can be seen as damaging to debate over real alternatives or incompatible views of the world" (p. 245). Thus, accepting difference, which is at the core of this framework and of radical democracy, is incompatible with the overarching goal to reach consensus.

The complexity of these theories and the nature of the democracy each proposes is reflected in comments by interviewees. One senior council staff member stated that environmentalist groups and submitters "may well have a different viewpoint, but again it's a matter of trying to make sure the process is fair and reasonable to all parties". Yet he simultaneously questioned the validity of environmentalists' evidence based on their "philosophical stance" (participant 7). As discussed in 5.4.1, according to this council officer, the perceived philosophical stance that environmentalists had demonstrated their advocacy, meaning that the objectivity of their evidence was questionable (participant 7). This participant's views show that individuals may hold contradictory values of aiming for democracy on the one hand, while also persisting with dominant ideologies on the other, such as measurable knowledges that are dominant under neoliberalism (see Chapter five). 
Hillier (2002) suggests that consensus cannot generally be expected due to differing world views, but that:

a negotiated agreement does offer the theoretical advantages over an elite decision of including diversity, of recognising and admitting the power differences, tensions and conflicts, not merely between specific interests, but between conceptions, forms of knowledge, and ways of valuing and discussing things (p. 69).

However, as discussed shortly, evidence from the participants would suggest in general that negotiations are fraught with compromise, manipulation and cooption (participants 2, 3 and 10). Furthermore, as Purcell (2009) suggests, deliberative democracy approaches (such as communicative planning and the overarching goal for consensus), are often enlisted to support neoliberalism, which "seeks actively to co-opt and incorporate democratic resistance" (p. 141), as seen in Chapter five's discussions.

While numerous participants expressed that in a case like Escarpment Mine agreement by all parties would not be possible, the commissioner interviewed did believe that consensus was generally possible. He stated "[i]t's already shown that it is. I mean certainly because quite often, hearings are avoided by pre-hearing mediation" (participant 4). This is where the council mediates between the developer and opposition in order to amend the application to an acceptable proposal. But the question is what the implications are of mediation type approaches in cases like Escarpment Mine, particularly in light of general concerns about how agreement may be achieved.

Formal mediation was not undertaken between Bathurst and environmentalists opposed to Escarpment Mine. Nonetheless, perceptions about mediation illustrate a reluctance to be involved in any kind of mediation due to the likelihood of compromise when in search of some kind of agreement. One environmentalist who made a submission opposing the mine noted that Bathurst had publicly announced that they were seeking mediation with opposition, yet never contacted her group about it (participant 10). Another environmentalist, representing a larger organisation, was open to discussing potential compromises with Bathurst's proposal for a protected area. However, she "came away from that meeting and it was very clear that the kind of reserve they were talking about and what we were 
talking about were not going to match", despite the willingness on her part for "a bit of give and take" (participant 2). After discovering that their proposals were incompatible, the group publicly proposed a conservation site for the whole of the plateau, fitting with their values and expertise of the area. This illustrates a shift from agonism towards antagonism. Attempts at compromise between Bathurst and the group can be seen as engaging the adversary in discussion with both accepting the other's knowledge as legitimate, and later, antagonistic as this engagement ended and did not commence again. It is antagonistic in that the group's proposal for a conservation area indicates a position that does not allow or incorporate Bathurst's position; but similarly, Bathurst's proposal did not allow or incorporate the environmentalists' conservation concerns.

Three environmentalists commented that any kind of mediation was not valuable in previous cases nor would be valuable in this case (participants 2, 3 and 10). In another case, Environment Court mediation was seen as " bending everybody's arms behind their backs to make them agree to something, but the result was that an internally inconsistent agreement was reached" (participant 10). However, the commissioner interviewed indicated that it was not expensive to lodge an appeal in the Environment Court, and prior to a hearing, Environment Court mediation was a promising option which did not require experts or even lawyers (participant 4). The commissioner interviewed felt that, in general, most of the outcomes of this type of mediation favoured the opposition, leading to tighter restrictions on the applicant: "the applicant finishes up with a tighter or more restrictive outcome than what the commissioners might have granted" (participant 4). But another participant stated that pre-court mediation was "an absolute waste of time" in all the cases they had been involved in, as the mediated outcomes were not desirable to any of the parties involved (participant 3). Although such processes may be superficially regarded as an agonistic approach, incorporating disagreeing viewpoints may cause extensive compromise and disregard the disagreement it initially aimed to respectfully engage.

The risk of co-option was highlighted as an issue by one participant, and that mediation between opposing parties could inherently exclude voices acting in the public interest: 
as well as maybe giving in on things you really shouldn't, I guess there's the danger that a deal will be made that the particular interests of the groups that are there will be met, but that wouldn't be in the general public's vested interests (participant 10).

This participant suggested that reaching agreement can involve exclusion of important voices, and that just because an agreement is made, does not mean that the public's interests, or indeed the overarching democratic principles of equality, justice and rule of the people, are achieved.

The potential for compromise in other situations also arose as an issue. One environmentalist suggested that collaborative decision-making processes that her organisation had been involved with on other issues, had been "fraught with bullying" (participant 2). She also noted that "it has to be really well facilitated" in order for it to be effective. Two environmentalists mentioned two other cases where they critiqued collaborative and negotiable approaches as sites of coercion and compromise (participants 10 and 11). This is reiterated in the literature; the use of deliberation in planning practice has been critiqued as a site for coercion and co-option (Carpini et al., 2004; Ganesh \& Zoller, 2012).

One senior council officer suggested that biodiversity offsetting was a way for a developer to compromise, but that certain opposition groups may be "philosophically" opposed with an "unwillingness to accept compromise" (participant 7). Equally the company's lack of willingness to compromise was highlighted as an issue by one environmentalist, who said that "there's potential for a deal, but it would need the coal miners to get into a place where they'd be willing to make a deal, because at the moment, they're totally not" (participant 10). The company's mitigation plans for damage to conservation on the Denniston Plateau was for pest control in other areas (Resource and Environmental Management Nelson Limited, 2011). This was seen to be irrelevant to the damage that would be caused to the biodiversity on the plateau (participants 2, 3, 10 and 13). This demonstrates conflicting discourses, with the privileging of the company's discourse to the extent that the environmentalist discourse is neither respected for its difference nor incorporated equally with the company's - both of which would have implied equality, one of the founding principles of democracy. 
A member of one of the smaller environmental groups in opposition suggested that they do not expect their formal submissions to have much influence, because they tend to choose issues that they feel strongly about where no part of the proposal is reversible. This means that they are "not submitting to ... changing the conditions or letting the project go ahead but with a lower impact, we're generally trying to stop projects" (participant 14). Participant 7, a senior council officer, suggested that the more "vocal" environmental groups "have the philosophical viewpoint that there shouldn't be coal mining...[which is] diametrically opposite to the proposal; then you don't tend to get a lot of common ground." This illustrates elements of antagonism in the environmentalists' approach, yet in order to achieve the ethos of democracy (in particular equality and justice), this antagonism is appropriate. Justice, when applied to concerns about the global adverse effects of climate change, would indicate the need to halt any significant project that contributes to climate change - the tenet upon which the climate justice movement is based. Additionally, the irreversibility of the project also indicates the company's antagonistic approach in disregarding the on-going difference of those in opposition. This irreversibility denies the possibility for the decisions to be made open for further debate. Given these opposing stances, agreement would not be possible in this case. Consensus should not and cannot be the overarching goal, illustrating a flaw in this kind of context of deliberative democracy and collaborative planning approaches with their fundamental aim for reaching agreement.

Furthermore, compromise under neoliberal hegemony means that the very realm of compromise in negotiations is limited: "[c]itizens might have formal decisionmaking power, but their range of decisions can become so narrow as to not really be decisions at all" (Purcell, 2009, p. 145). When negotiation is imminent, often the mitigation measures such as the biodiversity trading discussed in Chapter five are so limited in scope that the opposition is unable to make any agreement without fully compromising their values. Thus, any such decision is not incorporating disagreement; rather it is weakening the core reasons for disagreement in the first place. This is certainly not an agonistic approach. If agonism were present, the decision-making process would not push opponents to compromise their opinions 
for the sake of reaching agreement; rather they would be engaging with each other as adversaries and accepting that some differences are irreconcilable.

\subsubsection{The binding formal process with the impossibility of agreement}

Linking to section 6.3, the formal process only creates binding agreements, preventing the possibility of agreeing on an outcome or renegotiating the decisions in future. Even though there were various conservation, mitigation and rehabilitation conditions included in the final decision to grant the mine, one council officer noted that they "ran out of time" to have thorough conditions, meaning it would have to go to the Environment Court (participant 5). She said that she thought:

oh my god those conditions, because they're a bit poorly pulled together in a rush. And the biodiversity stuff, because that hadn't been really dealt with properly at the DoC level, yeah, it's kind of a bit of a mess too there I think too, so I don't know what the Environment Court is going to make of all that (participant 5).

In the rush to create a binding agreement, error was rife, consistent with Brand and Gaffikin's (2007) argument that collaborative planning often results in inexact decisions. They suggest that this is a result of the flawed aim for consensus: “collaborative planning's prioritization of consensus invariably produces this noncommittal, since its failure to accommodate a more candid agonistic discourse makes it vulnerable to euphemism, surface agreement and equivocation" (p. 305). This failure to achieve agonistic discourse, and the resulting inexact outcomes, is also consistent with the lack of transparency in the process and information available, as discussed in section 6.2.

In the Escarpment Mine decision, accommodating a more genuine agonistic discourse would have required more time, with more actors, and the deficit in this regard created equivocation. Brand and Gaffikin (2007) promote agonistic planning (consistent with radical democracy), which perceives "the primary purpose of at once nurturing the widest possible expression of a very differentiated plurality, and, at the same time, accepting the possibility of irreconcilable disagreement" (p. 306). It does not forsake consensus; rather it places reaching agreement as a lower priority than the expression of disagreement (Purcell, 2009). 
The issue of irreconcilability was highlighted by a well-experienced environmentalist - that regardless of the process, there will always be disagreement:

I'm not sure that the main issue here is one of process. The main issue here is of two conflicting world views. Two conflicting visions of the future (participant 1).

An antagonistic stance exists if, and only if, neither party considers the others views as acceptable or legitimate. In this case, as discussed in Chapter five, antagonism characterised the relationship because environmentalists' knowledges were not perceived as legitimate. Several participants (1, 2, 5, 9 and 14) suggested that in this case (and similar cases), there was no room for negotiation as the conflict of world views and opinions would mean that there is no "process that could resolve that with both parties coming out and feeling ok" (participant 2).

This also points to a core failing of deliberative or collaborative approaches. Bäcklund and Mäntysalo (2010) state:

The ability to recognize the better argument requires a shared reality with shared problems. Habermasian communicative planning theory is unable to acknowledge conflicting conceptions of reality as being equally valid (p. 341).

As discussed in depth in Chapter five, quantifiable objective knowledges were the dominant reality. Environmentalists' realities involved a holistic and global approach to the environment while the council and company had a reality that considered the environment in parts. The latter approach is a perspective facilitated by the effects based regime under the RMA that narrows the scope of what can be considered in a decision. Communicative planning cannot account for the different world views, thus the "better" argument will never arise because there will never be agreement on the reasons argued (Bäcklund \& Mäntysalo, 2010). This steers the ideal process to become one that accepts underlying difference, not as something to be disregarded, but as something to be worked with.

\subsection{Noise, antagonistic activism and legitimate voices}

Antagonistic activism (such as protest) should be an acceptable way for environmentalists to voice their disagreement. There is value in respecting 
antagonistic views; it aids the shift towards agonism and respectful dialogues, and also raises new issues for discussion (see Ganesh and Zoller, 2012). Past cases of environmentalist opposition to planning consent cases in New Zealand as discussed in Chapter three illustrate the value and effectiveness of antagonistic activism in combination with participation in the formal process. Ganesh and Zoller (2012) suggest that activists are framed in ways that suggest they are incapable of conversation, dialogue, or relationship building. Yet, they note, activists often attempt and exhaust dialogic methods of resistance before turning to other methods such as direct action and protest. In this case for example, some environmentalists had attempted to influence the decisions in the formal participation process in 2010 before making the conservation of the Denniston Plateau one of their major public campaigns in 2011 (participant 3). In such circumstances, I suggest that antagonistic activism should be considered a legitimate voice. In giving space for and hearing such activism, it may appear to be Mouffe's transformation of antagonism to agonism. But a more fitting way of conceptualising of antagonistic activism as legitimate may be Rancière's concepts of noise and the political.

In the case of Escarpment Mine, there appears to be a disconnect between environmentalist action outside the formal process and participation in the formal process itself. Though not specific to this case, the commissioner interviewed said that in general activism, protest, petitions or campaigns were not considered by commissioners in the decisions they made to grant consents (participant 4). He also noted that he does not (and that it would not be appropriate to) discuss any aspect of a decision outside of the formal process:

it's made very clear to everybody, whoever the chair is generally speaking says at the commencement of the hearing, we will make our decision based on the information we receive here at this hearing (participant 4).

However, as discussed in Chapter five, environmentalists perceived their participation in the formal process to be futile, and that the ability to make change lay more in campaigning, activism, and creating a public movement calling for change. 
This disconnect between the formal process and activism outside this process is also illustrated in the level of participation in the formal process and in campaigning and activism. In the council officers Section $42 \mathrm{~A}$ report, issues that submitters expressed were described as arising in certain percentages of the submissions. For example, it was written that $8 \%$ of submissions raised concerns relating to coal's greenhouse gas emissions (Ridge \& Inwood, 2011), yet one of the groups who submitted on this issue was Forest and Bird, who represents approximately 50,000 members across New Zealand (Royal Forest and Bird Protection Society of NZ Inc, 2010). This misrepresents the strength of the arguments, particularly considering other submissions, representing individuals, appear to have been counted equally in this report. In contrast, as part of the campaign against Escarpment Mine, an online petition was established in 2012, that to date has had over 10,000 online individual signatures (AVAAZ, 2012). While submissions made in the formal process numbered only 98 with 41 opposed (Ridge \& Inwood, 2011), the numbers of those opposing (or supporting) the project in the public sphere appear to be much larger than the formal process can recognise. Yet the formal process is the only form of public participation that is taken into account in the decisions that are made.

With the apparent aim for reaching agreement and disregarding underlying difference, it seems that the formal decision-making process is based on a deliberative democracy and communicative planning model. Mouffe (2000) suggests that when politics is based on the aim of consensus, genuine disagreement is forced outside of political processes, and into more activism. As Bäcklund and Mäntysalo (2010) suggest of Mouffe's work, “[s]uch actors would thus become alienated from the political scene, becoming enemies to the political system, instead of adversaries within politics" (pp. 342-343). Thus, environmental activism and campaigning is perceived as antagonistic and outside of the decisionmaking process.

If the Environment Court decides to grant the consents for Escarpment Mine ${ }^{36}$, it is likely that even more activism against it will arise. Although not a common view of

${ }^{36}$ At the time of writing, this was yet to be announced. 
all the participants, one participant noted that they would be willing to carry out direct action if Bathurst is granted the consents (participant 12). She was angry, arguing that process was undemocratic, making her desperate and willing to undertake extreme measures. However another noted that he knew the limits of the law and was not willing to undertake any illegal activity (participant 8). Furthermore, participant 8 noted that, while he supported the actions of the occupiers in the Save Happy Valley campaign (see Chapter three), this kind of radical action somewhat distanced the public and was not able to influence the formal processes that made decisions to grant consents for the mine. The environmentalist movement against Escarpment Mine may become more diverse as more people make different choices about how to express their opposition in order to effect change.

As discussed in Chapter three, the previous cases of antagonistic activism can effect change and may result in an outcome that aligns with a mainstream view over time. Antagonistic activism is important, especially in the case where activists have already attempted and exhausted deliberations and negotiations, and their opinions in such processes have been excluded. As McClymont (2011) suggests, "[e]xcluding a view does not eliminate it, but removes it from the arena of debate" (p. 251), which is a finding well-documented by research in consensus-based decision-making (McClymont, 2011). Radical democracy critiques deliberative democracy's aim for consensus. Yet radical democracy's emphasis on agonism (Mouffe, 2000, 2005) may prevent the recognition that antagonistic activism can have a significant role in achieving the democratic ideals of equality, justice and rule of the people.

Rancière's (1999) noise is one way of thinking about how activism can have influence in decisions. Noise can be defined as most powerful actors in society, "characteriz[ing] those included under the banner of their own exclusion (the subaltern) as mere noise, as the murmurs of the incomprehensible, spontaneous, or irrational within the field of the political" (Williams, 2007, p. 131). The opposition to Escarpment Mine can be conceptualised as "noise" as the opinions and knowledges that environmentalists bring to the table are excluded from the arena of the political, as determined by the decision-makers and the formal 
process. For example, climate change was excluded from being a legitimate argument, and the fragmented approach to the environment was far privileged over a more holistic approach that argued for the intrinsic ecological value of the plateau. These different world views were made invisible in the process, and thus, can be considered noise.

In this concept of noise, Rancière (1999) states that the 'police' is: an order of bodies that defines the allocation of ways of doing, ways of being, and ways of saying, and sees that those bodies are assigned by name to a particular place and task; it is an order of the visible and the sayable that sees that a particular activity is visible and another is not, that this speech is understood as discourse and another as noise (p. 29).

In the Escarpment Mine case, the 'police' are the structures of the formal decisionmaking process, which force activists to engage in the formal process in order to be somewhat heard. This is because the formal process is supposedly depoliticised, yet environmentalists' expertise is delegitimised in the formal process under a 'police' logic that prioritises other values, such as economic development. This means that political activity must occur outside the formal process. Rancière (1999) suggests that something is not simply political because of power relationships that exist in it. Rather, "[f] or a thing to be political, it must give rise to a meeting of police logic and egalitarian logic" (p. 32). The framework's ideal of equality implies that democracy is only possible when equality is present, both in the formal process and in the broader context. Rancière's idea implies that the political is when equality is challenged against the dominant and prevailing institutions. In the case of Escarpment Mine, the way in which environmentalists' knowledges were disregarded is certainly an expression of inequality, and this has been challenged through the activism and campaigning that has occurred outside of this process.

Rancière (1999) states that:

Political activity is whatever shifts a body from the place assigned to it or changes a place's destination. It makes visible what had no business being seen, ... it makes understood as discourse what was once only heard as noise (p. 30).

Political activity in Escarpment Mine will occur when activism against it becomes visible to the decision-makers and becomes a legitimate voice within the formalised processes. However it is not clear from the literature whether the shift 
from 'noise' to a legitimate voice within the formal processes necessitates a change in the decision, or simply that the discourse is now accepted as valid argumentation.

In one sense, the formal participation process under the RMA has attempted to transform antagonism to agonism by giving space for disagreeing voices to participate and engage respectfully. However, in incorporating such voices, as shown in 6.4, privileging this agonistic approach creates a site where compromise is rife, essentially denying the very disagreement that it once aimed to include. And, as illustrated in Chapter five, this formalised process in one sense privileges environmentalists' attempts at agonism, while at the same time excludes environmentalists' opinions in the decision-making process. Antagonistic activism is therefore a force that environmentalists can mobilise to show the strength of their knowledges and arguments. Such activism is also valuable for consciousness raising and creating a value-shift in society. It must be valued in order for democratic politics to take place and challenge the status quo.

\subsection{Synopsis: Disagreement and democracy as expressed through agonism and antagonism}

The formal participation process under the RMA offers an opportunity for the public to be involved in decision-making. An environmentalist with decades of experience indicated he was "not against the RMA process, because things were a lot worse before we had it, a lot lot worse" (participant 8). Yet the critiques of the RMA process by this environmentalist and others throughout this research imply a strong dissatisfaction with the way in which the participation process runs. Little (2010) interprets Mouffe (2000), saying that ironically, "the risk of contemporary democracy ...is that at the same time as it opens up opportunities for a more radical politics, it closes down these possibilities through excessive proceduralism and policing of the political order" (p. 972). Contemporary democracy, such as in New Zealand with laws like the RMA, includes formalised participation processes that inherently exclude voices that are not considered legitimate by the 'police'. As May (2010) suggests, "Progressive institutions... seem either to evolve into institutions that are antithetical to their original aims or alternatively to be 
incapable of sustaining themselves" (p. 102). The RMA, with a participatory ethos which was progressive at the time it was established, has been unable to maintain its participatory nature. Perhaps in the attempt to increase democracy in decisions about the environment, the institutionalised nature of the RMA's participation process has closed down some opportunities for a more radical politics that would involve more equality in participation, accepting underlying difference, keeping decisions open for further deliberations and accepting antagonistic activism as a legitimate voice.

This chapter has reflected on the framework and its relevance in environmentalists' participation in the council-led decisions about Escarpment Mine. The lack of transparency in the process and in the availability of information illustrated how equality was not progressed, and how this contributed to antagonism. The fixed nature of the agreements exhibited the exclusion of important voices in the decision-making. The way in which difference was expressed through the relationships between the council and environmentalists illustrated the fluidity and complexity between agonism and antagonism. The formal process's aim for reaching consensus showed the way in which consensus involves exclusion, compromise or closing down the possibilities for radical politics. Lastly, this chapter considered the role of antagonistic activism as a valuable means for effecting political change.

Considering these arguments, I turn back to the framework to demonstrate how the normative ideals of the framework have not been expressed. I affirm that some parts of the framework that should ideally be agonistic have manifested as antagonism. Thus, these parts do not fulfil the primary principles of democracy; equality, justice and rule of the people. 


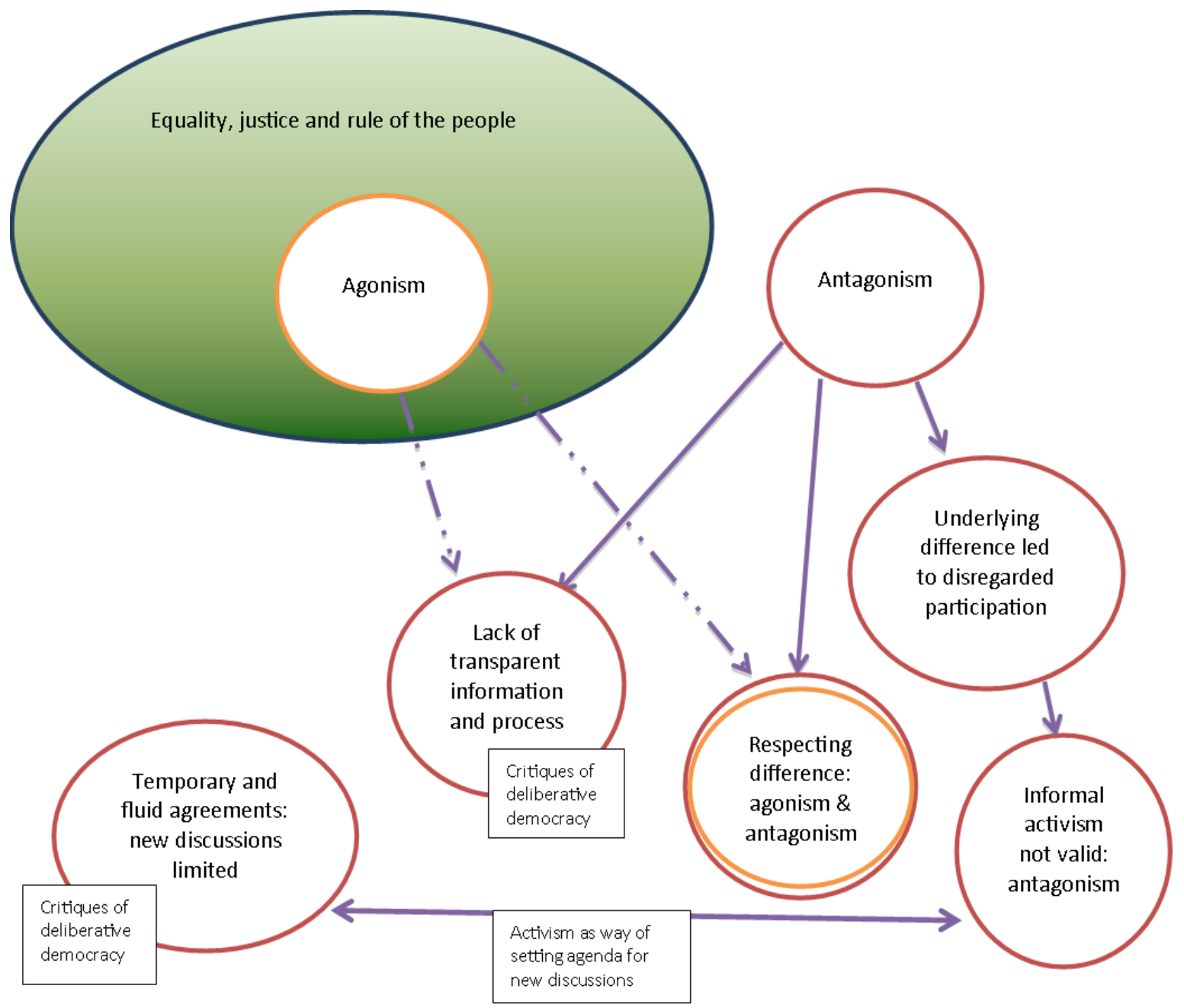

Figure 6.2: The democratic framework as per the case of Escarpment Mine, the decisions and environmentalist participation

As we can see in Figure 6.2, compared to Figure 6.1, the ethos of democracy (equality, justice and rule of the people) is far from being attained in this case, due to a distinct lack of agonism and the way that antagonistic activism was relegated to noise outside the process. Aspects that in Figure 6.1 that were ideally agonistic (in orange circles), have mostly changed to antagonistic (in red circles). This case has also reflected less relationship to the concept of agonism (with relationships between agonism and other principles represented as weak by dotted purple arrows). The majority of the ideal framework (Figure 6.1) did not manifest. Thus, the contrary reality, as represented in Figure 6.2, mostly falls outside of the ethos of democracy (equality, justice and rule of the people) that initially encompassed the entire framework (represented by the green circle). 
Figure 6.2, representing this decision, may also be indicative of the difference in the scope of the decision and how environmentalists perceive the ideals of equality and justice compared to the council and the company. For example, with the issue of climate change, environmentalists are seeing the decision-making process as adversely affecting equality and justice globally. Potentially the council officials are allowing for the values of equality and justice in the effects of this specific case, rather than extending these principles to a larger scale. Dryzek (Dryzek, 2013) suggests that democratic systems should be able to go beyond the boundaries of states to enhance the democratic principles of justice and equality. Yet, the decision-makers form the police order that defines what discourses are visible and legitimate in the formal decision-making processes, denying the larger issues that democratic principles apply to. The legitimising of certain discourses and not others also raises questions about how agonism and antagonism can be defined, when the parties involved have differing amounts of power in the decision-making process. Furthermore, the reflections on the framework raise questions about where the boundaries of equality and justice are situated, and to what extent these principles are evaded when the boundaries are conceived of differently.

Antagonism is not necessarily inferior to agonism, despite Mouffe's goal of transferring antagonism to agonism. However, whether the antagonism sits within the broader democratic ideals of equality, justice and rule of the masses is critical as to whether this type of antagonism should be accepted as valid activity in democracy. 


\section{Chapter seven: \\ Concluding and including disagreement in democracy}

This thesis set out to demonstrate how democracy is actualised or constrained through environmentalist actions about decisions made for coal-mining on conservation land, with participation in democracy both through formal processes and informally through environmental activism. Democracy, in the words of Derrida, is something that can never be fully attained but simply worked towards (May, 2010), consistent with radical democrats' idea that democracy is an on-going process (Bohman, 1996). The findings of this research demonstrate that so-called democracy deals with disagreement in a variety of ways that do not necessarily coexist with the ethos of democracy; equality, justice and rule of the people. Democracy, in the case of Escarpment Mine, is a work in progress within the complex context of New Zealand's environmentalism and its influence on environmental decision-making.

This concluding chapter reflects on the main arguments from the findings and the literature. I also address the limitations of this research, and areas that have emerged as priorities for further research. Lastly, I conclude with recommendations of varying scope: suggesting changes for policy and best practice, as well as proposing new ways of thinking about democratic decisionmaking processes.

\subsection{Conclusion of findings}

The overarching research objective of this thesis is to understand how democracy is actualised or constrained through environmentalist actions about decision made on coal-mining in conservation land. Such actions comprise of participation in 
democracy through informal actions or activism, and formal participation as prescribed by legislation. This thesis has answered the research objective by analysing the influence that environmentalists were able to have on the decisions made about Escarpment Mine, and exploring how the case reflected democratic principles in relation to this inability to have influence.

The context to the Escarpment Mine case was discussed in Chapter three, along with the rise of neoliberal politics in New Zealand and how this has shaped the decision-making processes under the RMA. The RMA was shown to be neoliberal, privileging technical and economic knowledges (Perkins \& Thorns, 2001) and disregarding issues of power in the participation processes (Gunder \& Mouat, 2002). The three parallel cases demonstrated the nexus between informal participation in democracy through activism and formal participation processes under legislation. The cases highlighted that both types of participation are part of democracy, and both are effective in influencing decisions made, particularly when combined, as seen in ' 2 precious 2 mine' and the Mokihinui case.

Research question one asked how theories of democracy, participation and activism address disagreement in decisions about the environment. Chapter four reviewed literature on democracy and disagreement in order to address this question. It focused on deliberative democracy (and associated communicative planning) and radical democracy (with agonistic planning). Through analysing the reasonings for and critiques of each of these theories, I created a framework for democracy that was situated within the ethos of equality, justice, and rule of the people. The framework was used to explore the case of Escarpment Mine.

Research questions two and three, respectively, asked how environmentalists influenced the decisions made about Escarpment Mine, through participation in democracy through the formal council-led process under the RMA and through environmental activism. These questions were addressed in Chapter five. Neither informal nor formal participation in democracy by environmentalists had influence on the commissioners' decisions to grant consents for Escarpment Mine. It is plausible that activism and campaigning has influenced society's perception and values about mining on conservation land, but this is outside the scope of this 
research. Two environmental groups appealed the commissioners' decision in the Environment Court. This was not the focus of this research, and the Environment Court decisions are yet to be announced. It is unknown whether environmentalists will have had more influence in these decisions than in the council-led process.

The findings explored in Chapter five illustrate that the neoliberal discourses were prevalent in the decisions, and that it displaced and disregarded other knowledges that were raised primarily by environmentalists. The emphasis was on 'apolitical', objective and quantifiable knowledges, such as those that were technical, economic and that fragment the environment. Knowledges that were disregarded in the process are those that consider the environment as an ecological whole and went beyond the local scale. This included interactions within and between ecosystems and landscapes on the plateau, and with the global adverse effects of climate change, which will be contributed to by the greenhouse gases from the end-use of the coal mined. The privileging and disregarding of certain knowledges raises questions for democracy, in that such power imbalances do not achieve the goals of equality, justice and rule of the people.

Finally, returning to the theoretical framework established through addressing research question one and reviewing literature in Chapter four, I turned to address research question four which asked how environmentalist action, both through formal processes and through other actions, reflects democratic principles. Chapter six reflected on the framework for democracy in light of the findings, thereby addressing research question four. I argue that due to an absence of equality, justice and rule of the people, this case fails to meet the framework of democracy as outlined in Chapter four. Underlying differences between environmentalists, the councils and the company, particularly with the difference in privileged knowledges as discussed in Chapter five, mostly contradicted the concept of agonism and thus failed to fulfil democratic ideals. There was a lack of transparency in both the formal decision-making process and in the information available to inform the decisions. While some of the council officials perceived the environmentalists as biased and overly subjective, numerous participants (including one council officer) expressed concern about the conflict of interest that the commissioners had or may have had as the decision-makers in this process. 
The company was also perceived to be deceitful in their communications with submitters. DoC did not present an oral submission at the hearing, reducing the ecological information available about the Denniston Plateau in the decisions made. Furthermore, while DoC provided some information to environmentalists under the OIA, a third request was declined unless the environmentalists paid over $\$ 1000$, which they were not willing to do. Consequently, transparency in the process and access to information in order to participate fully in the deliberations were not fulfilled.

Chapter six also discussed the nature of temporary agreements and how in a case like Escarpment Mine, where the process produces a binding agreement, is unlikely to ever fulfil the principles associated with recognising the value of temporary agreement. This ideal would be similar to Dryzek's (2001) workable agreement, and Mouffe's (see Little, 2002) desire for decisions to be open to further and future debate. In terms of the ideal framework of accepting underlying difference, I analysed the relationships between environmentalists and councils, as well as the flaws of aiming for consensus. This included the compromise and manipulation that environmentalists perceived to be rife in mediation in other cases, and the impossibility of reaching agreement when a proposal would create irreversible adverse effects.

Informal activism was not considered a legitimate voice to be considered by the decision-makers. Moreover, it contributed to the perception that environmentalists' evidence was not objective as it asserted that their stance was "philosophical" or driven by values and emotions. This aligns with neoliberal politics that privileges measurable knowledges and claims to be apolitical. Antagonistic activism outside of the formal process (despite aiming to uphold the democratic ideals of equality, justice and rule of the people) is excluded by such privileging of neoliberal discourses and made to be seen as irrational and confrontational. Rancière's (1999) concept of noise complements this situating of activism as outside of the realm of consideration by decision-makers. Political activity occurs when this 'noise' is made visible by the power structures at play, and included in the realm of discussion. This was yet to fully occur in the case of Escarpment Mine. 
Similar to Mouffe's (2005) radical democracy that requires a broad consensus on the ideals of equality and liberty and the principles of pluralism and how they underpin the way that democratic institutions function, the framework in this thesis requires agreement on the overarching democratic principles of equality, justice and rule of the people. When these principles are not met in any other aspects of the framework, democracy is not fulfilled, as is the case of Escarpment Mine. I recognise that the framework is just one view of democracy and that it is open to contestation. Nevertheless, it is drawn from a noticeable discourse in political theory that has been taken up in planning theory and practice in various ways.

As identified in Chapter one, there are several gaps in the literature that this research addresses. Firstly, this research has contributed to literature about environmentalism in New Zealand, by focusing on environmentalists' activism and participation in formal decision-making processes specific to Escarpment Mine. Secondly, meeting a gap suggested by Bäcklund and Mäntysalo (2010), this research has connected agonistic planning theory with democracy theory, through analysing the Escarpment Mine case both in theory and practice. Lastly, and perhaps most critically, the point of departure for this research has situated the influence of activism alongside the influence in participation processes. As Young (2001) suggests, there is little research into the role of activism in democracy outside of formal processes, and this research has contributed to this body of literature by exploring the role of antagonistic activism in achieving the ethos of democracy in parallel with participation in formal decision-making processes.

\subsection{Limitations of this research}

The limitations of this research relate to the small scope of the study. Firstly, while the choice of a single case study is justified through the constructivist and poststructural methodology and the scale of a project for a Master's topic, it would be beneficial to have comparative case studies to test the generalizability of the findings. It may also have been beneficial to study the Environment Court process for Escarpment Mine in addition to the council hearing, with an opportunity to 
expand on or compare the findings. However, the Environment Court hearing and decision (to be released later in 2013) did not fit within the Master's timeframe.

Second, there were two parties that were not willing to be interviewed. Bathurst declined an interview on the grounds that it may adversely affect the Environment Court hearing that had not yet taken place. Interviewing Bathurst representatives would have contributed to my understandings of agonism and antagonism in this case, with particular regard to how it was expressed through Bathurst's relations and consultation with environmentalists. Additionally, while no clear reasons were given, I was unsuccessful in finding someone in DoC willing to be interviewed despite being directed to various contacts. Interviewing a DoC representative would have been beneficial in completing the picture about their reasons for not being present at the hearing, and thus, the way in which their participation (or lack of) displayed elements of agonism, antagonism, equality, justice and transparent access to information.

\subsection{The way forward for disagreement in democratic environmental decision-making}

In light of the findings of this research, I propose two broad avenues for furthering the possibilities for disagreement in democracy: suggestions for further theoretical engagement and a more pragmatic policy oriented set of recommendations.

\subsubsection{Future research: agonism and the impossibility of agreement}

Four main areas of further research have arisen as a result of the findings of this thesis.

1. How do we define the space and fluidity between agonism and antagonism? Definitions of agonism and antagonism, and the fluid spaces between them, need to be clarified if research of this kind is to progress meaningfully. For example, is antagonistic environmentalist activism antagonistic because it is confrontational or can such confrontation be also considered agonistic in different contexts? How can adversaries respectfully engage each other (as in agonism) when their discourses and knowledges compete and have no commonalities (as in antagonism)? 
2. What is the role of the democratic ethos of equality, justice and rule of the people in determining agonism?

There is a lack of specificity with these terms and they are contested in the literature. Each has different implications for and intersections with agonism. Determining the definitions for these terms will build the understanding of the conditions under which agonism can occur.

3. How can the role of agonism and antagonism be reconciled with the formality of a decision-making process that is adversarial by nature?

The processes such as the council hearing and Environment Court are established as adversarial processes to enhance the certainty of decisions while still allowing for public participation and appeal. In particular, the fixity of policies, district and regional plans and resource consents, as well as the prescriptions of the RMA, constrain possibilities for more flexible decision-making processes. Yet agonism and antagonism are fluid relationships, and both imply that agreements are temporary and open to further discussion. The question is, then, how the fluidity of agonism and antagonism can operate under the fixity of such agreements, and whether a reconciliation is possible.

\section{Finally, what is the role of antagonism in different cases and contexts?}

Establishing the normative criteria of antagonism is essential for understanding how such antagonism fits within the democratic ideals. As discussed in this research, certain antagonisms lie outside of the realm of equality, justice and rule of the people, and thus do not fulfil democracy. Yet other antagonisms are essential for the functioning of democracy, if the underlying values stem from these democratic ideals and the antagonistic behaviour leads to the formal politics becoming more democratic. Mouffe $(2000,2005)$ discusses the role of radical democracy as transforming antagonism to agonism, which privileges agonism over antagonism. However, as discussed in this thesis, there is space in democratic processes for antagonism to make a meaningful contribution to democracy. Accordingly, I ask under what conditions does antagonism arise in a way that is productive, rather than as totalitarian and oppressive? 


\subsubsection{Recommendations for planning consent practice}

In addition to areas for further research, there are some practical considerations that may benefit planning practice for environmental decision-making in New Zealand under the RMA.

\section{Neutrality of commissioners}

Various participants suggested that commissioners should be chosen in a more neutral way, as it appears that they are chosen based on prior experience, and some alignment between the council and previous experience of the commissioners' decisions. Four environmentalists recommended having independent commissioners not appointed by councils (participants 8, 9, 12 and 14). One said "there needs to be just more neutrality in the people that are actually... listening to the arguments" (participant 9). The accreditation process that, while not yet mandatory for commissioners, is currently being encouraged, may be a step in this direction. The accreditation was discussed in section 6.2.1. However, the database of accredited commissioners might not be functioning as well as it could be. As stated by one of the council officers interviewed, an ecologist would have been ideal to be on the hearing committee, but they were unable to find an appropriate ecologist at that time who was not already connected to a mining company (participant 5). It is unknown whether they made use or were aware of the database of accredited commissioners, or indeed, whether such a database would actually increase the likelihood of neutral commissioners. Measures to enhance such neutrality and barriers to those with conflicts of interest need to be investigated.

\section{Landowner's obligation to present in council hearing}

In order for the RMA planning consent process to lead to a well-informed outcome, it should be mandatory for the landowner to present a submission at the councilled hearing. In this case, DoC was the landowner and did not present a submission. According to numerous participants $(3,5,9,10,11$ and 13$)$, this absence contributed to a distinct lack of ecological knowledge informing the decision. 


\section{Legitimation of differing knowledges and views containing emotion and lay-}

knowledge

The role of 'expertise' needs to be addressed, as well as the different weighting given to different knowledges that may be equally 'expert' according to qualification or experience. Another recommendation is to have participation processes that are less dismissive of voices that are perceived to be tainted by emotion or a "philosophical stance". How this should be implemented is an area for further research.

\subsection{Imagining the unimaginable}

One environmentalist was certain that the process would need to be very different to deal with the problems that society faces:

I think the process is so woefully inadequate. Just to deal with our day to day human reality let alone to deal with our society trying to address climate change, which I don't think overall it is, because of the powers that be. But we would need some pretty awesome and different looking tools I think, to really do that (participant 11).

While some practical recommendations can be deduced from my research, participants felt that it was hard to imagine an ideal democratic participation process in detail that was different from the one that they knew under the RMA. When asked what an ideal democratic decision-making process would look like, some hesitated, others said they did not know then provided hesitant suggestions, and one person said a completely different set of tools was needed but did not know what these tools would be (participants 3, 5, 6, 7, 8, 9, 10 and 11).

As May (2010) comments, Socrates asked "[h]ow... will we know we have found what we're looking for if we don't know what it is in the first place?" (p. 3). Although we may not be able to imagine a world that is fully equal, just or ruled by the people, and if democracy is only ever an on-going process and not an achieved state (Bohman, 1996), our only option is to continue working on equally and justly incorporating disagreement in decision-making. Foucault argued that "I think that to imagine another system is to extend our participation in the present system" (1977, p. 136, as in May, 2010). This research has aimed to extend the concept of democracy through analysing environmentalists' participation in decision-making about Escarpment Mine. 


\section{References}

"The activist who turned police informer". (2008, December 13). The activist who turned police informer, Sunday Star Times. Retrieved from http://www.stuff.co.nz/sunday-star-times/features/760466/The-activistwho-turned-police-informer

Abelson, J., Forest, P.-G., Eyles, J., Smith, P., Martin, E., \& Gauvin, F.-P. (2003).

Deliberations about deliberative methods: issues in the design and evaluation of public participation processes. Social Science \& Medicine, 57(2), 239-251. doi: 10.1016/s0277-9536(02)00343-x

Archer, T., McGarry, S., \& Heal, W. (2011). In the matter of the Resource Management Act 1991 and in the matter of an application by Buller Coal Limited for resource consents for the Denniston Plateau Escarpment Mine Project: Decision of commissioners appointed by West Coast Regional Council and Buller District Council (pp. 115).

Arnold, N. (2010). Mad with power, The Nelson Mail. Retrieved from http://www.stuff.co.nz/nelson-mail/features/weekend/3593641/Madwith-power

Arnstein, S. (1969). A ladder of citizen participation. Journal of the American Institute of Planners, 35(4), 216-224.

AVAAZ. (2012). AVAAZ.org community petitions: No coal mine on the Denniston Plateau! Retrieved January 28, 2013, from http://www.avaaz.org/en/petition/No_coal_mine_on_the_Denniston_Platea $\mathrm{ux} /$

Barry, J. (1996). Sustainability, political judgement and citizenship: Connecting green politics and democracy. In B. Doherty \& M. de Geus (Eds.), Democracy and green political thought: Sustainability, rights and citizenship (pp. 115131). London: Routledge.

Baxter, J. (2010). Case Studies in Qualitative Research. In I. Hay (Ed.), Qualitative Research Methods in Human Geography (3 ed., pp. 81-98). Don Mills, Ontario: Oxford University Press.

Baxter, P., \& Jack, S. (2008). Qualitative Case Study Methodology: Study Design and Implementation for Novice Researchers. The Qualitative Report, 13(4), 544559.

Beaumont, J., \& Loopmans, M. (2008). Towards radicalized communicative rationality: Resident involvement and urban democracy in Rotterdam and Antwerp. International Journal of Urban and Regional Research, 32(1), 95113.

Beetham, D. (2010). Towards a Universal Framework for Democracy Assessment. Democratization, 11(2), 1-17.

Bellamy, P., \& Henderson, J. (2002). Democracy in New Zealand. Stockholm: International IDEA. 
Benhabib, S. (1992). Situating the self: Gender, community and postmodernism in contemporary ethics. Cambridge: Polity Press.

Berry, M. (November 29, 2012). Coal challenge goes to Supreme Court. Christchurch, New Zealand: The Press, Fairfax NZ News.

Bohannan, H. (2011). Under: the Resource Managment Act 1991. In the matter of: applications by Buller Coal Limited to the Buller District Council and West Coast Regional Council for resource consents relating to the Escarpment Mine Project. Retrieved February 18, 2013, from http://www.wcrc.govt.nz/escarpment/hearing/Applicant/Evidence\%20of $\% 20$ Hamish\%20Bohannan\%20\%20Managing\%20Director\%20Bathurst.pdf

Bohman, J. (1996). Public Deliberation: Pluralism, Complexity, and Democracy. Cambridge, Massachusetts: The MIT Press.

Bond, P., \& Dorsey, M. (2010). Anatomies of environmental knowledge and resistance: Diverse climate justice movements and waning econeoliberlism. Journal of Australian Political Economy, 66, 286-316.

Bond, S. (2007). Participation, Urbanism and Power. University of Otago, Dunedin.

Bond, S. (2011a). Negotiating a 'democratic ethos': moving beyond the agonistic communicative divide. Planning Theory, 10(2), 161-186. doi: $10.1177 / 1473095210383081$

Bond, S. (2011b). Being in myth and community: resistance, lived existence and democracy in a north England mill town. Environment and Planning D: Society and Space, 29, 780-802.

Brand, R., \& Gaffikin, F. (2007). Collaborative planning in an uncollaborative world. Planning Theory, 6, 282-313.

Brulle, R. J. (2010). Politics and the Environment. Handbooks of Sociology and Social Research, 2, 385-406. doi: 10.1007/978-0-387-68930-2_21

Buller District Council and West Coast Regional Council. (2011a). Escarpment Mine Project: Hearing information. Retrieved January 22, 2013, from http://www.wcrc.govt.nz/escarpment/hearing.html

Buller District Council and West Coast Regional Council. (2011b). Escarpment Mine Project: More information. Section 92 Request for Information. Retrieved January 14, 2013, from http://www.wcrc.govt.nz/escarpment/moreinfo.html

Butcher, G. V. (2011). In the matter of the Resource Management Act 1991 AND in the matter of an application by Buller Coal Limited to mine coal on the Denniston plateau.

Bäcklund, P., \& Mäntysalo, R. (2010). Agonism and institutional ambiguity: Ideas on democracy and the role of participation in the development of planning theory and practice - the case of Finland. Planning Theory, 9, 333-350.

Büscher, B., Sullivan, S., Neves, K., Igoe, J., \& Brockington, D. (2012). Towards a Synthesized Critique of Neoliberal Biodiversity Conservation. Capitalism Nature Socialism, 23(2), 4-30. doi: 10.1080/10455752.2012.674149 
Carpini, M. X. D., Cook, F. L., \& Jacobs, L. R. (2004). Public deliberation, discursive participation, and citizen engagement: A review of the empirical literature. Annual Review of Political Science, 7(1), 315-344. doi:

10.1146/annurev.polisci.7.121003.091630

Carter, N. (2007). The Politics of the Environment: Ideas, Activism, Policy (2nd ed.). Cambridge: Cambridge University Press.

Castree, N. (2010). Neoliberalism and the biophysical environment 1: What 'Neoliberalism' is, and what difference nature makes to it. Geography Compass, 4(12), 1725-1733.

Cathles, G. (2000). Friends and allies: the role of local campaign groups. In B. Doherty, M. Paterson \& B. Seel (Eds.), Direct action in British Environmentalism (pp. 167-182). London: Routledge.

Cheek, J. (2008). Foucauldian Discourse Analysis. In L. Given (Ed.), The SAGE Encyclopedia of Qualitative Research Methods (Vol. 1, pp. 355-357). Thousand Oaks, California: SAGE Publications, Inc.

Coal Action Network, A. (2012). About. (25 April 2012).

Coal Action Network Aotearoa. (2012). About. Retrieved 25 April 2012, from http://coalactionnetworkaotearoa.wordpress.com/about/

Cohen, J., \& Fung, A. (2004). Radical Democracy. Swiss Journal of Political Science, 10(Winter), 23-34.

Coleman-Ross, H. (2010). Thousands march against mining, stuff.co.nz. Retrieved from http://www.stuff.co.nz/national/3647465/Thousands-marchagainst-mining

Cook, K. (2008). Discourse. In L. Given (Ed.), The SAGE Encyclopedia of Qualitative Research (Vol. 1, pp. 216-217). Thousand Oaks, California: SAGE Publications, Inc.

Costantino, T. (2008). Constructivism. In L. Given (Ed.), The SAGE Encyclopedia of Qualitative Research Methods (Vol. 1, pp. 117-121). Thousand Oaks, California: SAGE Publications Inc.

Creswell, J. (2003). Research design: qualitative, quantitative, and mixed methods approaches. Thousand Oaks, California: SAGE Publications.

Davies, B., \& Gannon, S. (2005). Feminism/Poststructuralism. In B. Somekh \& C. Lewin (Eds.), Research Methods in the Social Sciences (pp. 318-325). London: SAGE Publications.

Department of Conservation. (2010, April 29). Media release: DOC to appeal Mokihinui decision. Retrieved 24 September, 2012, from http://www.doc.govt.nz/about-doc/news/media-releases/2010/doc-toappeal-mokihinui-decision/

Department of Conservation. (2011). Briefing to the incoming Minister of Conservation 2011 - 8.1 Public conservation land. Retrieved February 12, 2013, from http://www.doc.govt.nz/publications/about-doc/briefing-tothe-incoming-minister-of-conservation-2011/8-appendix-2/8_1-publicconservation-land/ 
Department of Internal Affairs. (2011). localcouncils.govt.nz: West Coast Regional Council. Retrieved February 12, 2013, from http://www.localcouncils.govt.nz/lgip.nsf/wpg_URL/Profiles-CouncilsWest-Coast-Regional-Council-Main?OpenDocument

Doherty, B., Paterson, M., \& Seel, B. (2000). Direct action in British environmentalism. In B. Doherty, M. Paterson \& B. Seel (Eds.), Direct action in British environmentalism (pp. 1-24). London: Routledge.

Downes, D. (2000). The New Zealand Environmental Movement and the Politics of Inclusion. Australian Journal of Political Science, 35(3), 471-491.

Dryzek, J. (2001). Legitimacy and economy in deliberative democracy. Political Theory, 29(5), 651-669.

Dryzek, J. (2013). The deliberative democrat's Idea of Justice. European Journal of Political Theory, 1-18.

Dunn, K. (2010). Interviewing. In I. Hay (Ed.), Qualitative Research Methods in Human Geography (3 ed., pp. 101-137). Don Mills, Ontario: Oxford University Press.

Eckersley, R. (1992). Environmentalism and political theory: Toward an ecocentric approach. Albany: State University of New York Press.

Faulks, K. (1999). Political Sociology: A Critical Introduction. Edinburgh: Edingburgh University Press.

Fawcett, B. (2008). Poststructuralism. In L. Given (Ed.), The SAGE Encyclopedia of Qualitative Research Methods (Vol. 2, pp. 666-670). Thousand Oaks, California: SAGE Publications Inc.

Flyvbjerg, B. (2006). Five Misunderstandings About Case-Study Research. Qualitative Inquiry, 12(2), 219-245. doi: 10.1177/1077800405284363

Forest and Bird. (2012a). Save the Denniston Plateau:Ours Not Mine. Retrieved 24 April 2012, from http://www.forestandbird.org.nz/what-wedo/campaigns/save-the-denniston-plateauours-not-mine

Forest and Bird. (2012b). About us. Retrieved 25 April 2012, from http://www.forestandbird.org.nz/about-us

Forest and Bird. (2012c, December 20). Denniston: Environment Court hearing comes to an end. Retrieved February 19, 2013, from http://www.forestandbird.org.nz/what-we-do/news/dennistonenvironment-court-hearing-comes-end

Forest and Bird. (2012d, May 22). Media release: Forest \& Bird welcomes victory for Mokihinui River. Retrieved 24 September 2012, 2012, from http://www.forestandbird.org.nz/what-we-do/publications/mediarelease/forest-bird-welcomes-victory-mokihinui-river

Foucault, M. (1982). The Subject and Power. In J. Faubion (Ed.), Michel Foucault: Power. Essential Works of Foucault 1954-1984 (Vol. 3, 1994, pp. 326-348). London: Penguin.

Fuller, G. (2008). Handy guide to New Zealand law. Auckland, New Zealand: G. A. Pindar and Son (New Zealand) Ltd. 
Fung, A. (2005). Deliberation before the revolution: Toward an ethics of deliberative democracy in the unjust world. Political Theory, 33, 397-419.

Ganesh, S., \& Zoller, H. M. (2012). Dialogue, Activism, and Democratic Social Change. Communication Theory, 22, 66-91.

Gergen, K., \& Gergen, M. (2008). Social Constructionism. In L. Given (Ed.), The SAGE Encyclopedia of Qualitative Research Methods (Vol. 2, pp. 816-820).

Thousand Oaks, California: SAGE Publications, Inc.

Gottlieb, R. (2001). Environmentalism Unbound. London: MIT Press.

Greenpeace. (2010). john key, I can smell the smokestacks on your breath. Kakariki Winter 2010: Steering a new course, 46.

Guha, R. (2000). Environmentalism: a global history. New Delhi: Oxford University Press.

Gunder, M., \& Mouat, C. (2002). Symbolic violence and victimization in planning processes: A reconnoitre of the New Zealand Resource Managment Act. Planning Theory, 1, 124-145.

Hartley, S. (2010, 31 March). Bathurst to buy L\&M coal assets. Retrieved February 12, 2013, from http://www.odt.co.nz/news/business/99766/bathurstbuy-lampm-coal-assets

Heatley, P. (2012, March 7). Press release: Crown Minerals Act review gets under way. Retrieved September 27, 2012, from http://www.beehive.govt.nz/release/crown-minerals-act-review-getsunder-way

Held, D. (2006). Models of Democracy. Cambridge: Polity Press.

Hillier, J. (2002). Shadows of power: An allegory of prudence in land-use planning. London: Routledge.

Holstein, J., \& Gubrium, J. (2011). The Constructionist Analytics of Interpretive Practice. In N. Denzin \& Y. Lincoln (Eds.), The SAGE Handbook of Qualitative Research (4 ed., pp. 341-358). Thousand Oaks, California: SAGE.

Howarth, D. (2000). Discourse. Buckingham: Open University Press.

Innes, J., \& Booher, D. (2004). Reframing Public Participation: Strategies for the 21st Century. Planning Theory \& Practice, 5(4), 419-436. doi:

$10.1080 / 1464935042000293170$

IPCC. (2007). Summary for Policymakers. In S. Solomon, D. Qin, M. Manning, Z. Chen, M. Marquis, K. B. Averyt, M. Tignor \& H. L. Miller (Eds.), Climate Change 2007: The Physical Science Basis. Contribution of Working Group I to the Fourth Assessment Report of the Intergovernmental Panel on Climate Change. Cambridge, United Kingdom and New York, NY, USA: Cambridge University Press.

Jackson, T., \& Dixon, J. (2007). The New Zealand Resource Management Act: an exercise in delivering sustainable development through an ecological modernisation agenda. Environment and Planning B: Planning and Design, 34, 107-120. 
Jasonoff, S. (2006). The Value of Legality in Environmental Action. In J. Bauer (Ed.), Forging Environmentalism: Justice, Livelihood, and Contested Environments (pp. 329-346).

Jeong, H. (2002). Citizen involvement in the environmental policy process in Korea. The Good Society, 11(2), 46-56.

Kobayashi, A. (2001). Negotiating the personal and the political in critical qualitative research. In M. Limb \& C. Dwyer (Eds.), Qualitative

Methodologies for Geographers: Issues and Debates (pp. 55-72). New Yorks: Oxford University Press.

Laclau, E., \& Mouffe, C. (2001). Hegemony and Socialist Strategy: Towards a radical democratic politics (2nd ed.). London: Verso.

Land Information New Zealand. (n.d.). New Zealand Small Scale Topographic Maps. Retrieved February 12, 2013, from http://www.linz.govt.nz/topography/topo-maps/nz-small-scale-maps

Larner, W. (2002). Neoliberalism and Tino Rangatiratanga: Welfare State Restructuring in Aotearoa/New Zealand. In C. Kingfisher (Ed.), Western Welfare in Decline: Globalisation and Women's Poverty (pp. 147-163). Philadelphia: University of Pennsylvania Press.

Lawson, T., \& Garrod, J. (2001). Dictionary of sociology. London :: Fitzroy Dearborn.

Limb, M., \& Dwyer, C. (2001). Introduction: doing qualitative research in geography. In M. Limb \& C. Dwyer (Eds.), Qualitative Methodologies for Geographers: Issues and Debates (pp. 1-22). New York: Oxford University Press.

Little, A. (2002). Community and radical democracy. Journal of Political Ideologies, $7(3), 369-382$.

Little, A. (2010). Democratic Melancholy: On the Sacrosanct Place of Democracy in Radical Democratic Theory. Political Studies, 58(5), 971-987. doi: 10.1111/j.1467-9248.2009.00807.x

Maloney, S. D., \& Miller, J. A. (2008). An Act is Worth a Thousand Words: A Place for Public Action And Civic Engagement in Deliberative Democracy. Theoria, December, 81-103. doi: 10.3167/th.2008.5511705

Maron, M., Hobbs, R., Moilanen, A., Matthews, J., Christie, K., Gardner, T., .. . McAlpine, C. (2012). Faustian bargains? Restoration realities in the context of biodiversity offset policies. Biological Conservation, 155, 141-148.

Martin, D. (2011, July 26). Forest and Bird Weblog: Irreplaceable. Retrieved September 27, 2012, from http://blog.forestandbird.org.nz/irreplaceable/ Mason, J. (2002). Qualitative researching. London: SAGE Publications Ltd. May, T. (2010). Contemporary Political Movements and the Thought of Jacques Ranciere: Equality in Action. Edinburgh: Edinburgh University Press Ltd.

McCarthy, J., \& Prudham, S. (2004). Neoliberal nature and the nature of neoliberalism. Geoforum, 35(3), 275-283. doi: 10.1016/j.geoforum.2003.07.003

McClymont, K. (2011). Revitalising the political: Development control and agonism in planning practice. Planning Theory, 10, 239-256. 
Meridian Energy. (2009). Meridian Energy Annual Report for the year ended 30 June 2009 (pp. 141).

Meridian Energy. (2010). Meridian Energy Annual Report for year ended 30 June 2010 (pp. 99).

Meridian Energy. (2012, May 22). Media release: Meridian exits Mokihinui Hydro Project. Retrieved 21 September, 2012, from http://www.meridianenergy.co.nz/company/news/mediareleases/company/meridian-exits-mokihinui-hydro-project/

Ministry for the Environment. (2009a). Resolving Resource Management Act concerns. An everyday guide to the RMA, series 1.2 (Second edition ed., pp. 12). Wellington, New Zealand: Ministry for the Environment.

Ministry for the Environment. (2009b). Your guide to the Environment Court. An everyday guide to the RMA, series 6.1. Wellington, New Zealand: Ministry for the Environment.

Ministry for the Environment. (2011). Making Good Decisions: A training, assessment and certification programme for RMA decision-makers. Retrieved January 29, 2013

Ministry of Business Innovation and Employment. (2011). Outcome of Schedule 4 stocktake process. Retrieved October 5, 2012, from http://www.med.govt.nz/sectors-industries/naturalresources/minerals/schedule-4-of-the-crown-minerals-act-1991/outcomeof-schedule-4-stocktake-process

Ministry of Economic Development. (2010). Maximising our Mineral Potential:

Stocktake of Schedule 4 of the Crown Minerals Act and beyond. Summary of Submissions. (pp. 177): Ministry of Economic Development.

Ministry of Economic Development. (2011). New Zealand Energy Strategy 20112021: Developing our energy potential and the New Zealand Energy Efficiency and Conservation Strategy 2011-2016. Wellington: Ministry of Economic Development.

Ministry of Economic Development. (2013). Operating coal mines. Retrieved February 19, 2013, from http://www.nzpam.govt.nz/cms/coal/coalresources/operating-coal-mines

Mokihinui Hydro Proposal Decision Summary 31 March 2010, West Coast Regional Council and Buller District Council 32 (2010).

Mokre, M. (2006). Deregulation and democracy: The Austrian case. The Journal of Arts Management, Law, and Society, 35(4), 305-318.

Mouffe, C. (1992). Dimensions of Radical Democracy: Pluralism, Citizenship, Community. London: Verso.

Mouffe, C. (2000). The Democratic Paradox. London: Verso.

Mouffe, C. (2005). For an agonistic public sphere. In L. Tønder \& L. Thomassen (Eds.), Radical democracy: Politics between abundance and lack (pp. 123132). Manchester: Manchester University Press.

Munton, R. (2003). Deliberative democracy and environmental decision-making. In F. Berkhout, M. Leach \& I. Scoones (Eds.), Negotiating Environmental 
Change: New Perspectives from Social Science (pp. 109-136). Cheltenham, UK: Edward Elgar Publishing Limited.

Mutz, D. C. (2008). Is Deliberative Democracy a Falsifiable Theory? Annual Review of Political Science, 11(1), 521-538. doi:

10.1146/annurev.polisci.11.081306.070308

Nathan, S. (2013). West Coast places. Retrieved March 8, 2013, from http://www.teara.govt.nz/en/west-coast-places

North, M. (2011). In the matter of the Resource Managment Act 1991 and in the matter of Buller Coal Ltd's proposal to operate an opencast mine (with associated infrastructure) on the Denniston Plateau known as the Escarpment Mine project. Retrieved February 18, 2013, from http://www.wcrc.govt.nz/escarpment/hearing/Submitters/F\%20\&\%20B \%20-\%20Michael\%20North\%20evidence.pdf

NZPA. (2006, January 25). Protesters plot occupation of Happy Valley coal mine. Retrieved September 27, 2012, from http://www.nzherald.co.nz/royalforest-and-bird-protection-society-ofnz/news/article.cfm?o_id=254\&objectid=10365214

NZPA and NZHerald Staff. (2010, May 1). Huge protest says no to mining on conservation land. Retrieved October 5, 2012, from http://www.nzherald.co.nz/nz/news/article.cfm?c_id=1\&objectid=106420 83

ONE News. (2010, May 1). Thousands make mining message clear. Retrieved October 5, 2012, from http://tvnz.co.nz/national-news/thousands-marchagainst-mining-3505002

Oreskes, N. (2004). The Scientific Consensus on Climate Change. Science, 306, 1686. Orum, A. M., \& Dale, J. G. (2009). Political Sociology: Power and Participation in the Modern World. New York: Oxford University Press.

Parliamentary Commissioner for the Environment. (2009). Stockton revisited: The mine and the regulatory minefield. Wellington.

Parliamentary Commissioner for the Environment. (2010). Making difficult decisions: Mining the conservation estate. Wellington: Parliamentary Commissioner for the Environment.

Patton, P. (2005). Deleuze and democratic politics. In L. Tønder \& L. Thomassen (Eds.), Radical democracy: Politics between abundance and lack (pp. 50-67). Manchester: Manchester University Press.

Peacock, H., Allan, S., \& Bayley, S. (2008). West Coast Regional Council and Buller District Council JointS42a Planning Officers' Report: Applications For Resource Consents Rc07150 (01-26) And Rc07/180 (A-H) - Meridian Energy Limited Mokihinui Hydro Proposal Mokihinui River. Buller District Council and West Coast Regional Council website.

Peat, N. (1994). Manapouri saved! New Zealand's first great conservation success story. Dunedin, New Zealand: Published by Longacre Press for the Guardians of Lakes Manapouri, Monowai and Te Anau.

Peck, J., \& Tickell, A. (2002). Neoliberalizing Space. Antipode, 34(3), 380-404. 
Perkins, H., \& Thorns, D. (2001). A decade on: reflections on the Resource Management Act 1991 and the practice of urban planning in New Zealand. Environment and Planning B: Planning and Design, 28, 639-654.

Peräkylä, A., \& Ruusuvuori, J. (2011). Analyzing talk and text. In N. Denzin \& Y. Lincoln (Eds.), The SAGE Handbook of Qualitative Research (4 ed., pp. 529544). Thousand Oaks, California: SAGE Publications.

Pløger, J. (2004). Strife: Urban planning and agonism. Planning Theory, 3(71), 7192.

Potter, J. (2008). Discourse Analysis. In L. Given (Ed.), The SAGE Encyclopedia of Qualitative Research (Vol. 1, pp. 217-220). Thousand Oaks, California: SAGE Publications, Inc.

Pugh, J. (2005). The disciplinary effects of communicative planning in Soufriere, St Lucia: governmentality, hegemony and space-time politics. Transactions of the Institute of British Geographers, 30(3), 307-321.

Purcell, M. (2009). Resisting neoliberatization: Communicative planning or counter-hegemonic movements? Planning Theory, 8, 140-165.

Ranciere, J. (2004). Introducing disagreement. Angelaki, 9(3), 3-9.

Rancière, J. (1999). Dis-agreement: Politics and philosophy (J. Rose, Trans.). Minneapolis: University of Minnesota Press.

Resource and Environmental Management Nelson Limited. (2011). Escarpment Mine Project Consent Conditions. Retrieved January 15, 2012, from http://www.wcrc.govt.nz/escarpment/decision.html

Ridge, T., \& Inwood, R. (2011). Joint S42A Planning officer report: Applications for resource consents, Buller Coal Ltd, Escarpment Mine Project (pp. 74). New Zealand: West Coast Regional Council and Buller District Council.

Robbins, P. (2012). Political ecology: A critical introduction (2 ed.). West Sussex, UK: Wiley-Blackwell.

Rootes, C. (2003). The transformation of environmental activism: An introduction. In C. Rootes (Ed.), Environmental Protest in Western Europe (pp. 1-19). Oxford: Oxford University Press.

Rowe, G., \& Frewer, L. J. (2000). Public Participation Methods: A Framework for Evaluation. Science, Technology, \& Human Values, 25(1), 3-29.

Royal Forest and Bird Protection Society of NZ Inc. (2010). Submission on application by L \& M Coal for resource consents for the Escarpment Mine Project and associated infrastructure. Retrieved January 28, 2013, from http://www.wcrc.govt.nz/escarpment/submissions.html

Rubin, H., \& Rubin, I. (1995). Qualitative interviewing: The art of hearing data. Thousand Oaks, California: SAGE Publications, Inc.

Rutherford, H. (2012). Key denies pressuring DoC over mining, Dominion Post online. Retrieved from http://www.stuff.co.nz/dominionpost/business/6617808/Key-denies-pressuring-DoC-over-mining

Sherwood, A., \& Phillips, J. (n.d.). Coal and coal mining. Retrieved March 8, 2013, from http://www.teara.govt.nz/en/coal-and-coal-mining

Solid Energy. (2011). Annual Report: Solid Energy New Zealand Ltd. 
Solid Energy. (2012). Stockton Opencast Mine. Retrieved October 5, 2012, from http://www.solidenergy.co.nz/index.cfm/1,203,0,0/Stockton.html

Stark, S., \& Torrance, H. (2005). Case Study. In B. Somekh \& C. Lewin (Eds.), Research Methods in the Social Sciences (pp. 33-40). London: SAGE Publications.

Steeman, M. (2012, June 23). Palmer tips 2014 for partial sale. Retrieved September 26, 2012, from

http://www.stuff.co.nz/business/industries/7156610/Palmer-tips-2014for-partial-sale

Stephenson, K. (2011). No public consultation over mine, New Zealand Herald online. Retrieved from

http://www.nzherald.co.nz/environment/news/article.cfm?c_id=39\&objec tid $=10769949$

Talisse, R. B. (2005). Deliberativist responses to activist challenges. Philosophy \& Social Criticism, 31(4), 423-444. doi: 10.1177/0191453705052978

The Environment Court of New Zealand. (2012). Notice of Hearing. In J. King (Ed.). Auckland, New Zealand: Auckland Environment Court Registry.

The Environment Court of New Zealand. (n.d.). Practice Notes - Expert Witnesses Code of Conduct. Retrieved March 13, 2013, from http://www.justice.govt.nz/courts/environment-court/legislation-andresources/practice-notes/expert-witness.html

The Wire (Radio show). (2007, May 28). Save Happy Valley Coalition [Radio interview]. Auckland: 95bFM.

TVNZ. (2012, October 29). Protest as court considers West Coast mine decision. Retrieved February 12, 2013, from http://tvnz.co.nz/nationalnews/protest-court-considers-west-coast-mine-decision-5169238

United Nations. (1992). Rio Declaration on Environment and Development. Paper presented at the United Nations Conference on Environment and Development, Rio de Janeiro. http://www.un.org/documents/ga/conf151/aconf15126-1annex1.htm

Waitt, G. (2010). Doing Foucauldian Discourse Analysis - Revealing Social Realities. In I. Hay (Ed.), Qualitative Research Methods in Human Geography (3 ed., pp. 217-240). Don Mills, Ontario: Oxford University Press.

Walker, S., Brower, A. L., Stephens, R. T. T., \& Lee, W. G. (2009). Why bartering biodiversity fails. Conservation Letters, 2, 149-157.

Walter, R. (2008). Foucault and Radical Deliberative Democracy. Australian Journal of Political Science, 43(3), 531-546.

Walton, S. (2007). Organization \& Environment, 20(2), 177-203.

Weaver, C. K., \& Motion, J. (2002). Sabotage and subterfuge: public relations, democracy and genetic engineering in New Zealand. Media Culture Society, 24, 325-343.

West Coast Environment Network. (2011a). Campaign to stop the Escarpment Mine, Denniston Plateau, September 2011 update. Retrieved 10 November 2011, from 
http://coalactionnetworkaotearoa.wordpress.com/2011/09/15/campaign

-to-stop-the-escarpment-mine-september-2011-update/

West Coast Environment Network. (2011b). Submission to the West Coast

Regional Council and Buller District Council on the Escarpment Mine

Proposal (pp. 16). Buller District Council and West Coast Regional Council website.

West Coast Regional Council and Buller District Council. (2010). The Mokihinui

Hydro Proposal. from http://www.wcrc.govt.nz/mokihinui/index.htm

Wheen, N. (2002). A history of New Zealand environmental law. In E. Pawson \& T. Brooking (Eds.), Environmental Histories of New Zealand (pp. 261-274).

Melbourne: Oxford University Press.

Williams, G. (2007). The Mexican Exception and the "Other Campaign". South Atlantic Quarterly, 106(1), 129-151.

Wilson, R. (1982). From Manapouri to Aramoana: The battle for New Zealand's environment. Auckland, New Zealand: Earthworks Press.

Yin, R. (2009). Case study research: Design and methods (4 ed.). Thousand Oaks, California: SAGE Publications, Inc.

Young, I. (2001). Activist Challenges to Deliberative Democracy. Political Theory, $29,670-690$.

Young, R. (2012). 200 jobs held up by mine opponents, The Press. Retrieved from http://www.stuff.co.nz/the-press/news/7726284/200-jobs-held-up-bymine-opponents 


\section{Appendices}

\section{Appendix 1: Interview information sheet and consent form}

\section{Participant information sheet}

Research title: Democracy, disagreement and environmentalists' participation: A case study of coal mining on conservation land

Researcher: Lillian Fougère, School Geography, Environment and Earth Sciences, Victoria University of Wellington

I am a Masters student in Environmental Studies at Victoria University of Wellington. For my Master's thesis, I am researching how environmentalists are involved in decision-making about coal-mining on public land, through both informal participation or activism, and formal participation as offered through legislation. To inform this research, I am interviewing people who have been involved in decision-making processes surrounding the proposed Escarpment Mine on the Denniston Plateau. I would like to invite you to be interviewed.

The interview will take up to one hour. With your consent, I will take notes and digitally record it. After the interview, I will transcribe and/or summarise the interview, and provide you with a written copy to check for accuracy. All information will be stored in a locked cupboard or with a password protected file.

I will keep your personal details and identity confidential. I may quote you directly but your real name will not be identifiable in my thesis, nor the specific organisation you are part of. You can provide me with a preferred pseudonym if you wish, or I may assign you with a pseudonym. While your name and organisation will not be identified in my thesis, there may be situations where other individuals who are intimately involved in the case may be able to identify you. I will ensure that any identifiers (such as age, specific occupation, resident location) will be ambiguous in my thesis to avoid the potential for such 
identification. You may decline to answer any questions and you may withdraw any information you provide by 3 August 2012.

On completion of my research, a copy of my thesis will be deposited in the Victoria University Library and will be available online. A copy of the research findings will be available for you at the completion of my research if you wish. Findings from this research may also be published in academic or professional journals, and may be used to inform future research. The data I collect will be kept for five years following the completion of my thesis, and it will then be destroyed.

If you have any questions or would like more information about this research, please contact:

\section{Lillian Fougère}

Phone: 0211864281

Email: Lillian.Fougere@vuw.ac.nz

Dr. Sophie Bond (supervisor)

Phone: 044635217

Email: sophie.bond@vuw.ac.nz

This project has received approval from the Human Ethics Committee of Victoria University of Wellington. 


\section{Participant consent form}

Research title: Democracy, disagreement and environmentalists' participation: A case study of coal mining on conservation land

Researcher: Lillian Fougère, School Geography, Environment and Earth Sciences, Victoria University of Wellington

Please read the above information sheet. If you are comfortable with the research conditions outlined above, please fill out and sign below.

I, (name) have read the information sheet provided. I understand the reasons for this research. I have had the opportunity to ask questions about this research and have had them answered to my satisfaction.

I consent to participating in an interview and for this interview to be recorded. I am aware that my name and identity will be kept confidential. I consent to being quoted from this interview, so long as quotes are not attributed to my name or organisation.

I understand I can stop this interview at any point and do not have to answer any questions I am not comfortable with. I understand a transcript and/or summary of this interview will be given to me to check that I am comfortable with the information I provide.

I understand that this interview will be analysed for the Masters research as outlined in the information sheet. I also consent to information from this interview being used in further publications and to inform future research.

After the completing the interview, I understand I have until Friday 3 August 2012 to withdraw the information I have given, and that if this is the case, the interview will be digitally deleted.

I agree to participate in this research.

Signature:

Preferred pseudonym (optional):

Date: 


\section{Research findings}

If you would like to find out about the findings of my research, please tick below:

$\square$ I would like to receive a summary of findings

$\square$ I would like to be notified where I can access the full thesis online

The best way to make contact about these findings is by:

$\square$ Email:

$\square$ Postal address:

Thank you for your participation in this research. 


\section{Appendix 2: Interview topic guides}

The following questions were used as a topic guide in interviews with environmentalists and council and government officers. While all of these topics were addressed during the interviews, given the nature of semi-structured interviews, questions changed and new themes emerged as the interviews progressed.

\section{Questions for environmentalists}

1. What is your role in (organisation)? Voluntary role or employed?

2. How long have you been involved in this organisation, and in environmentalism in general?

3. How did you find out about the proposed Escarpment Mine? How (and when) did the council/Department of Conservation/Bathurst Resources Ltd present the information to you about the proposals for the consents applied for?

4. How long have you been involved in action against the Escarpment Mine proposal?

I am going to ask you questions both about your involvement in formal consultation through the resource consent process, and your involvement in environmentalist actions, such as protest, petitions and publicity.

5. How have you or your organisation participated in formal submission processes? Eg. submission on the resource consents in 2010, and appealing the resource consent in the Environment Court.

6. What was involved for you personally in this submission process?

7. So that's about the formal process. - What other actions have you been involved in, as part of the protest against Escarpment Mine?

8. How do you feel that these actions influenced the consequent decisions made about the mine?

9. How would you compare the effects that you saw after both your activism and formal participation?

Now some more general questions about the decision-making processes 
10. What do you think about who was/is involved in the decision to grant the resource consents (at the council level) and the permits that may be given by the Department of Conservation? Eg, who the public voted for in the current government/council, who was on committees, the council/government officers involved, who participated in formal submission etc).

11. Were you aware of other groups (residents/iwi/individuals/heritage) taking action outside of the formal submission process?

12. What do you think of environmentalists' influence compared to these other groups: in formal submissions, and through their actions outside of formal processes?

13. Knowledges and power - Something I'm interested in is how different arguments carry different weight to those that make the decisions, and how the different perspectives sway the decisions to a different degree. What kinds of perspectives appeared to have the most power in the formal submission process and in other actions?

Eg, knowledges/discourse/perspectives, Eg, technical information about the site, scientific information about climate change or conservation, feelings and emotional/spiritual connections with the area.

Relationships and underlying difference, agonism, what kind of democracy

framework

14. Did you work with other types of groups (residents/iwi/heritage) to make your arguments?

15. Does your organisation (or you) often submit or protest against similar issues?

16. How would you describe your (or your group's) relationship to the decisionmakers - the councils involved? To Buller Coal/Bathurst?

Eg, are you known to decision makers? How has this relationship changed over time?

17. Has your position changed at all on being opposed to Escarpment Mine? Under what circumstances would your position change?

18. How did you communicate with Buller Coal/Bathurst or the council during the time leading up to the decisions made?

19. What do you think a democratic-decision making process would ideally look like, especially when there is strong disagreement about a proposal? Can you give an example of a democratic process? 
20. What do you think about consensus decision-making? Is it possible, and should it be a goal?

21. Do you feel that your actions as an environmentalist contribute to the democratic-nature of a decision-making? How so?

22. What do you think the role of environmentalism is in the broader sense of democracy?

(What do you think of in democracy?)

\section{Questions for council officers}

1. What is your role in (organisation)? How long have you been in this role, or similar roles?

2. How long have you been involved in the decision-making process for the Escarpment Mine proposal?

I am going to ask you questions both about the formal submission processes through Resource Management Act, and your perceptions of environmentalist actions, such as protest, petitions and publicity.

3. What was your role in the formal submission processes? At what stage did you become involved?

4. When did you first come into contact with the public about this case, and what was the nature of this communication?

5. Did you notice a presence of environmentalists in the formal submission process? How much influence did their involvement have in this formal process?

6. So that's about the formal process. - What other actions against Escarpment Mine, such as protest, petitions, and publicity, have you been aware of?

7. Do feel that these actions influenced the consequent decisions made about the mine? (Prompt - Under RMA, potentially excludes - Should this be the case?)

8. How would you compare the influence of both the environmentalist action within and outside of the formal submission processes?

Now some more general questions about the decision-making processes 
9. What do you think about the amount of discussion and deliberation that the council had before making the decisions to grant a resource consent?

10. What do you think about who was involved in that decision? (For example, through who the public voted for in the current government/council, who was on committees, the council/government officers involved, who participated in formal submission etc).

11. Were you aware of other groups (residents/iwi/individuals/heritage) taking action outside of the formal submissions?

12. What do you think of environmentalists' influence compared to these other groups: in formal submissions, and through their actions outside of formal processes?

13. Knowledges and power - Something I'm interested in is how different arguments carry different weight to those that make the decisions, and how the different perspectives sway the decisions to a different degree. What kinds of perspectives appeared to have the most power in the formal submissions process and in other actions?

Eg, knowledges/discourse/perspectives, Eg, technical information about the site, scientific information about climate change or conservation, feelings and emotional/spiritual connections with the area.

Relationships and underlying difference, agonism, what kind of democracy framework

14. How would you describe your relationship to the environmentalists involved? Eg, are they known to you as regular submitters? How has this relationship changed over time?

15. At any point, did you reach agreement with any of the environmentalists? If so, did this agreement change, and how?

16. What do you think a democratic-decision making process would ideally look like, especially when there is strong disagreement about a proposal?

17. What do you think about consensus decision-making? Is it possible, and should it be a goal?

18. Who should be involved in the formal decision-making process? What is the best form of participation in such decisions and why? What practicalities are involved? 
19. How do you feel that your actions as a council/government officer contribute to the democratic-nature of a decision-making?

20. What do you think the role of environmentalism is in the broader sense of democracy?

(What do you think of in democracy?)

\section{Questions for Commissioner}

1. How long have you been a councillor, and how frequently have you been commissioner? What is the process for choosing commissioners?

2. How long were you involved in the decision-making process for the Escarpment Mine proposal?

I am going to ask you questions about the formal consultation processes and the way that actions of "interest groups"/stakeholders/community might or might not influence decisions that are made by commissioners.

3. What is the role of commissioners in the formal consultation or submission processes?

At what stage do you become involved?

4. Do you come into contact with the public (in this case?), and what was the nature of this communication? How would you describe the nature of your relationship with the public (including those against a proposal or a decision that is made?)

5. What does a commissioner do if they notice a presence of public protest against a proposal, both within the formal submission process or outside of this process? How much influence does either of these actions have on the decisions the commissioners make?

6. How would you compare the influence of both the action within and outside of the formal submission processes, and the influence it has on any decision?

7. What do you think about the range of people participating in decisions that are made?

8. Who should be involved in the formal decision-making process? What is the best form of public participation in such decisions and why? What practicalities are involved? 
9. What do you think a democratic-decision making process would ideally look like, especially when there is strong disagreement about a proposal?

10. What do you think about consensus decision-making? Is it possible, and should it be a goal?

11. How do you feel that your actions as a commissioner contribute to the democratic-nature of a decision-making?

12. What do you think the role of environmentalism, activism or protest is in the broader sense of democracy? 


\section{Appendix 3: Human ethics approval}

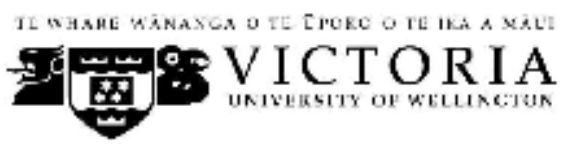

MEMORANDUM
Phone $\quad 0-4-4635676$

Fax $\quad 0-4635209$

Email Allisonkirkman®vuw.ac.no

\begin{tabular}{l|l}
\hline TO & Lillian Fougère \\
\hline COPY TO & Sophie Bond \\
\hline FROM & Dr Allison Kirkman, Convener, Human Ethics Committee \\
\hline
\end{tabular}

\begin{tabular}{l|l}
\hline DATE & 9 June 2012 \\
\hline PAGES & 1 \\
\hline
\end{tabular}

SUBJECT $\quad$ Ethics Approval: 19347

Democracy, disagreement and environmentalists'

participation: a case study of coal mining on conservation land

Thank you for your application for ethical approval, which has now been considered by the Standing Committee of the Human Ethics Committee.

Your application has been approved from the above date and this approval continues until 18 March 2013. If your data collection is not completed by this date you should apply to the Human Ethics Committee for an extension to this approval.

Best wishes with the research.

Allison Kirkman

Human Ethics Committee 